\title{
FUTURE WIND POWER PRODUCTION VARIATIONS IN THE SWEDISH POWER SYSTEM
}

Jonas Olsson

Lars Skoglund 


\begin{tabular}{|l|l|l|}
\hline $\begin{array}{l}\text { From } \\
\text { Vattenfall Research and Development AB, U-NE }\end{array}$ & $\begin{array}{l}\text { Date } \\
2010-06-11\end{array}$ & Serial No. \\
\hline Author/s & Access & Project No. \\
Jonas Olsson & Full Access & PR.138.1.4.96 \\
Lars Skoglund & Reviewed by \\
\hline $\begin{array}{l}\text { Customer } \\
\text { Jens Madsen } \\
\text { Sven-Erik Thor }\end{array}$ & Fredrik Carlsson, U-NE \\
\cline { 2 - 3 } & Issuing authorized by \\
\hline Key Word & Viktoria Neimane, U-NE \\
Wind Power, Reserve Power, Stochastic variations & $\begin{array}{l}\text { No. of pages } \\
79\end{array}$ & $\begin{array}{l}\text { Appending pages } \\
12\end{array}$ \\
\hline
\end{tabular}




\section{Summary/Abstract}

The future for wind power in Sweden is a well covered issue by many reports bringing up different problems and trying their best to simulate the future system with different tools. Summarizing these reports and comparing their conclusions is a difficult task not only due to the many reports but also since they are based on different data and focus on different aspects of the potential problems.

The only thing that can be said certain is that the current electric power system is not constructed for a large expansion of an intermittent power source which will have such a geographical spread as the potential wind power expansion. Geographical spread should not be mistaken to be an equal installation of wind power over the entire country of Sweden or an equal spread between the different areas of the electric power grid. Geographical spread means that wind power will be built on locations where wind potential is good.

In this report the focus lies on magnitude of the future variations from wind power when the capacity is expanded. The base for the thesis is statistic data from the wind power production in 2009 from three different sources. The data has been used in an attempt to predict the future variations from wind power if the expansion is done in accordance with how the wind power has been expanded up to this point. The data has partly been divided into different times of the year, in this case following the seasons of the year, spring, summer, autumn and winter. And also into the geographic areas of Sweden which is normally used to describe the cross-sections in the transmission system.

The results found indicates that for a system which is geographically large as Sweden the variations from wind power, between two hours, will only during a few times every year be more than $\pm 10 \%$ of the installed wind power capacity. However there can be variations in the different transmission system areas which are larger and occur more often. There are also a few times every year that the variations might cause problems. The problems might occur due to the relation between the variation and the available reserves, especially when looking at future scenarios with quite large wind power penetration. This might cause problems the southern part of Sweden where the plan for expansion includes a large amount of wind power and there are little local balancing resources. 


\section{Acknowledgements}

This report is a master's thesis performed at Vattenfall Research and Development AB in Råcksta. The report was supervised and approved by Chalmers University of Technology, Departement of Energy and Enviroment, Division of Electric Power Engineering. The work was funded by Vattenfall Vindkraft.

The authors of the report were Jonas Olsson and Lars Skoglund, both students a Chalmers University of Technology. The authors were writing this report as their final, 20 weeks, thesis for a master's degree from the Sustainable Energy Systems programme at Chalmers.

Jonas and Lars would like to thank the persons contributing to the final result of the master's thesis;

Emil Eriksson, Viktoria Neimane, Urban Axelsson and Magnus Andersson at Vattenfall Research and Development who helped answering questions and giving us feedback on the report.

Kjell Lindquist, Johan Hagsten and Dennis Waltin at Vattenfall Nordic Generation Management who gave us data and helped us to understand how the electric power system and power market works in reality.

Christer Bäck at Svenska Kraftnät who gave us a deeper understanding about the role of a TSO and gave us Svenska Kraftnäts visions and plans for the future electric power system.

Our opponents, Emil Jonasson and Alfred Emanuelsson who, despite several postponed presentations, stood by us and took the time to read the report and be at the presentation.

Dr. Fredrik Carlsson, our supervisor at Vattenfall Research and Development. And, of course, our examiner and guide during the process of completing this master's thesis, Professor Lina Bertling. 


\section{Distributionlist}

\begin{tabular}{|l|l|l|l|}
\hline Company & Department & Name & Number of \\
\hline Vattenfall & U-NE & Fredrik Carlsson & \\
\hline Vattenfall & U-NE & Viktoria Neimane & \\
\hline Vattenfall & U-NE & Urban Axelsson & \\
\hline Vattenfall & WTT & Sven-Erik Thor & \\
\hline Vattenfall & U-SD & Jens Madsen & \\
\hline & & & \\
\hline & & & \\
\hline
\end{tabular}




\section{Abbreviations}

AGC - $\quad$ Automatic Generation Control.

ISO - Independent System Operator. The ISO is responsible for keeping the electric power system in balance when there is more then one transmission system operator, like in Germany.

Intermittent - Means irregular in the way of constant ceasing and beginning.

Renewable - Renewable refers to renewable energy sources which are naturally reproduced. The following are considered to be renewable according to the EU: solar, wind, wave, geothermal, hydroelectric and biomass.

SvK - Svenska Kraftnät, owner and operator of the transmission system in Sweden. SvK also handle the balancing in the system before and during the production hour.

TSO - Transmission System Operator. Own and operates the transmission system, also responsible for keeping the electric power system in balance. 
$\begin{array}{lll}1 & \text { INTRODUCTION } & 1\end{array}$

1.1 Background 1

1.2 Purpose 2

1.3 Outline of the report 2

2 INTRODUCTION TO WIND POWER 4

2.1 Wind power history 4

2.2 Production of wind power in Sweden during $2009 \quad 7$

2.2.1 Hourly production in Sweden during $2009 \quad 7$

2.2.2 Hours with low production 8

2.3 Power output and forecasting 9

$\begin{array}{lll}2.4 & \text { Production within the hour } & 11\end{array}$

$\begin{array}{lll}2.5 & \text { Wind power production variation hour-to-hour } & 13\end{array}$

2.6 Market and system effects due to wind power production 13

$\begin{array}{lll}2.7 & \text { Knowledge concerning expansion effects } & 14\end{array}$

$\begin{array}{llr}2.8 \text { Yearly production } & 15\end{array}$

2.8.1 Operating hours $\quad 15$

$\begin{array}{lll}2.8 .2 \text { Cut-off wind } & 15\end{array}$

$\begin{array}{ll}2.8 .3 \text { Aggregation } & 16\end{array}$

$\begin{array}{lll}2.9 & \text { Planned expansion } & 16\end{array}$

$3 \quad$ POWER SYSTEM FUNCTION AND MARKET 18

$\begin{array}{lll}3.1 & \text { Power system in Sweden } & 18\end{array}$

$\begin{array}{lll}3.2 & \text { Definition of regulating power } & 18\end{array}$

3.2.1 Primary regulating power 18

$\begin{array}{ll}\text { 3.2.2 Secondary regulating power } & 19\end{array}$

$\begin{array}{lll}3.2 .3 & \text { System reserves } & 19\end{array}$

3.2.4 Hydro power as regulating power 20

$\begin{array}{lll}3.3 & \text { Importance of frequency control }\end{array}$

$\begin{array}{lll}3.4 & \text { Transmission system } & 21\end{array}$

$\begin{array}{lll}3.5 & \text { Power Market } & 24\end{array}$

3.5.1 Pricing of electric power 24

3.5.2 Nord Pool 24

4 WIND POWER IMPACT ON ELECTRIC POWER SYSTEM AND MARKET 27

$\begin{array}{lll}4.1 & \text { Background and previous publications } & 27\end{array}$

4.1.1 Previous modelling of the electric system with increased wind power capacity 
4.1.2 Correlation of wind power and spatial smoothing effects 28

4.2 Two potential problem scenarios 28

4.2.1 Lack of local regulating sources and transmission limitation 28

4.2.2 Low consumption and lack of down regulating capacity 29

$\begin{array}{lll}4.3 & 29\end{array}$

4.3.1 Kjell Lindquist, Vattenfall Nordic Generation Management $\quad 30$

4.3.2 Christer Bäck, Svenska Kraftnät 30

5 MODEL $\quad 32$

5.1 Presentation of data 32

5.1.1 Data from Vattenfall 32

5.1.2 Data from SvK 34

5.2 Definitions $\quad 35$

5.3 Visualisation of how wind power production varies with time 36

5.3.1 Production from one wind turbine, hour to hour 37

5.3.2 Production from one wind farm, hour to hour 38

5.3.3 Wind production in larger areas $\quad 40$

5.4 Production divided by season 44

5.5 Correlation 46

$\begin{array}{lll}\text { 5.5.1 Correlation used for the model } & 47\end{array}$

5.5.2 Summarize of correlation for production and production variations 50

5.6 Understanding from the model used for the simulation 50

$6 \quad$ SIMULATION 51

6.1 Results $\quad 52$

6.2 Most frequent variations $\quad 55$

6.3 Worst case scenario $\quad 55$

6.4 Important scenario not found in data $\quad 57$

6.5 Simulation is worst case scenario 58

$7 \quad$ POSSIBLE FUTURE SOLUTIONS $\quad 59$

$\begin{array}{lll}7.1 & \text { AGC } & 59\end{array}$

$\begin{array}{lll}7.2 & \text { SmartGrids } & 59\end{array}$

$\begin{array}{lll}7.3 & \text { Hydro pump storage } & 60\end{array}$

$\begin{array}{lll}7.4 & \text { Plug in hybrid electric vehicles } & 62\end{array}$

$8 \quad$ CONCLUSIONS AND FUTURE WORK $\quad 64$

$\begin{array}{lll}8.1 & \text { Conclusions } & 64\end{array}$

$\begin{array}{lll}8.2 & \text { Future work } & 67\end{array}$

$9 \quad$ REFERENCES $\quad 68$ 


\section{Appendices}

APPENDIX A

APPENDIX B

APPENDIX C

APPENDIX D 


\section{Introduction}

\section{$1.1 \quad$ Background}

Today the long term goals for development within areas such as unemployment, economic growth, environment etc. in Europe are focused towards 2020. The environmental goals are summarized as the EU 20/20/20 program [1] and aim towards 20\% reduction of green house gas emissions in 2020 when compared to 1990 levels. They also aims to increase the share of renewable energy sources such as wind-, solar- and wave power together with bio fuels in the European final energy consumption by $20 \%$ and furthermore to increase energy efficiency by $20 \%$. Some of the renewable energy sources are still in the development phase, for example wave power, while others are being used in large scale, like wind power and bio fuels.

Today $39.8 \%$ of the final energy use in Sweden comes from what the EU considers as renewable energy sources. The individual goal for Sweden is that $49 \%$ of the energy in the final energy consumption should come from renewables [2]. In order to achieve this goal within the electric power generation sector, Sweden will primarily expand electric power generation from two renewable sources, biomass and wind. The Swedish energy agency has set a goal of making it possible to generate $10 \mathrm{TWh}$ of electricity from wind by 2016 and $30 \mathrm{TWh}$ by 2020. In 2020, this would mean that $20 \%$ of the total electricity demand of 150 TWh per year will come from wind [3]. Mappings of the Swedish wind power potential show that it is possible to generate $50 \mathrm{TWh}$ of electricity yearly. These three different figures, 10, 30 and 50 TWh will from here on be called the three scenarios. If the goal 10 TWh electricity yearly from wind should be possible to achieve by 2016, around $400 \mathrm{MW}$ of new wind power needs to be built every year until then [4].

Wind power is an intermittent power source which makes production planning difficult [5]. The tools available are based on statistics and computer simulated models which doesn't always have a sufficient reliability. Rapid changes in wind speed and wind direction lead to rapid changes in power production, these variations are called stochastic variations. The stochastic output from wind turbines to the power systems need to be balanced by other power sources in order to avoid a decrease in electric power quality in form of fluctuating frequency in the electric power system [6].

Today wind power in Sweden stands for about $2 \mathrm{TWh}$, or 1.2\% [6], of the total electric energy generation. What will happen in the electric power systems if the share of wind power is largely increased? Will there be problems and how and when will they occur?

The main problems that are brought up in other reports [5][6][7] when looking at effects of wind power introduction in the electric power system are forecast uncertainties and the stochastic variations in production. The former one is due to the fact that wind power production cannot be forecasted on a long term basis. This is primarily a market problem since power are up for auction 24 hours before the delivery hour, so there is an uncertainty for wind power producers to know if 


\section{Vattenfall Research and Development $A B$}

they will be able to produce the same amount as they have sold. The forecast problem is not a problem during the production hour since the forecast becomes more accurate the closer the production hour it is made [8]. The latter problem is stochastic variations in power generation which occur due to momentary fluctuation in wind speed, like when the wind is gusty. Fast increase or decrease in wind speed will cause problem in the electric power system as stochastic variations due to the rapid changes that have to be balanced very fast by some other generator. Some say that if the expansion of wind power is conducted over a large geographic area, like the country of Sweden, peaks and dips in the electric power production will occur at the same time in the interconnected system leading to somewhat automatic balancing [7].

\section{$1.2 \quad$ Purpose}

There is a number of published reports bringing up the question whether a large expansion of wind power will cause problems in the Swedish electric power system due to the intermittency of the wind [6][7][9]. If wind power in Sweden is expanded according to the visions of the Swedish Energy Agency, there might occur problems due to forecast uncertainties as well as rapid, large changes in generation also called stochastic variations [7]. This report will focus on the latter of the two questions and will try to answer how large and rapid the changes within the electric power system might be if wind power is expanded to produce 10,30 or $50 \mathrm{TWh}$ on a yearly basis according to the three scenarios. This report will also present the view that different actors (generation companies and transmission authorities) on the electric power market have on the possible problem and how they are preparing to meet the challenge.

The magnitude of the stochastic variations when wind power production is increased according to the three scenarios will be calculated by analyzing existing production data from Swedish wind turbines. The installed capacity is then increased in areas where there are existing plans to build more wind power due to good wind conditions. This gives a model that should be able to simulate a normal production year on an hour to hour basis for the expanded wind power capacity. The results from the simulated system are then to be used to identify what kind of problems that will occur first in the electrical system.

\subsection{Outline of the report}

The outline of the report is divided into the following stages and chapters:

Chapters 2-4 is the first stage containing a literature study in order to get familiar with the different concepts used in the report. Chapter 2 describes actual wind power production and the planned wind power expansion in Sweden. Chapter 3 present the electric power market and its function. Chapter 4 is a summary of the previous research on how an expansion of wind power capacity can affect the electric power system and the electric power market. Chapter 4 also presents previous models constructed and used to simulate the electric power system and an expansion of wind power capacity. 
The second stage consists of interviews with the different actors in the electrical system with a certain focus on wind and hydro power generation and the Swedish transmission system operator (TSO) Svenska Kraftnät (SvK). This aims to getting an up to date view of the situation and possible problems with larger wind capacity in the Swedish electric power system.

In stage three, a model based on statistical data is used to simulate the future electric power generation from wind power in Sweden. This simulation aims at seeing how big the variations from wind power will be if the expansion is done according to the mapping of Swedish wind power potential. The simulation has also been divided into parts showing the production in different areas of Sweden, these areas are based on limitations in transmission capacity.

The data used for the wind power model is based on production data from Vattenfall's wind turbines located in Sweden. There are different time frames available for some of the turbines but since a common time frame is needed to implement all available data in the model the duration, 1 hour is selected. The input data to create the model therefore consist of the hourly production in $\mathrm{MWh} / \mathrm{h}$ during 2009 for Vattenfall's wind turbines in Sweden. For some calculations wind production data from SvK has been used, this data includes more wind turbines but does not have specific data for each turbine or farm to do all needed calculations. Where the SvK data is used it is clearly stated.

The fourth stage is a summary of the conclusions from the previous stages and uses them to evaluate possible problems and solutions for the different actors that are affected as well as for the whole electric power system. 


\section{Introduction to wind power}

\subsection{Wind power history}

Even though the technique on how to convert kinetic wind energy into electrical energy has been known for more than a hundred years [10] it isn't until the last 10 - 20 years that wind power has gone through its true revolution regarding expansion rate. This is valid for Sweden [7] and for most of the industrial world [11].

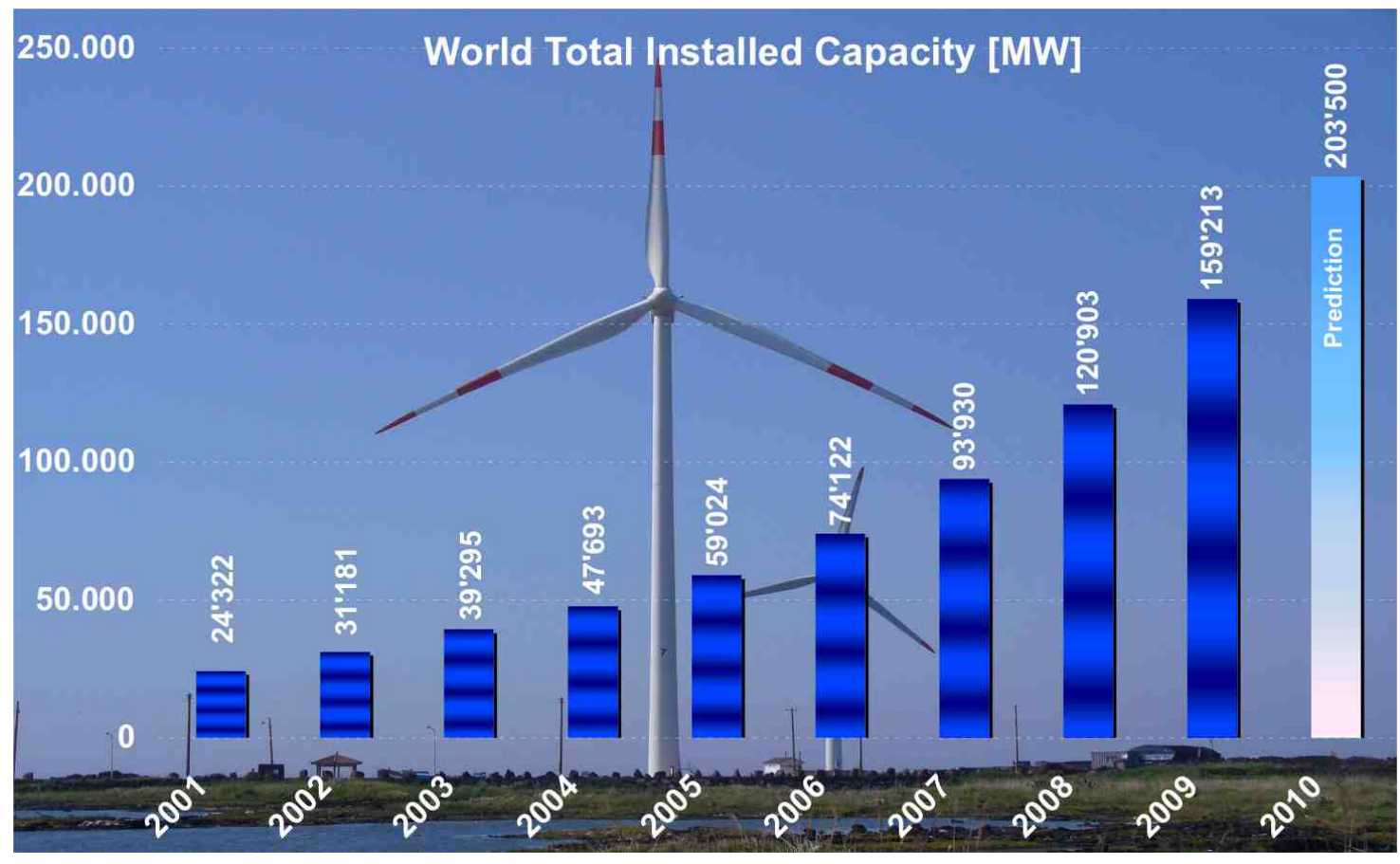

Figure 1: Development of the total installed wind power capacity in the world [11].

In Figure 1 the world's wind power capacity expansion during the last ten years can be seen. If the prediction for 2010 is correct, the world wide wind power capacity almost ten folded in only ten years [11].

The most probable reason for the rapid expansion is the correlation between power production from non renewable fuels, such as coal, natural gas and oil, and the increasing greenhouse effect [12].

Wind power is seen as a renewable energy conversion method [13], kinetic energy in the wind is converted into electric power. When constructing a wind turbine there is however a need for non renewable materials and there is also emissions of greenhouse gases in the manufacturing and construction process. But when looking at the net emissions during the life time of a wind turbine it shows that the turbine is fully green within a few months up to a few years. The lifetime of a 


\section{Vattenfall Research and Development $A B$}

wind power turbine is often projected to 20-25 years [14]. By subtracting the time that it takes for the wind turbine to replace the emissions allocated to the construction from the total lifetime and the total amount of generated electric power during that lifetime the net emissions per $\mathrm{kWh}$ from a wind power turbine is much lower than electric power produced in conventional fossil fuelled plants [15].

The way the energy market, both in Sweden and in the world, is constructed today, wind power is generally not profitable without support [16]. This is due to the fact that most non renewable fuels are relatively cheap and that the price for emitting non renewable green house gases is quite low, or sometimes totally free, as in large greenhouse gas emitting countries such as China and USA. Even though the wind power technique is quite mature, very little research is done in comparison to other techniques such as steam cycles used when generating electric power from coal, gas, oil or uranium. This means that over time, wind power could perhaps be cheaper seen to the price per produced unit of electric energy, if more research is performed [7].

One way of producing cheaper wind power is to construct larger wind turbines, meaning turbines with a higher electric power output. These turbines have a larger physical size, but they only demand one site and one building- and operation permission, just as smaller wind turbines [17].

\section{Number of turbines and the installed capacity for wind power in Sweden}

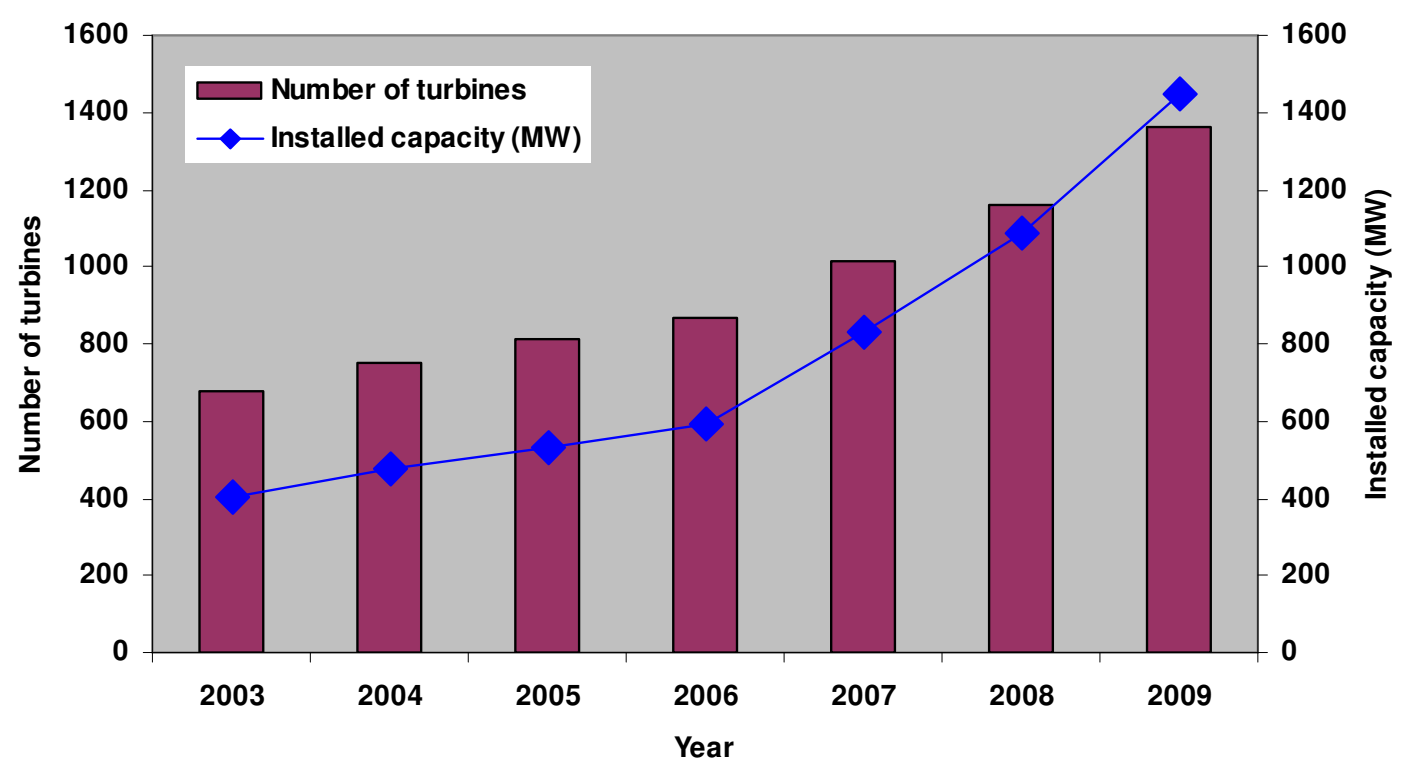

Figure 2: Number of turbines and the installed capacity for wind power in Sweden [18].

In Figure 2 it can be seen that in the year of 2003 the capacity for all Swedish wind turbines was $400 \mathrm{MW}$ whilst in 2009 the capacity was $1450 \mathrm{MW}$ [18]. When studying newly built and planned 
wind turbines, the capacity of wind turbines is today often closer to $2 \mathrm{MW}$ or sometimes even larger [19]. From the blue line in Figure 2 it's also possible to follow the total Swedish wind power capacity and its expansion from year 2003 until year 2009.

For each wind turbine type there is a power curve showing the relation between wind speed and power output.. A typical power curve is showed in Figure 3. From the power curve in Figure 3 one can see that the turbine starts to generate electric power at approximately $2 \mathrm{~m} / \mathrm{s}$ and that the electric power generation increases rapidly until $8 \mathrm{~m} / \mathrm{s}$. At $12 \mathrm{~m} / \mathrm{s}$ it produces at its maximum and at $30 \mathrm{~m} / \mathrm{s}$ the wind turbine is turned off. This power curve is for an offshore wind turbine or for an onshore wind turbine that is situated on a location with high wind speeds. In the power curve, the produced power from the turbine increases quite rapidly in the wind speed interval of 4-10 $\mathrm{m} / \mathrm{s}$. This is a direct effect of the fact that the correlation between wind speed and energy content in the wind has a cubic relation, meaning that if the wind speed is doubled the energy content in the wind is increased eight times [20].

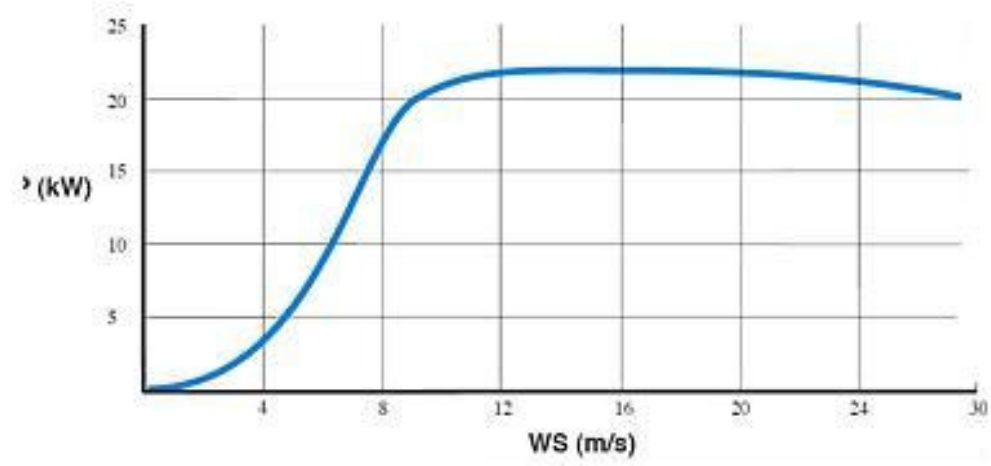

Figure 3: Power curve example of power output from a turbine at different wind speeds [20].

From Figure 3 one can also see that if the wind speed varies between $2-10 \mathrm{~m} / \mathrm{s}$ in relatively short period of times, the wind turbine will deliver electric power at its minimum and maximum in a short period of time. If the wind turbine has a high rated power and is situated together with a large number of other wind turbines, in a wind farm, the power output from the farm can also vary from its minimum to its maximum and back again during short periods of time [20].

In modern wind turbines there are techniques to prevent the electric power output of the turbines to depend too much on the changes of the wind speed. This is done by conserving some of the energy in the mass of the rotating blades and by pitching the blades to extract more or less energy from the wind [21]. 


\subsection{Production of wind power in Sweden during 2009}

In 2009 the total wind power production capacity in Sweden was approximately 1450 MW [18]. That total capacity is not to be seen as if the production at most time is equal to $1450 \mathrm{MWh} / \mathrm{h}$. By the usage of real production data for the year of 2009 this is exemplified in 2.2.1.

\subsubsection{Hourly production in Sweden during 2009}

For 2009 there are logs on how much electric power that was generated by wind turbines in Sweden. These logs are collected and put together into a complete document by SvK. A more specific presentation and explanation of this data is done later on in chapter 5.1.

However, by using this data it is possible to show how the hourly generation of electric power from wind turbines is distributed throughout the year. As stated earlier, the total wind power capacity in Sweden is approximately 1450 MW. In Figure 4 it is shown how much electric power that is generated hourly from wind turbines during 2009 .

\section{All Swedish wind turbines hourly production for 2009 , total capacity $1450 \mathrm{MW}$}

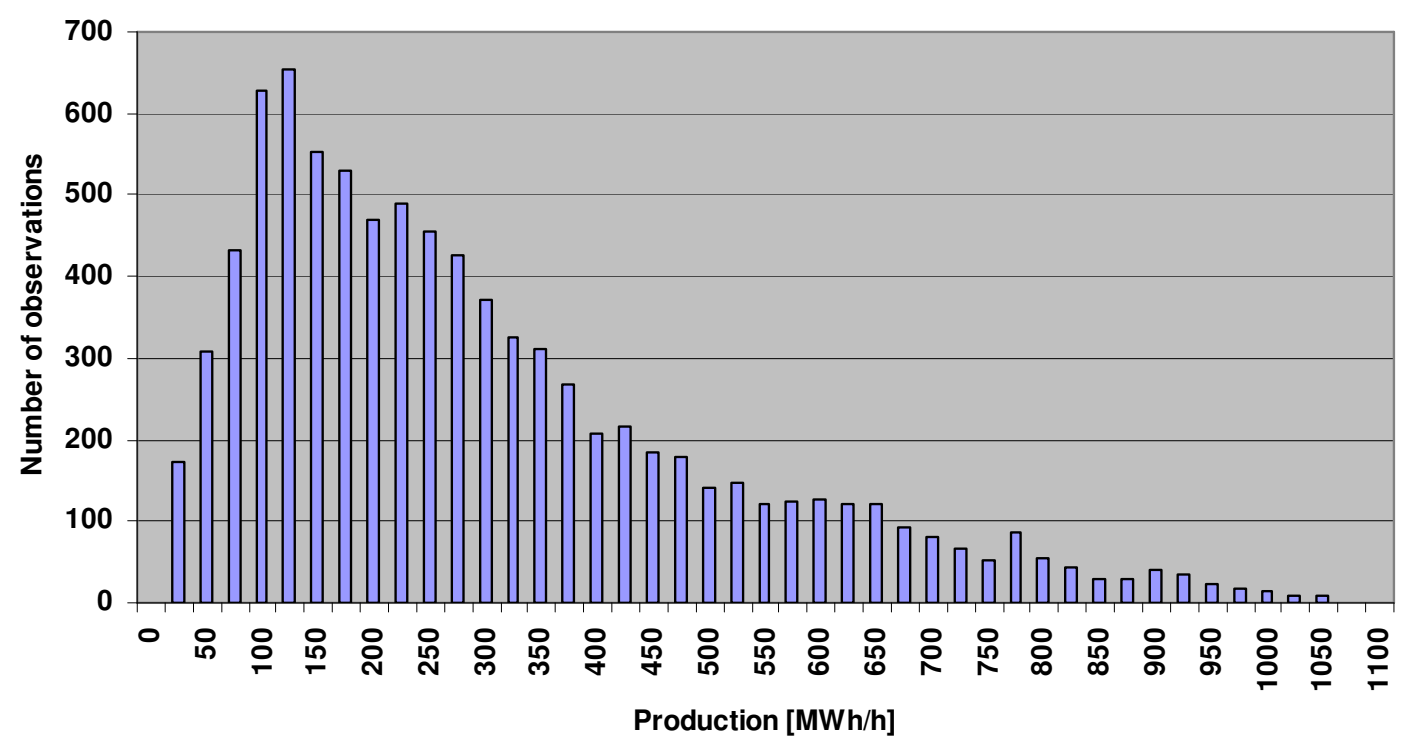

Figure 4: Histogram presenting hourly production for all Swedish wind turbines during 2009 [22].

The bars in Figure 4 represent the production and are not chronographically sorted, instead all hours with the same production is added to one bar. The total number of observations corresponds to the total number of hours during one year (8760 hours). 
In Figure 4 it is possible to see that, for some 300 hours there is a production corresponding to 50 $\mathrm{MWh} / \mathrm{h}$ (bar two from the left) and $350 \mathrm{MWh} / \mathrm{h}$ (bar fifteen from the left). For zero hours of the year of 2009 , the production was at a maximum possible value $(1450 \mathrm{MWh} / \mathrm{h})$ in the entire system, the maximum actual production was approximately $1050 \mathrm{MW}$ and this occurred during approximately 10 hours.

\subsubsection{Hours with low production}

By using the same data that was used for Figure 4 it is possible to show for how many hours of the year of 2009 that the wind power production was lower than 5\% of the total installed wind power capacity. This is illustrated in Figure 5 and gives a picture of how wind power at relatively large scale produces electricity.

\section{All Swedish wind turbines 2009 yearly production $<5 \%$ of capacity, total capacity $1450 \mathrm{MW}$}

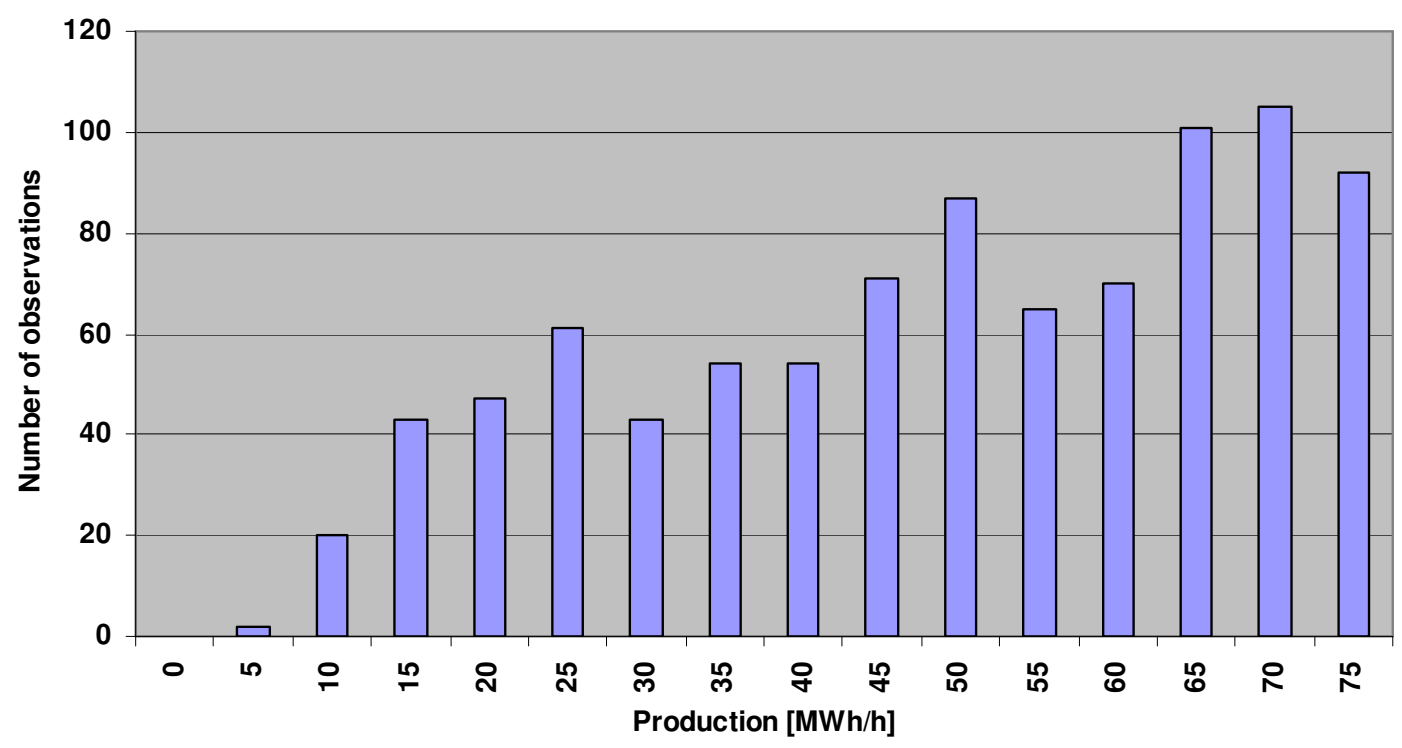

Figure 5: Number of observations where wind power production during one hour was lower than $5 \%$ of the total Swedish wind power production capacity [22].

By studying Figure 5 above the following can be seen:

For approximately 1000 hours of the total 8760 hours of 2009, which is more than $10 \%$ of the year, the total production from all Swedish wind turbines was less than $5 \%$ of the total installed capacity. The information in Figure 4 and Figure 5 shows that all wind turbines never produce electric power at maximum rate and during a large part of the time, just a minor part of the capacity is used. 


\section{Vattenfall Research and Development AB}

However, during the majority of the time there is some production and as stated earlier the total production during 2009 was 2 TWh. Giving an average utilization factor of $16 \%$, meaning that if the production would be even during the year, the total capacity of $1450 \mathrm{MW}$ would in average be producing at $228 \mathrm{MW}$ throughout the year.

\subsection{Power output and forecasting}

As mentioned in the introduction of this report, electric power in Sweden is bought and sold on a Nordic market site; this site is called Nord Pool. On Nord Pool all electric power is sold for the upcoming day at 12:00 am one day in advance [23]. This means that when a generation company give their offers for the electric power they intend to sell for the next day, it can be as long as 36 hours until they are supposed to generate the power that they are selling. For commonly used electric power plants, such as hydro power or thermal power plants, this is normally not a problem due to that the power producer is aware of the levels in the hydro dams and the fuel reserve in the thermal plant. This means that it is unusual for hydro plants or the thermal plants to be unable to produce the power that they have already sold on the market [23].

With wind power the situation is completely different since electric power generated from wind turbines is intermittent, i.e. just as electric power generated from the sun and the waves. This means that factors that are not controllable will set the conditions for production from these generation alternatives. For wind turbines and wind farms it means that the power output will vary with the wind speed and that no electric power is generated at low, or non-existing, wind.

Another problem with selling electric power generated by wind turbines in Sweden is that the producer sells an amount of electric energy evenly divided over an entire hour on Nord Pool [23], when in fact the wind power actually produced can vary within much shorter period of times than one hour. This makes forecasting a very important tool for the power producer, for them to be able to sell the right amount of wind power (forecasting means that the power producer tries to predict how much wind power that will be produced depending of the upcoming weather situation) [23]. This is especially important, since a producer that sells more energy than he can deliver is forfeited when the balancing is made the day after production [22].In Figure 6 and Figure 7, the measured hourly production in $\mathrm{MWh} / \mathrm{h}$ during a 24 hour period for Vattenfalls wind farm Lillgrund, situated offshore in the south of Sweden, and the forecasted production in $\mathrm{MWh} / \mathrm{h}$, is shown. The date for the data used in these figures is January $1^{\text {st }} 2009$. Lillgrund has a maximum capacity of $110 \mathrm{MW}$, evenly divided on 48 wind turbines [24]. 
Hourly production for Lillgrund, 1 January 2009

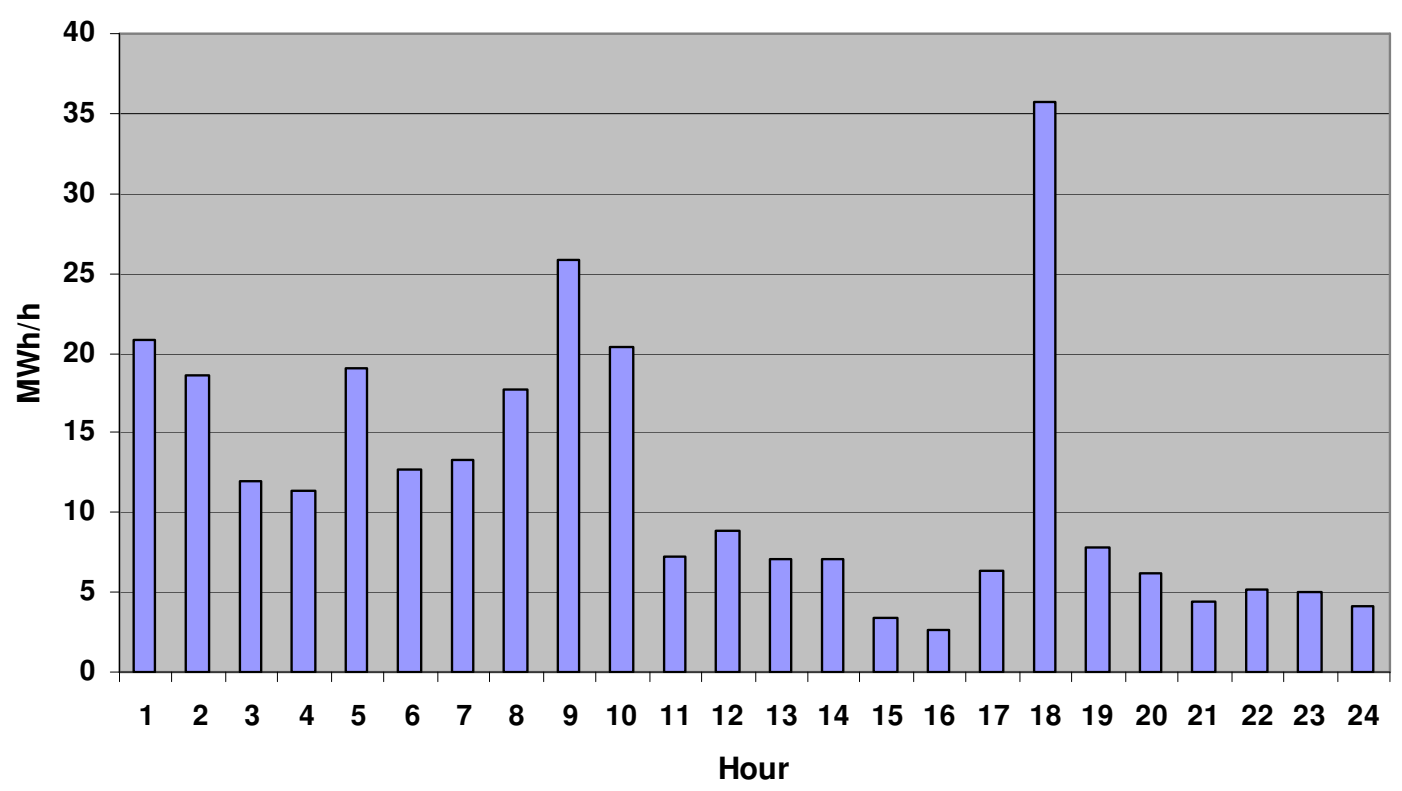

Figure 6: Exemplification from data of Lillgrund's production during one day. Chosen day is the $1^{\text {st }}$ of January 2009 [25].

As can be seen in the Figure 6 the production from hour to hour can vary drastically. If studying hour 17 and compare it with hour 18, the production increases with almost $30 \mathrm{MWh} / \mathrm{h}$ in just one hour. When comparing hour 18 and 19, the production decreases with $28 \mathrm{MWh} / \mathrm{h}$. The measurement $\mathrm{MWh} / \mathrm{h}$ is used as an average and is the most commonly used unit when selling and buying power. It is not the same as delivering for example $35 \mathrm{MW}$ constantly during the entire hour which will be explained in chapter 2.4. In hydro power plants or thermal power plants it most probably means that the plant has delivered $35 \mathrm{MW}$ constantly during the deliverance hour, but when studying intermittent power producing units this is not the case. 


\section{Hourly production and forecast of production Lillgrund, 1 January 2009}

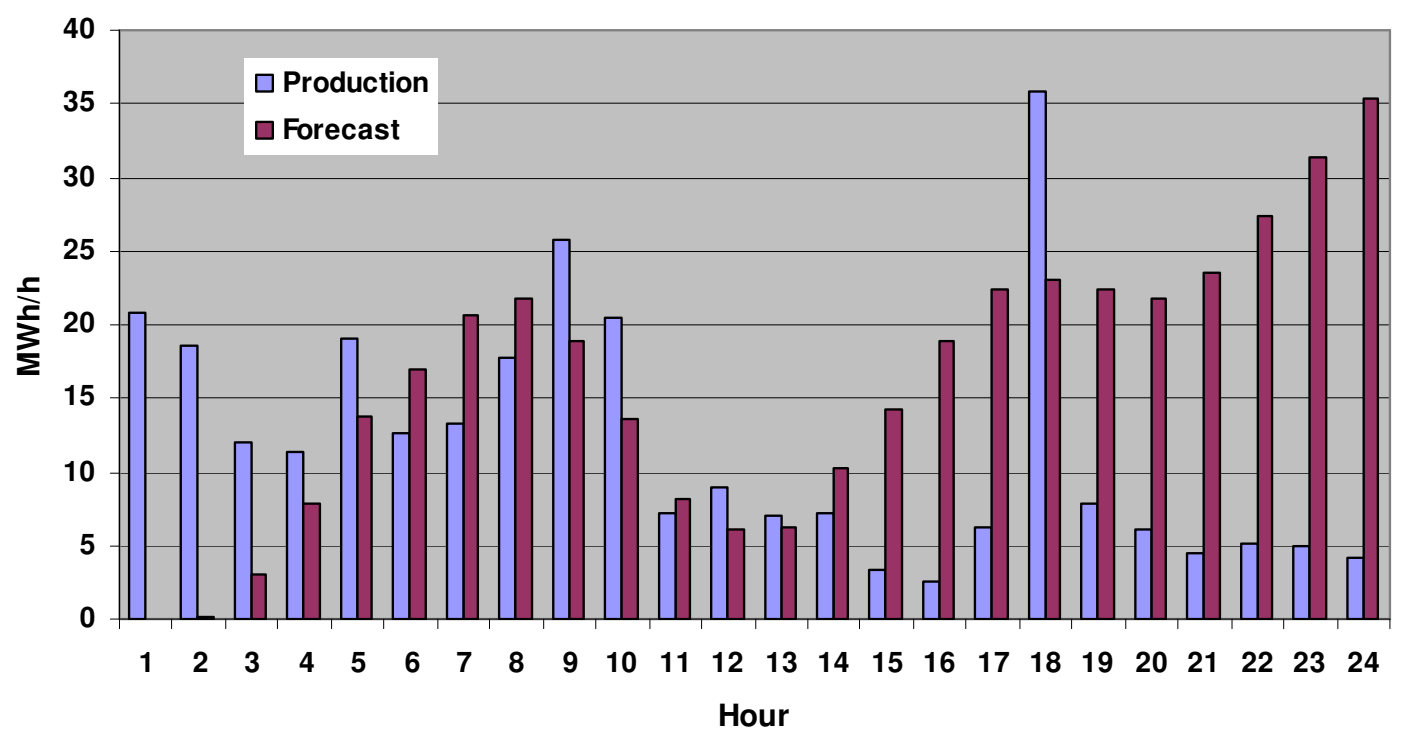

Figure 7: Comparison of forecasted ( 24 hour in advance) and real production during the $1^{\text {st }}$ of January 2009 for Lillgrund wind farm [25].

Figure 7 shows the difficulty to make correct forecasting. One can see that for none of the 24 hours, the forecast is correct. The dark red bars shows what is forecasted and sold to the market whilst the blue bars shows what is actually produced. If studying hour 24, one can see that the forecasted production is $35 \mathrm{MWh}$, at the same hour only $4 \mathrm{MWh}$ is produced, giving an error of $31 \mathrm{MWh}$. In this report, problems regarding forecasting are not included. It is however an important tool and one of the key stones if wind power is to play a major part in a future electric power system [26].

\subsection{Production within the hour}

This report focuses on the stochastic variations from electric power generated by wind turbines and the effects of these variations on the electric power system, especially if wind power will increase significantly in Sweden. In Figure 8 the power output from Lillgrund wind farm during one hour divided into five minutes intervals is shown. The date is still January $1^{\text {st }} 2009$. 
Production every 5-minute intervall Lillgrund 1 January 2009

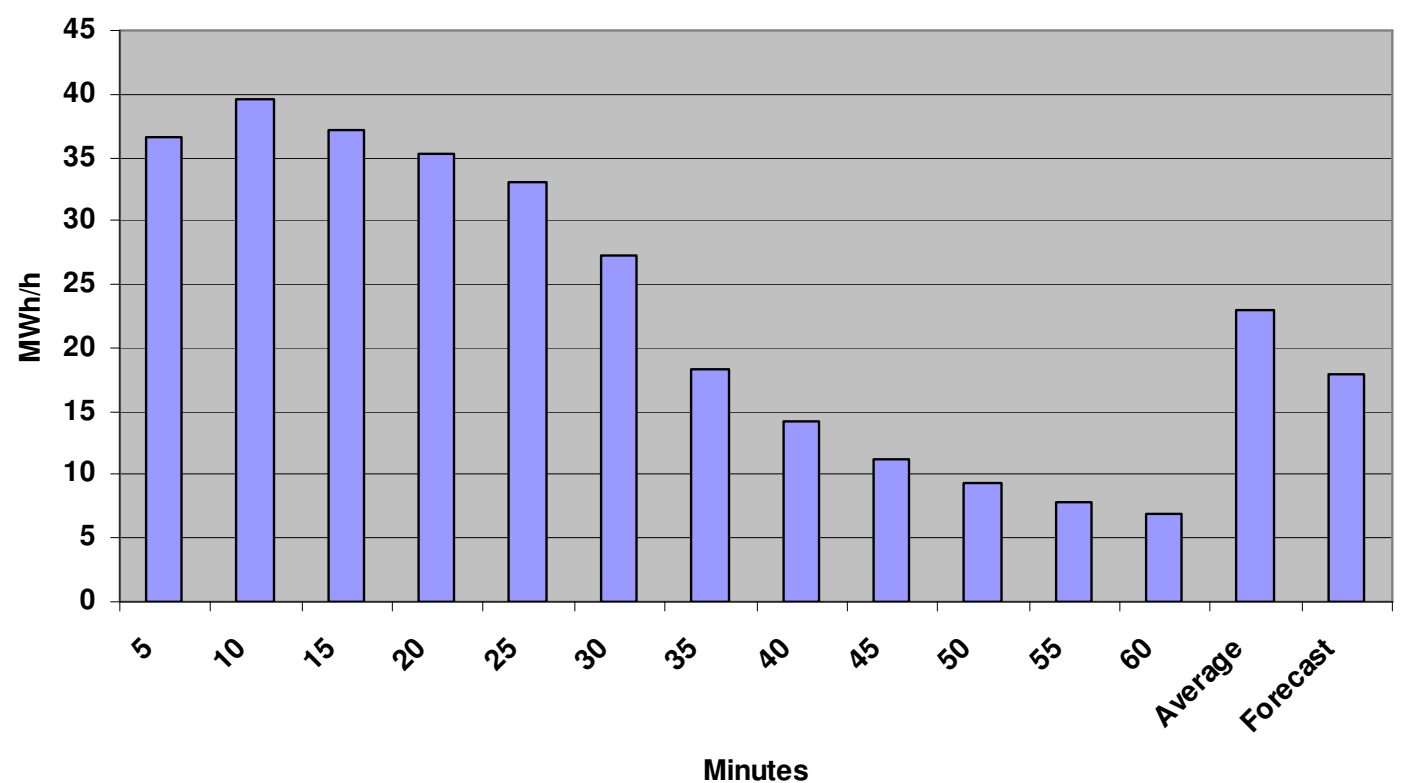

Figure 8: Wind power production during one hour [25].

As one can see in Figure 8, the production within the hour varies between $40 \mathrm{MWh}$ in the second 5 -minute interval to $7 \mathrm{MWh}$ in the last 5-minute interval. The average production is $23 \mathrm{MWh}$ whilst the forecasted production was $18 \mathrm{MWh}$. So, when thinking of wind power production one must always have in mind that forecasted and sold production is not the same as real production. And produced production during one hour is almost never constant. When looking in the logs from the production from wind turbines, the most commonly logged time frame is one hour, but in that hour the production can vary with large numbers, according to Figure 8. 
Production every 5-minute intervall Lillgrund 4 January 2009

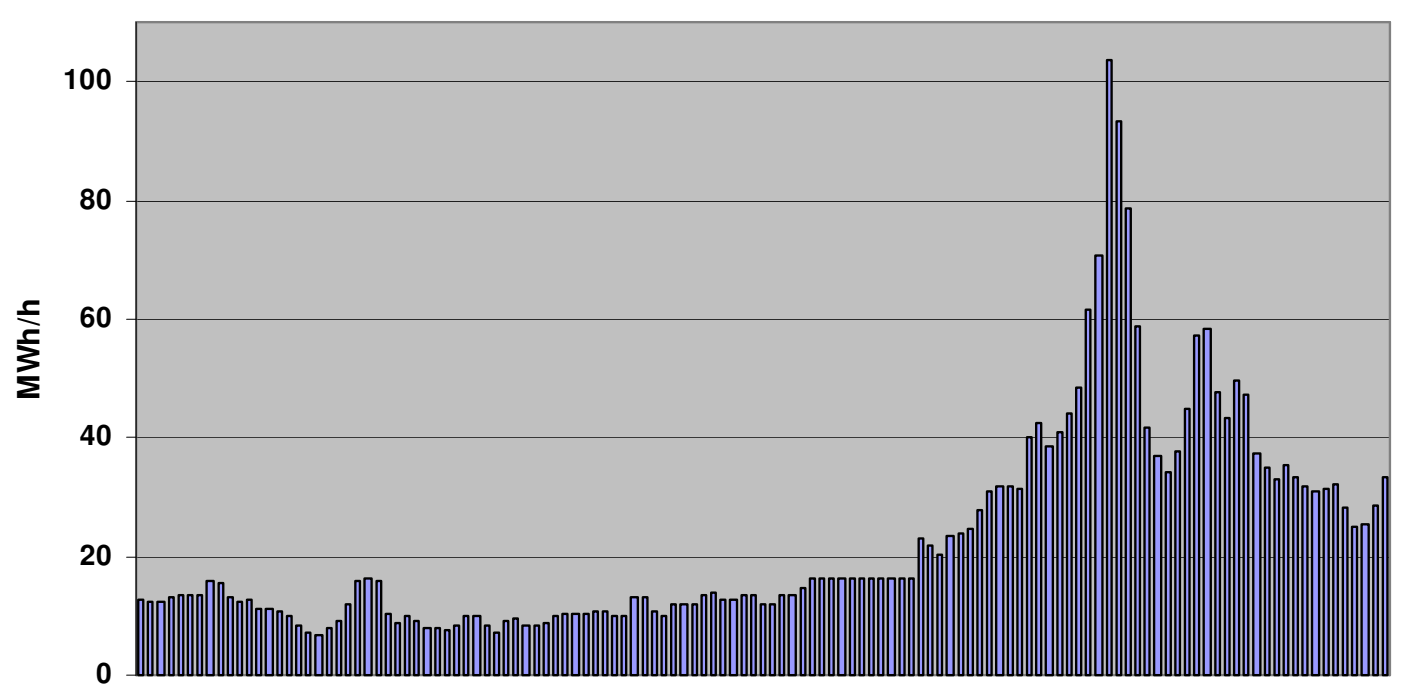

Minutes

Figure 9: Production from Lillgrund during the $4^{\text {th }}$ of January 2009 in 5-minutes interval [25].

In Figure 9 the production at Lillgrund wind farm from the $4^{\text {th }}$ of January 2009 is shown to give a picture of how the production varies during a day when the time frame is made smaller.

\subsection{Wind power production variation hour-to-hour}

In the previous chapters production forecasting, real production and production within the hour has been presented. To learn how the real production varies hour-to-hour for one wind turbine, one wind farm, or from all wind turbines in one predefined geographic area a new concept is presented. This concept is based on the difference in production from one hour to the next hour. In the model constructed later on in the report, this concept is presented in detail, but the functionality of the concept is the following:

In order to know how large variations from wind power production that the power system must be able to balance, the largest hour-to-hour production variations for different wind power capacities must be investigated. This will be done with development rates corresponding to the goal of a production of 10/30/50 TWh electric energy yearly from wind turbines in the Swedish system.

\subsection{Market and system effects due to wind power production}

In Figure 7, that shows the difference between real wind power production and forecasted production, and in Figure 8, that shows the production variations within the hour. One must understand that at all times the wind power production does not correspond to the forecasted 


\section{Vattenfall Research and Development AB}

production another generating source must balance the deficit or surplus of wind power production. This is due to that the forecasted electric energy is already sold and that there are consumers expecting to have the electric energy delivered during the hour they have bought the specific amount.

As long as there are relatively small amounts of installed wind power capacity in Sweden this is not a big problem. This is due to that another power generating source can cover for the missing wind power, or in a case of wind power surplus, another power generating source can generate a little less power [27].

If the market rules change in a favourable way for forecasting accuracy and more forecasting research is done to increase the total accuracy of the forecasting, it is possible to expand wind power production with less power system effects than if the forecasting accuracy is kept at the same level as today [27]. This is due to that if the TSO and the power producers know how the wind power production will vary over time it is much easier for them to balance the power from the wind turbines with other power generating sources, than if they do not know how it will vary [28].

If forecasting accuracy is improved, the real production of wind power will still look like in Figure 8. At some point, the total capacity of wind power in case of an expansion will be so large that it is not possible to balance it with the current power system, even if one knows how the wind power production will vary. This is due to that there are not unlimited power sources that can balance the wind power productions fluctuations and there is not unlimited unused capacity in the transmission and distribution grid [5].

As mentioned in the introduction to this report, just a few percent of Sweden's electric power need is generated by wind power today, but the goal for Sweden is to increase the wind power share in the electric power system significantly.

In the present Swedish electric power system, wind power does not cause big problems today [5]. But at what wind power capacity does electrical power system problems occur and where do these problems occur? Allocation, increased knowledge and possible solutions to these possible problems are one of the main tasks for this report.

\subsection{Knowledge concerning expansion effects}

Before the creation of a model later on in this report, there are effects on the electrical power system that occur when expanding wind power capacity over a larger geographical area.

There is a positive effect that has been investigated when expanding wind power capacity over a larger area. This effect is called spatial smoothening effect. This means that if wind power expands over a larger area and a system boundary is created around the wind turbines, there will be a positive smoothing effect of production variations due to the fact that the wind turbines are 


\section{Vattenfall Research and Development $A B$}

situated in areas with different wind properties. If there is no wind in area $\mathrm{A}$, there is a quite high probability that there is wind in area $\mathrm{B}$ or $\mathrm{C}$, if area $\mathrm{A}, \mathrm{B}$ and $\mathrm{C}$ is situated with a quite large distance between them. Since there are different wind properties in area A, B and C, the wind power production from area $\mathrm{A}, \mathrm{B}$ and $\mathrm{C}$ will not look the same [27]. To investigate how this positive effect might be achieved in Sweden, a mathematical function correlation will be used. A more detailed explanation of correlation and the power system effects by large scale wind power expansion in Sweden is made in chapters 5 and 6.

\subsection{Yearly production}

Wind power production is of course directly dependent of the wind property of the area where the wind turbines are placed. When an area is investigated for future wind power expansion many factors must be considered. Two of these factors will briefly be presented for the future work in this report.

\subsubsection{Operating hours}

The first factor is operation hours of a wind turbine. When talking of wind power the term operation hours for a specific turbine or farm is often mentioned. A normal number of operation hours is somewhere between 2000 and 3000 hours per year, giving a utilization factor of somewhere between 20\% - 35\% (the 2000-3000 hours divided by 8760 hours in a year). This might be understood as if the wind turbine or farm operates at full power for $20 \%-35 \%$ of the year. This is not true. In fact the turbine or farm is most likely to deliver power during much more than $20 \%-35 \%$ of the year. The total delivered electrical energy during one year is however divided with the capacity of the turbine or farm times the total hours of one year giving this ratio [20].

\subsubsection{Cut-off wind}

The second factor to keep in mind is more related to specific weather conditions. All modern wind turbines have a maximum wind speed of where it is designed to operate below, so called cut-off wind. If that specific wind speed is exceeded the turbine is turned off in order to protect it from damage [20].

Since high wind speeds does not occur suddenly, but gradually, wind turbines will produce at its maximum power right before being turned off in the event of a cut-off wind speed [37]. At the time a storm front reaches a wind farm, the entire farm would be turned off during a very short period of time. This would give a power production drop equal to the entire wind farm capacity [20]. 


\subsubsection{Aggregation}

As mentioned earlier, there is chance that an entire wind farm can be turned out of wind almost simultaneous if the cut off wind speed occurs. This has a negative effect for the power system, due to that power of equal size as the capacity of the wind farm is lost in a very short period of time. One way of minimizing this large power loss is to install wind turbines with an aggregation power curve. A typical aggregation power curve can be seen in Figure 10. By exploring the figure it is possible to understand that when the wind speed exceeds $25 \mathrm{~m} / \mathrm{s}$ the power output from the wind turbine is lowered until the wind speed reaches $35 \mathrm{~m} / \mathrm{s}$ and the turbine is turned off [20].

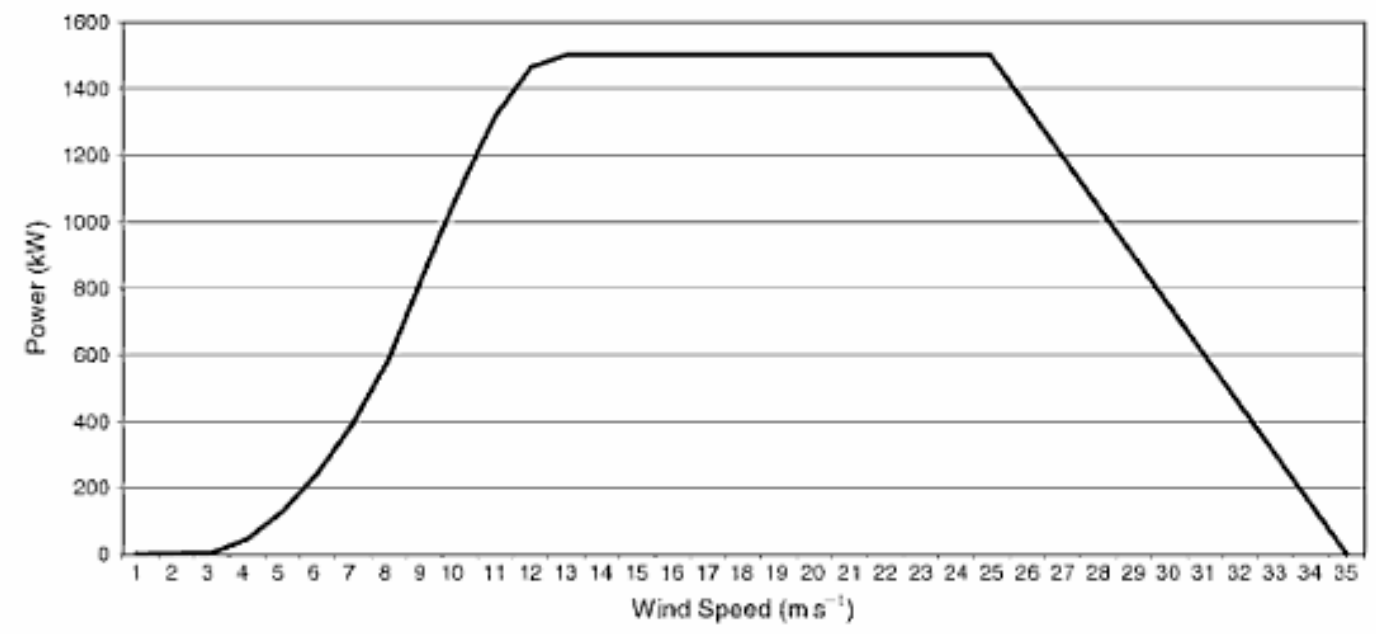

Figure 10: Power curve for a wind turbine with aggregation capacity [20].

\subsection{Planned expansion}

The planned expansion of wind power in Sweden is based on studies that take several factors into consideration before recommending a site for exploitation. This means that studies are made on where to locate the wind turbines and wind farms in order to achieve a high rate of full load hours. Several other factors are also important such as grid connection possibilities and possibilities to get to the potential sites. When a company have found an interesting site they need to apply for permission from different authorities before starting to exploit the site. Vindforsk has summarized these studies from different companies and through that survey it is possible to somewhat predict how the increased wind power expansion will be distributed geographically and also in time. The maps published by Svensk Vindenergi that summarizes the operational farms, the once under constructions and the once having and seeking permits can be found in the appendix. If the Swedish wind power is expanded to produce 10/30/50 TWh per year the installed capacity could be distributed as follows [30]. 


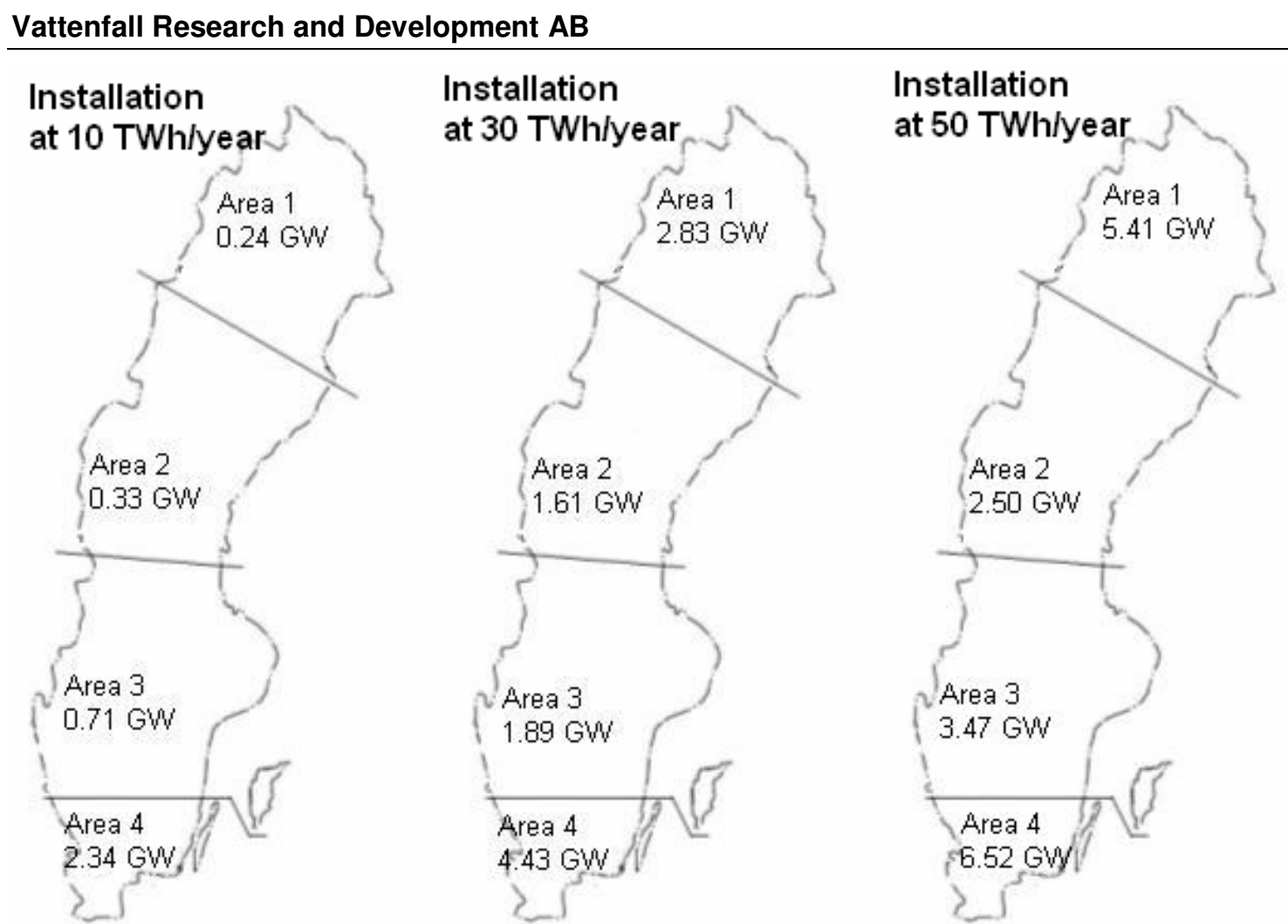

Figure 11: Planned expansion in different areas in GW depending on yearly production in TWh [30].

Table 1: Installed capacity in different areas when yearly production is 10TWh/year [30].

\begin{tabular}{llllll}
\hline Area & $\mathbf{1}$ & $\mathbf{2}$ & $\mathbf{3}$ & $\mathbf{4}$ & Total \\
\hline Installed capacity $(\mathrm{GW})$ & 0,24 & 0,33 & 0,71 & 2,34 & 3,62 \\
\hline Production (TWh) & 0,55 & 1,93 & 1,65 & 6,44 & 10,57 \\
\hline
\end{tabular}

Table 2: Installed capacity in different areas when yearly production is 30TWh/year [30].

\begin{tabular}{llllll}
\hline Area & $\mathbf{1}$ & $\mathbf{2}$ & $\mathbf{3}$ & $\mathbf{4}$ & Total \\
\hline Installed capacity $(\mathrm{GW})$ & 2,83 & 1,61 & 1,89 & 4,43 & 10,75 \\
\hline Production $(\mathrm{TWh})$ & 7,84 & 4,39 & 6,11 & 13,65 & 31,99 \\
\hline
\end{tabular}

Table 3: Installed capacity in different areas when yearly production is 50TWh/year [30].

\begin{tabular}{llllll}
\hline Area & $\mathbf{1}$ & $\mathbf{2}$ & $\mathbf{3}$ & $\mathbf{4}$ & Total \\
\hline Installed capacity $(\mathrm{GW})$ & 5,41 & 2,50 & 3,47 & 6,52 & 17,88 \\
\hline Production (TWh) & 15,14 & 6,86 & 10,57 & 20,85 & 53,41 \\
\hline
\end{tabular}




\section{Power system function and market}

\subsection{Power system in Sweden}

In 1909 the first large hydro power station in Sweden started delivering electric power to the grid, in the following four decades hydro power was expanded throughout the entire country. The majority of the hydro power potential is situated in the north of Sweden, whilst the majority of the consumers are situated in the south. In order to transfer the electric power to the consumers a transmission system consisting of high voltage lines was built. In the 1970's the first nuclear units were connected to the power grid and in the 1980's the latest nuclear reactors were put into service. The generation system Sweden has today consists mainly of centralized production from large hydro stations in the north and condensing power plants (nuclear) in the south. To transfer electric power from hydro power stations in the north to the population in the south, a transmission system consisting of mainly $400 \mathrm{kV}$ and $220 \mathrm{kV}$ power lines is used. The mix of hydro and nuclear units gives a flexible system that can deliver steady base load power (hydro and nuclear) and at the same time hold high flexibility towards load changes (hydro) [31].

\subsection{Definition of regulating power}

In an electric power system, the instantaneous consumption and production of electric power must at every time be equal due to the fact that electric power cannot be stored. The Nordic electric power system is designed for a frequency of $50 \mathrm{~Hz}$. If there is a larger demand than there is production the frequency will drop since energy will be taken from the rotating masses (generators and machines) and vice versa. The energy stored in the spinning masses of turbines, generators and machines will however give some perseverance in frequency change [32].

To be able to balance the production with respect to the fluctuations in consumption, some kind of balancing is needed. The source of balancing is called regulating power and is supplied by generating units that have a good ability to quickly change their electric power output, preferably both up and down. Regulating power can be divided into two different subcategories, primary and secondary regulating power, depending on how or when the regulating units are to be used. There is also a reserve in the system in order to be able to cover large disturbances like the fast shut down of a nuclear reactor or the failure of a large switchyard, causing lack of transmission capacity between regions. The reserves are provided as an ancillary service by certain generation companies towards Svenska Kraftnät [32].

\subsubsection{Primary regulating power}

Primary regulating or frequency controlled automatic operation reserves are power plants running at an intermediate level (in Sweden almost exclusively hydro plants) for fast increase or decrease of production. In the Nordic system primary regulating are designed to handle a 


\section{Vattenfall Research and Development $A B$}

fluctuation of $\pm 0.1 \mathrm{~Hz}$ which corresponds to $600 \mathrm{MW}$ of electrical power. The Swedish TSO is obligated to secure $235 \mathrm{MW}$ of those $600 \mathrm{MW}$ in Swedish power plants while the rest are divided by Norway, Finland and East Denmark. The amount that each TSO is obligated to secure depends on the country's electric power demand during the previous year [32]. The operational reserves will automatically regulate the production when an increase or decrease occurs in the system in order to stabilize the frequency at a new level that is within the range of $49.9-50.1 \mathrm{~Hz}$ [23][32][33].

\subsubsection{Secondary regulating power}

Secondary regulating, or frequency controlled manual operation reserves, consist of fast starting power plants such as hydro and gas turbines. The manual operation reserves is used to bring the frequency back to $50 \mathrm{~Hz}$ when a drop has occurred and the frequency has stabilized on a new level through the use of primary regulating. Secondary reserves can also be upgraded to become primary reserves when the primary reserves are put into action depending on if the primary reserve plants needs to keep running due to lack of generation capacity [23][32][33].

\subsubsection{System reserves}

System reserves are activated when the frequency drops below $49,9 \mathrm{~Hz}$ and should be fully activated at 49,5 Hz. System reserves are secured by the TSO (Svenska Kraftnät) by contracts with different generation companies in order to get a geographical spread of the reserves. The system reserves can also mean disconnection of certain industries and other large electric power consumers that have disconnection contracts with the TSO [23][32][33].

In area 1 and area 2 there is, as mentioned before, a large availability of hydro power providing these areas with the needed reserve power. In area 3 and area 4 however there is not enough hydro power to keep the balance at all times. Due to this problem there are power plants in area 3 and area 4 that can be used when a deficit of power is about to occur.

Table 4: Reserve power in area 3 and area 4. Divided into subcategories and in total [8].

\begin{tabular}{ccccc}
\hline Area & $\begin{array}{c}\text { Fast power } \\
\text { reserve [MW] }\end{array}$ & $\begin{array}{c}\text { Disturbance } \\
\text { reserve [MW] }\end{array}$ & $\begin{array}{c}\text { Condensing power } \\
\text { reserve [MW] }\end{array}$ & $\begin{array}{c}\text { Total reserves } \\
{[\mathrm{MW}]}\end{array}$ \\
\hline 3 & 774 & 751 & 465 & 1990 \\
\hline 4 & 17 & 473 & 660 & 1150 \\
\hline
\end{tabular}

In Table 4 the reserve power in area 3 and area 4 is summarized. The disturbance reserve is gas turbine power plants that are only used when there is a deficit of power, these disturbance reserve plants are owned by SvK or by generation companies. The condensing power reserve is power plants owned by generating companies. All three types of reserves must be able to deliver power 


\section{Vattenfall Research and Development $A B$}

no longer than 15 minutes after they have been ordered to start. For area 4 there is also a power reserve of $300 \mathrm{MW}$ that is used by both Sweden and Denmark [8][32].

The reserves can be used in different ways. If the bids from buyers of power, in a total, are larger than the bids from sellers of power on the power market, there will not be a market clearing price for that specific hour. SvK then offers some of the reserves to the market so that supply and demand of power will be equally large. The other alternative is that there for some reason is a deficit of power in the power system which cannot be matched with the bids for regulation power already accepted on the market. If the second alternative occurs, some of the power reserves are taken in use [8][32].

\subsubsection{Hydro power as regulating power}

The hydro power stations in Sweden can be divided into two groups, base load stations and power stations [34]. According to Vattenfall Nordic Generation Management, base load stations run at constant flow during the year and are normally not used as regulating stations. One example is Vietas which is situated as one of the first stations upstream in Stora Luleälven. Vietas is situated between two large reservoirs which make it possible to keep it running most of the year at a high level without exceeding the reservoirs minimum- or maximum level.

Power stations are hydro stations that have a high rate of installed power but seldom run at maximum capacity for very long. Further south in Stora Luleälv from Vietas there is a station called Harsprånget, which is situated between two fairly small reservoirs but has a high head and a very large installed capacity, approx. $1000 \mathrm{MW}$. This station has a very flexible regulating potential due to the large amount of installed power and can quickly balance a large drop in electric power generation or a fast and large increase in demand [34].

The way the stations are used is however mainly an economical question since they are all owned by different companies that compete on the same market. But when it comes to balancing within the hour hydro power is almost the only option especially in Sweden where the amount of installed capacity in hydro stations is quite large [33].

\subsection{Importance of frequency control}

When referring to electric power on a daily basis the most common term used is voltage, in the Nordic system the nominal voltage in sockets is $230 \mathrm{~V} \pm 10 \%$ [35][35]. The frequency in the system is directly related to the angular velocity of the spinning components in the system, all these components have frequencies, or velocities, where resonance occurs. Turbines in thermal power plants will have to be taken offline if the frequency drops below $47.5 \mathrm{~Hz}$. Water turbines, which are more robust, do not need to be disconnected until the frequency drops down to $45 \mathrm{~Hz}$. There are of course limitations on how much the frequency can increase but since the system is 


\section{Vattenfall Research and Development $A B$}

designed to balance consumption with production it is no problem for the TSO to lower the frequency by decreasing the production [32][33].

The problem with fluctuating frequencies of course also appears on the consumer side. Electrical equipment such as electric motors in industrial applications and household appliances are dependent on amplified current being delivered with a frequency of $50 \mathrm{~Hz}$. If the frequency increases the angular velocity will increase causing the motors to overheat which will lead to failure.

\subsection{Transmission system}

As mentioned before the Swedish transmission system consists of $400 \mathrm{kV}$ and $220 \mathrm{kV}$ power lines and are used to transfer large amounts of electric energy over long distances. The first transmission lines were used to deliver the electric power generated by the large hydro stations in the northern parts of Sweden to the consumers in the south. This is still the case which, can clearly be seen in Figure 12 [31]. 
DET NORDISKA ÖVERFÖRINGSNÄTET

The transmission grid in the Nordic countries

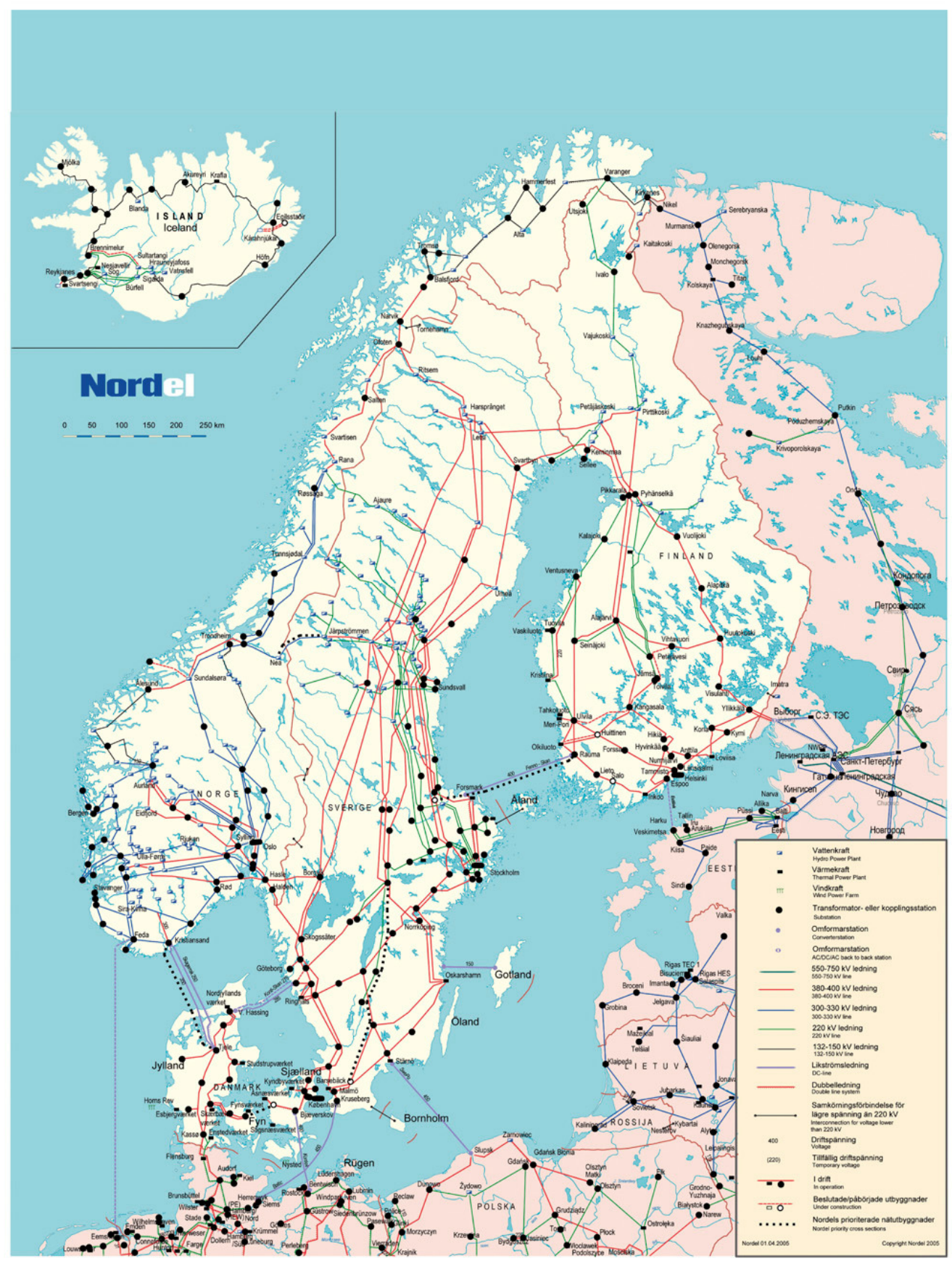

Figure 12: Nordic transmission system, $400 \mathrm{kV}$ lines are represented by red lines and 220 $\mathrm{kV}$ lines are represented by green lines [36]. 
Although the transmission system has a high capacity it is not unlimited. According to the TSO in Sweden (Svenska Kraftnät) there are three limiting bottlenecks, or so called cross-sections, in the system where congestion sometimes occur. Theses cross-sections can be seen in Figure 13 and their respective maximum transmission capacity in Table 5.

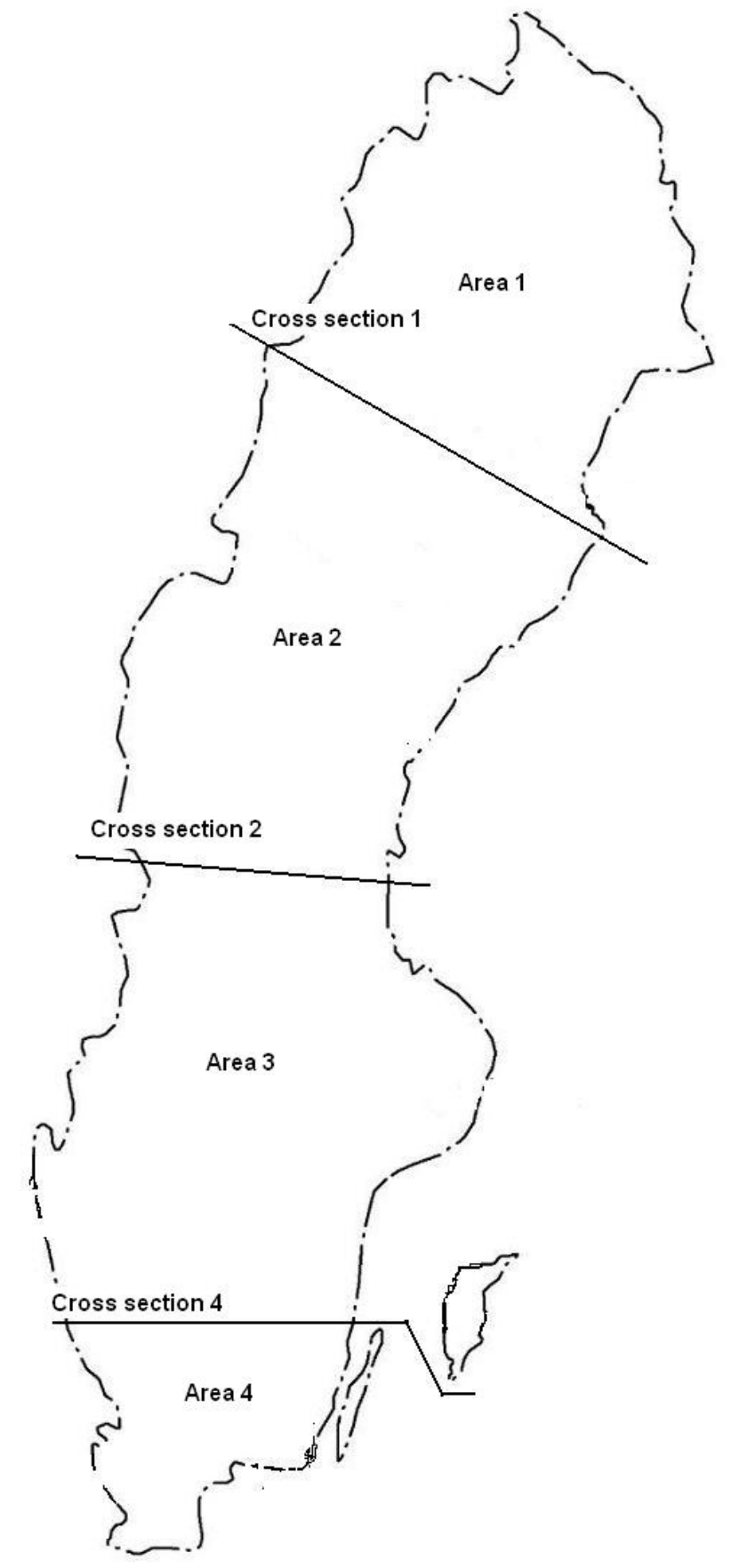

Table 5: Cross-section capacity [5].

\begin{tabular}{|c|c|}
\hline $\begin{array}{c}\text { Table Cross- } \\
\text { section }\end{array}$ & $\begin{array}{c}\text { Transmission } \\
\text { capacity [MW] }\end{array}$ \\
\hline 1 & 3200 \\
\hline 2 & 7000 \\
\hline 4 & 4500 \\
\hline
\end{tabular}

Table 6: Current installed wind power capacity in different areas [18].

\begin{tabular}{|c|c|}
\hline Area & $\begin{array}{c}\text { Wind power } \\
\text { capacity [MW] }\end{array}$ \\
\hline 1 & 65 \\
\hline 2 & 175 \\
\hline 3 & 670 \\
\hline 4 & 540 \\
\hline Total & 1450 \\
\hline
\end{tabular}

Figure 13: Cross-sections in the Swedish transmission system [5]. 


\section{Vattenfall Research and Development AB}

The map in Figure 13 also shows the different areas that the Swedish electric power system is divided into. These areas will be referred to in the model and simulation when wind power capacity is expanded. The current installed wind power capacity in the different areas can be seen in Table 6.

\subsection{Power Market}

In 1996 the Swedish power market was deregulated [31]. The deregulating was realized to create a competitive market for a efficient pricing of electric power. The market is designed so that the consumer can choose which company they want to buy their electric power from.

The transmission system is still a part of a nation wide monopoly, whereas the distribution grid is divided in local monopoly systems. However, all producers are allowed to deliver electric power through all distribution grids although they might not own the distribution network.

Today Sweden is a part of a Nordic electric power market and the market place where electric power is bought and sold is called Nord Pool.

The Swedish TSO, SvK is responsible for the balance in Sweden [23].

\subsubsection{Pricing of electric power}

The price that a Swedish consumer pays for electric power can be divided into three parts:

1. Consumed electric power, including certificates. This part is paid to the generation company and it is this part that is affected on the competitive market, since this power is bought and sold on the Nord Pool market place.

2. Usage of the grid. The nation wide transmission grid as well as the local distribution grid. This price is hard to affect as a consumer, due to the monopoly regarding grid ownership.

3. Tax and fees, normally called energy tax. Hard as a consumer to affect [23].

\subsubsection{Nord Pool}

Nord Pool is owned by the Swedish and Norwegian TSO's, SvK in Sweden and Statnett in Norway to equally large parts. Nord Pool has multiple markets, such as Elspot, Elbas and Eltermin [23]. On these markets power producers (companies that own electric power plants) and consumers (buyers of electric power) give their bid on what price they are prepared to sell at and which price they are prepared to buy at respectively. In this case a consumer means a electricity broker that buys large quantities of electricity and then sell the electricity to individual consumers, such as individual households. The different markets have the following functions:

- Elspot is the market place where electric energy is bought and sold for the upcoming 24 hours. The price per unit of electric energy and the amount of electric energy that is sold is settled on the market. The price and the amount of energy are settled on an hour basis. The producers are not allowed to set a price higher than what their real cost is. 
On the other side, we have the buyers of electric energy. The buyers give away their bids for how much electric energy they want to buy hour by hour and to what price. By pairing the highest bided price by the buyers with the highest selling price, of course with the right quantities, a market price is created. This market price will give all the sellers of electric energy the highest acceptable price and all the buyers that same price. To understand this function better, see Figure 14. The price that is accepted for each hour is called the market clearing price [23].

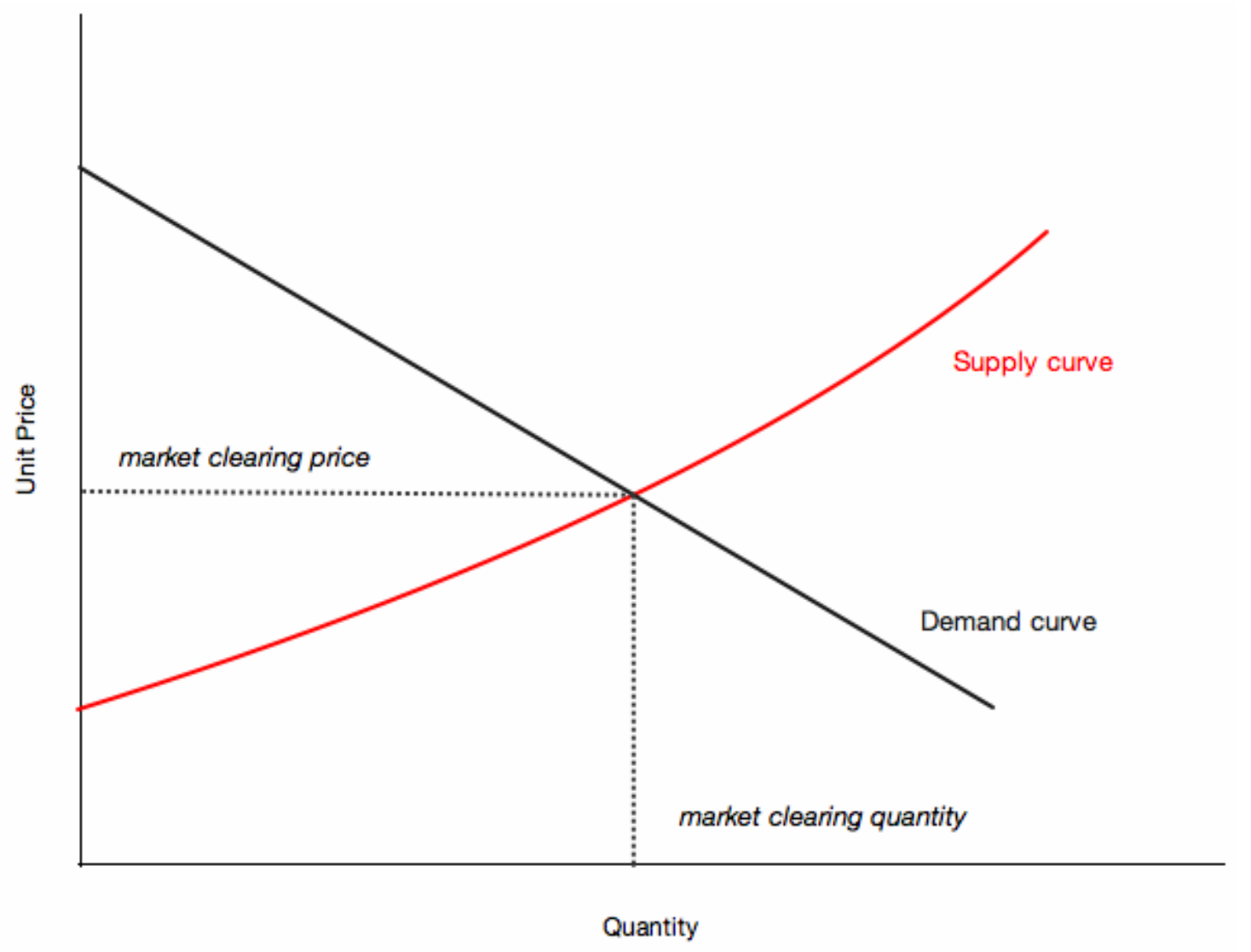

Figure 14: Example of the function of Elspot and Elbas. The red line is the supply out for sale by the producers while black curve is buyers bidding. The intersection is the market clearing price, and thereby the accepted price for one specific hour [23].

- Elbas is the adjustment market where electric energy can be bought and sold until one hour before deliverance. This market is created because the amount of energy that producers and consumers have bought respectively sold on Elspot might not correspond to the amount of energy they can sell or consume at that specific hour [23]. One reason for this is the problem with forecasting production and consumption 12-36 hours in advance.

- Eltermin is a market place for consumers that for some reasons do not want to rely on the spot market. For example companies consuming large quantities of electric energy. 
On this market these consumers can buy electric energy long before the actual consumption date and hour of deliverance, and thereby secure the price they pay for each unit of electric energy. This market is used both ways, meaning that a company can sell back the energy they have bought, but not need to use, to other consumers on the market [23]. 


\section{Wind power impact on electric power system and market}

\subsection{Background and previous publications}

There are several reports, both Swedish and European, which discusses the problems of implementing intermittent electric power generation to existing electric power systems. Several different aspects can be found since different systems are used as base. Although all these reports bring up interesting questions, the Nordic system is somewhat different from the European. Although material concerning both the Nordic and European system is used as references, the major focus will be on the Swedish electric power system and, to some extent, Nordic system in this report. For the studies concerning the Swedish and Nordic system, many of the studied publications are built on each other and use the same model to simulate a larger wind power penetration.

\subsubsection{Previous modelling of the electric system with increased wind power capacity}

Today the amount of installed wind power within the Swedish electric power system is approximately $1500 \mathrm{MW}$, producing $2 \mathrm{TWh}$ per year [6]. The wind turbines are geographically concentrated to the south of Sweden (Skåne, Blekinge, Västergötland, Halland and Gotland) where approx. 90\% of them are situated [26][37]. To get a picture of future production from wind power, when the capacity is expanded, models based on production data have been constructed in previous reports. This is made in order to be able to simulate possible production from future wind turbines and wind farms depending on installed capacity.

Elforsk is an organization co-owned between the organisation Swedish Energy and SvK [38]. Elforsk's purpose is to coordinate and rationalize research and development efforts within the electric power business. Elforsk has published a model for future wind power production based on data from the Swedish Meteorological and Hydrological Institute (SMHI). The data used consists of relevant parameters for 56 different locations in Sweden recorded during 1992 - 2001 from which the predicted electric power generation can be estimated. In the report Effektvariationer av vindkraft [39] from 2004, a yearly production of $10 \mathrm{TWh}$ (4000 MW installed capacity) is modelled to determine how the power production would fluctuate during different time spans.

The model is later used in the report $4000 \mathrm{MW}$ wind power in Sweden published by Elforsk in 2005 [28]. This report uses the model to simulate the demand of regulating power due to forecast errors and fluctuations in production from wind power. The conclusions drawn are that the need for regulating power to balance fluctuations in production on the timescale of seconds/minutes is estimated to be very small. There will however be an increase in need of regulating power within the timescale of 15 minutes to one hour due to uncertainties in the forecasts and stochastic variations from wind power production. According to the report, the demand for regulating power 


\section{Vattenfall Research and Development AB}

when the amount of installed wind power is $4000 \mathrm{MW}$ is $20 \mathrm{MW}$, for a one hour time span. For the same amount of installed wind power but a time span of four hours, the demand is $195 \mathrm{MW}$. Important to mention is that this simulation does not take transmission limitations into consideration.

The Swedish TSO, SvK, published in 2008 a report with the title Storskalig utbyggnad av vindkraft - Konsekvenser för stamnätet och behovet av reglerkraft [5]. This report is mainly based on the previously mentioned material from Elforsk, but it also takes the transmission limitations for wind power and regulating purposes power into consideration. The report states that the need for frequency controlled normal operation reserve will increase with 200-250 MW with $4000 \mathrm{MW}$ of wind power in the system, and 600-750 MW for $12000 \mathrm{MW}$ wind power. SvK also brings up the question about the limiting transmission capacity in Sweden, stating that if more than $4500 \mathrm{MW}$ of wind power is connected above cross-section 2 (se figure 3), the transmission capacity through section 2 needs to be increased by $2600 \mathrm{MW}$.

\subsubsection{Correlation of wind power and spatial smoothing effects}

There are a previous report [40] regarding the subject of expanded wind power and the potential for spatial smoothing effects. It is stated that if wind power expansion is made over a large geographic area the correlation between power generation from different wind turbines and wind farms would lead to spatial smoothing effect of local variation in generation. In other words the fast increase or decrease in production from a single wind farm will be smoother if the wind production capacity is spread over a larger area i.e. including more wind turbines.

\subsection{Two potential problem scenarios}

When studying published reports two potential problem scenarios are found that might occur at an early stage when the expansion of wind power is increased.

\subsubsection{Lack of local regulating sources and transmission limitation}

Available transmission capacity, or transmission limitations, is mentioned in other reports as one of the main concerns when simulating the expansion of wind power in Sweden [5]. The problem is the transmission limit through cross-section 2 which divides Sweden into two parts, north and south [5], se Figure 13. If wind power is largely expanded in northern Sweden only, local balancing with hydro power can be performed if the transmission capacity through cross-section 2 is not expanded. This scenario will most certainly be a problem, but since the hydro power is situated within the same area local balancing is possible [41]. There is however another important aspect when considering expanded wind power capacity and the transmission system. Even if the expansion of wind power is planned to be made throughout the entire country, see Figure 11, the largest expansion is planned in area 3 and 4 [30]. When the amount of wind power that is connected below cross-section 4 is increased, two main concerns will arise. Area 4 has low availability of hydro power which will make local balancing difficult, or expensive if local gas 


\section{Vattenfall Research and Development AB}

turbines are to be used. The regulating power and reserves must then either come through crosssection 4 or from intercontinental connections. If there is a large amount of electric power being generated from wind power, a large part of the connection lines, domestic and international, needs to be reserved as back up capacity if electric power generation from wind turbines drops [5][34].

\subsubsection{Low consumption and lack of down regulating capacity}

The lowest demand for electric power in Sweden occurs during hot summer nights, especially around the Swedish holiday of midsummer [5][8][33][34]. The present production during these low demand nights is covered by nuclear stations running as base load and hydro power used as base load and balancing. If wind power capacity were largely increased there would in this scenario be a problem if the production from wind turbines suddenly increases. If a large production increase would occur from the wind turbines there might not be enough hydro power in the system for balancing purposes. This would mean that the fluctuations from demand and production would be problematic to balance since the electric power would almost exclusively be generated by nuclear units and wind turbines [5][8][33][34].

\subsection{Interviews}

The effect on the electric power system when large amount of wind power is built in Swedish is a well covered issue and several reports have been published by different actors. To have the latest aspects this report will include a few interviews with some of the actors in the Swedish electric power system. The main goal with the interviews is to isolate the most important problems and/or solutions when wind power capacity is expanded. What will happen first and how would the different actors like to meet the problem? These interviews are also used to give the authors of this report a deeper knowledge of how the electric power system and market functions in Sweden.

The interviews were performed with a few prepared questions but then turned into open discussions in order to be able to focus on the topics that were brought up by the person that was interviewed. The questions that were asked in the beginning differed between the two persons that were interviewed, since the authors became more familiar with the subject over time but also to see if the second person that were interviewed agreed with the first persons statements.

The first person that was interviewed was Kjell Lindquist at Vattenfall Nordic Generation Management at the Vattenfall office in Råcksta. The recommendation to interview Kjell came from Dennis Waltin at the same department when receiving some of the data used later on in this report. Kjell is besides being one of the operators at Vattenfall Nordic Generation Management also involved and experienced in the regulating power area.

The second person interview was Christer Bäck at the Swedish TSO Svenska Kraftnät in Sundbyberg. The recommendation to interview Christer came from Kjell during the first interview since they have a lot of contact working with the same question but for different actors. 


\section{Vattenfall Research and Development AB}

Since Christer was interviewed later in the project the authors also chose to present the findings in the data up to the point of the interview to hear his views on the results so far.

During the interviews a new term were introduced, AGC which stands for Automatic Generation Control. AGC are not used at the moment in Sweden but will most probably be implemented shortly, AGC is however used in the Danish electric power system that is interconnected with Europe. AGC have not previously been presented in this report but are brought up in both interviews. In the interviews below the abbreviation are used and later on in the report AGC are presented in the "Future solutions chapter" where it is explained thoroughly.

\subsubsection{Kjell Lindquist, Vattenfall Nordic Generation Management}

Since the interview with Kjell took place quite early in the report process the authors where still learning a lot on how the electric power system works both on a technology level but also on a market level. The questions to Kjell and his answers can be found in appendices A.

According to Kjell there is a growing market within Sweden for ancillary services. By upgrading power stations during renovations Vattenfall have a good opportunity to cease a strong position for the future market. Implementing AGC regulating control systems on hydro stations as well as upgrading to modern generators will put the Vattenfall owned hydro power in the forefront. Important to know is that the implementation of AGC also requires a market function.

Kjell also confirms which problems that will occur first. The overall problem that will affect the entire country will occur during summer nights when consumption is low and almost all power is provided by nuclear units and very little hydro power is used. This is already today the most difficult time to balance the system. The geographic problem will probably become area 4 due to the lack of regulating power within the area combined with the quite small transmission capacity through section 4. But since these problems are of different nature they will not occur at the same time.

\subsubsection{Christer Bäck, Svenska Kraftnät}

Christer Bäck works at Svenska Kraftnät in Sundbyberg and is highly involved in the regulating market. Christer is an expert on regulating power but he also works with grid and generation management. Christer divides the possible problems into two types: market problems and system problems. The market problem will come in the form of larger uncertainties for the predicted production bids and will lead to increased cost for the generation companies due to larger balancing during the real production hour. The system problem is the stochastic variations during short periods of time, around 5 minutes, which will have to be met by primary regulating by the ISO/ TSO.

When shown the results from the data analysis Christer states that large variations during a period of 1 hour will not be a problem, a large variation during that kind of timeframe can probably be 


\section{Vattenfall Research and Development AB}

forecasted at a minimum of 2 hours before its occurrence and can therefore be balanced quite easily by the ISO/TSO. This will instead become a market problem when generation companies owning wind power needs to purchase large quantities of power on the spot market quite close to the production hour. This needs to be done in order to compensate for the wind power that they have sold on the market but will not be generated due to the forecast uncertainties.

According to Christer the most problematic variations from wind power will be the difference in production during an interval of a few minutes, so called stochastic variations. To balance these variations the electric power system will need to use the primary regulating power supplied mainly by hydro stations. The system will not know if the variation in frequency will depend on decreased consumption or increased production or vice versa. The changes will be met in the same way by primary regulating power. Since this according to Christer will mean that more primary regulating power is needed the implementation of AGC would be a good first step. These technologies would, in short, create a overlapping between primary and secondary regulating power where the ISO/TSO can waive secondary regulating power automatically from generation companies. 


\section{Model}

\subsection{Presentation of data}

To be able to show how wind power is produced over different timescales real wind power production data is needed.

The data used for modelling and later on for simulations, and also earlier used in the chapters regarding wind power production in Sweden during 2009 has three different sources, two of the sources are within Vattenfall AB (5.1.1) and the third source is SvK (5.1.2).

\subsubsection{Data from Vattenfall}

Vattenfall has wind power producing units that consists of one single wind turbine or multiple wind turbines seen as one producing unit in a wind farm.

For both individual turbines and wind farms, the data is sorted in production in $\mathrm{MWh} / \mathrm{h}$ during 5 minutes interval or one hour interval. Examples are shown in Table 7and Table 8

Table 7: Example of data from Vattenfall for Wind farm Lillgrund, logs of 5 minutes average production in $M W h / h$ [25].

\begin{tabular}{cc}
\hline Date and time & Production [MWh/h] \\
\hline $2009-01-01$ 00:05 & 9,2 \\
\hline $2009-01-0100: 10$ & 10,1 \\
\hline $2009-01-0100: 15$ & 10,4 \\
\hline $2009-01-0100: 20$ & 11,8 \\
\hline
\end{tabular}

For the case of 5 minute interval data, the production is continuously logged year by year every five minute. This gives twelve 5 minute intervals per hour, which gives 105120 readings per year. There are also data on one hour interval.

Table 8: Example of data from Vattenfall for Wind farm Lillgrund, logs of 1hour average production in $M W h / h$ [25].

\begin{tabular}{cc}
\hline Date and time & Production [MWh/h] \\
\hline $2009-06-01$ 00:00 & 17,3 \\
\hline $2009-06-0101: 00$ & 12,1 \\
\hline $2009-06-0102: 00$ & 15,8 \\
\hline $2009-06-0103: 00$ & 21,2 \\
\hline
\end{tabular}

These data in Table 7 and Table 8 come from Vattenfall production follow up. Data oriented in the same way is gathered from Vattenfall wind centre. The data from Vattenfall wind centre is 


\section{Vattenfall Research and Development $A B$}

more specific and ordered for each turbine, even if the turbine is located in a farm. So for data regarding Lillgrund, which is a farm consisting of 48 turbines, it is possible to extract how each and every turbine is producing over time. In Table 9 one more example is shown on how data from Vattenfall wind centre is given, in this case it is for the wind turbine Fanbyn outside of Sundsvall.

Table 9: Example of cumulative production for Fanbyn wind turbine given by Vattenfall wind centre [42].

\begin{tabular}{cc}
\hline Date and time & Cumulative production MWh \\
\hline $2009-06-0100: 00$ & 9251184 \\
\hline $2009-06-0101: 00$ & 9251377 \\
\hline $2009-06-0102: 00$ & 9251585 \\
\hline $2009-06-0103: 00$ & 9251758 \\
\hline
\end{tabular}

However, the production from Vattenfall wind centre is for some of the wind turbines and wind farms given as a cumulative value, meaning that the production for one hour is added to the previous hour and so on. To get the actual $\mathrm{MWh} / \mathrm{h}$ production one must subtract the values of two following hours, starting with the latest. 


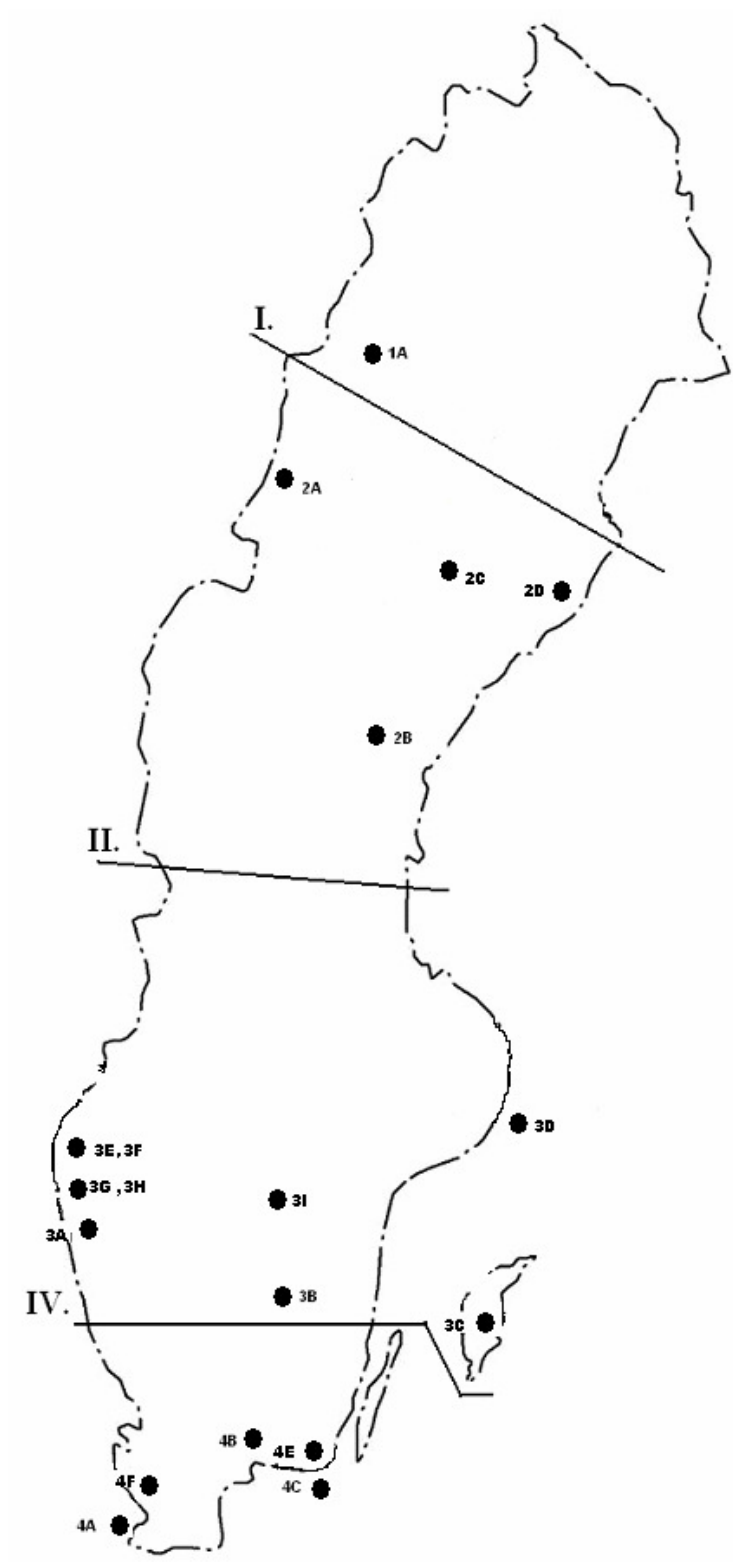

Area 1, one location

1A Suorva

Area 2, two locations

2A Klimpfjäll

2B Fanbyn

2C Stor Rotliden

2D Fanbyn

Area 3, six locations

3 A Hogenäset, Skärbo

3B Ryningsnäs

3C Stenkyrka, Kulle, Näsudden

3D Utö

3E Tannam

3F Lyse

3G Dusgård

3H Humlekärr

3I Hästholmen

Area 4, five locations

4A Lillgrund

4B Hedeskoga, Ruuthsbo

4C Yttre stengrynden, Utgrunden

4E Östra herrestad

4F Åstorp

Figure 15: Productions sites included in Vattenfall data [25][42].

\subsubsection{Data from SvK}

To be able to model and simulate how an entire area, see Figure 13, would behave with expanding wind power capacity wind power production data regarding that specific area for the present system is needed. That data is gathered from SvK. The data from SvK is in an hour to hour basis but with the production of the entire area, regardless of how is operating the wind turbines.

An example of how that data is given can be seen in Table 10. 
Table 10: Example of data given from SvK, hourly wind power production for each of the four areas in $\mathrm{MWh} / \mathrm{h}$ [22].

\begin{tabular}{ccccc}
\hline Date and time & $\begin{array}{c}\text { Production } \\
\text { area 1, MWh/h }\end{array}$ & $\begin{array}{c}\text { Production } \\
\text { area 2, } \mathbf{M W h} / \mathbf{h}\end{array}$ & $\begin{array}{c}\text { Production } \\
\text { area 3, } \mathbf{M W h} / \mathbf{h}\end{array}$ & $\begin{array}{c}\text { Production } \\
\text { area 4, } \mathbf{M W h} / \mathbf{h}\end{array}$ \\
\hline $\begin{array}{c}2009-06-01 \\
\text { 00:00 }\end{array}$ & 21,2 & 25,4 & 110,2 & 42,1 \\
\hline $\begin{array}{c}2009-06-01 \\
01: 00\end{array}$ & 24,7 & 29,1 & 131,2 & 54,9 \\
\hline $\begin{array}{c}2009-06-01 \\
02: 00\end{array}$ & 27,2 & 31,2 & 142,6 & 44,9 \\
\hline $\begin{array}{c}2009-06-01 \\
03: 00\end{array}$ & 21,9 & 21,8 & 128,3 & 51,2 \\
\hline $\begin{array}{c}2009-06-01 \\
04: 00\end{array}$ & 22,5 & 22,7 & 105,2 & 37,5 \\
\hline
\end{tabular}

As for the data from Vattenfall follow up and from Vattenfall wind centre the data from SvK is given on a yearly basis. From the SvK data it is not possible to get information on how much each wind turbine or wind farm produces. It is only possible to get information on how much wind power that totally is produced in each of the four areas.

\subsection{Definitions}

To get an as accurate simulation as possible a model based on the present Swedish system is constructed. To be able to build this model, the data presented above is used in different ways. The simulation is to give an as accurate behaviour as possible of a future Swedish system with different expansion rates of wind power producing capacity. The planned expansions rates are presented in chapter 2.9, and they are to correspond to the aims of 10/30/50 TWh of yearly wind power production in the Swedish system.

The output of the simulation is to give answers to how large the variations from wind power production can become, both in share of production capacity and in electric power, and how often these variations occurs. Due to, and as presented in chapter 5.1, that most data collected from Vattenfall $\mathrm{AB}$ and $\mathrm{SvK}$ is given in the form of hour to hour production the output of the simulation will not be able to give answer to how the production varies over a shorter time span than between two hours.

To get a better view of the data and make it easier to work with, the turbines and farms are grouped into area 1-4 depending on their location se Figure 13. Each area is then divided into four seasons: winter (December, January and February), spring (Mars, April and May), summer (June, July and August) and autumn (September, October and November).The season grouping is 


\section{Vattenfall Research and Development AB}

chosen because of the different conditions that can be found in the electric power system due to, primarily, weather conditions and transmission limitations.

To be able to construct a model the following is done:

- Step 1. Use data to show and understand how the production from one wind turbine, one wind farm, one area and all areas behaves hour to hour, for timescales of 24 hours, seasonally and yearly. Both for production and for production variation, the difference between production and production variations will be explained later on.

- Step 2. Use data to show how the production and production variations correlate over different distances as well as describing the concept of correlation.

The model, which in fact is a clarification of the present wind power system, is used to simulate a future system with different wind power capacities. More specific the following will be done to simulate a future system:

- Step 3. Use the understandings and results from the model to expand the system.

- Step 4. Due to that the Swedish system is divided into four different areas, see Figure 13, the production and production variations simulations will be done area by area, different timescales according to the timescales in the model will be used.

\subsection{Visualisation of how wind power production varies with time}

As presented earlier step 1 is to give understanding on how one wind turbine, one wind farm, one wind production area and all wind production areas are producing over different timescales. These different examples are illustrated in chapter 5.3.1 (single wind turbine), 5.3.2 (wind farm) and in 5.3.3 (one area and all areas). This will be done below in figures showing the behaviour. The specific data used is presented in each figure.

In most of the coming figures the term "Utilization factor" is used. The utilization factor is given in decimal form and by multiplying the utilization factor with the wind turbines or wind farms capacity the production in $\mathrm{MWh} / \mathrm{h}$ is given. The reason for using a utilization factor instead of using the actual capacity in MW is to understand the different production pattern and different changes in production between a wind turbine, a wind farm, a wind production area or all wind production areas. The utilization factor will make it easier to compare, for example, a small wind turbine with a large wind farm in order to see their differences and similarities.

In step 1 there will be two figures for each production unit, giving a total of eight figures. The figures are ordered in pairs, meaning that there are two figures for each producing unit. The first figure in the pair will show production during a 24 hour period and the second figure will show the production variation between two hours, during a 24 hour period.

The production variation is the difference in production between two hours followed by each others. To get the value of a production variation the following mathematical operation is done: 
Production variation in MW = Prod.var

Production in MW for one hour $=$ Prod

Hour number $\mathrm{n}=\mathrm{n}$

Prod.var. $=\operatorname{Prod}(\mathrm{n})-\operatorname{Prod}(\mathrm{n}-1)$

In the introduction to chapter 5 it is stated that utilization factor will be used in the following chapter to show production behaviour. Since utilization factor is used for production it will also be used for production variations. Giving the following mathematical operation:

Production variation in utilization factor $=$ Prod.var.Uf

Utilization factor $=$ Uf

Hour number $\mathrm{n}=\mathrm{n}$

Prod.var.Uf $=$ Uf(n) - Uf(n-1)

\subsubsection{Production from one wind turbine, hour to hour}

The figures below are to give understanding of how one wind turbine produces hour for hour during a 24 hour period and during an entire year. The wind turbine used is Fanbyn wind turbine $660 \mathrm{KW}$ : the data is taken from Vattenfall wind centre
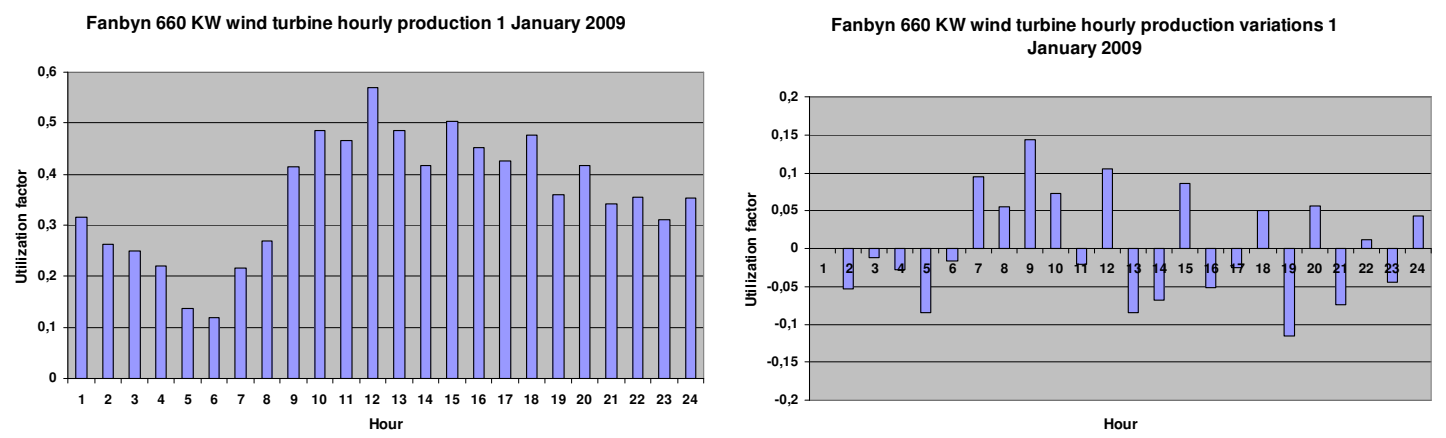

Figure 16: Fanbyn wind turbine, 1st of January 2009. Left: Hourly production during a 24 hour period. Right: Production variation between hours [42].

The date $1^{\text {st }}$ of January 2009 is randomly chosen. Important to see is the relatively big changes both in increase and decrease of production. To give a good understanding of the increase and decrease the right diagram in Figure 16 will show the production variations for the same time and the same wind turbine.

If looking at the left diagram in Figure 16 showing Fanbyn wind turbine hourly production for $1^{\text {st }}$ of January 2009, and compares is with the right diagram in the same figure showing Fanbyn wind turbine hourly production variations $1^{\text {st }}$ of January 2009. It is possible to see that the increase and 


\section{Vattenfall Research and Development $A B$}

decrease in production from the left diagram is matching the values for the bars in the diagram on the right. This how the right diagram is created. By letting the first hour production be the reference hour and then subtracting the production for hour two from hour one the values for the diagram on the right is given, and so on.

During one year there are 8760 hours. From one hour to the next hour the production from a single wind turbine can change, this can bee seen in Figure 16. By using the data collected from Vattenfall wind centre a summarization of how many production variations there are during one year is done. The production variations are grouped together to give a total number of observations of the variations that are equally large, regardless of when the variations occur. This is to give understanding of how large the variations are and how often they occur. The two diagrams in Figure 16 showing production variations pattern has their base from the same data.
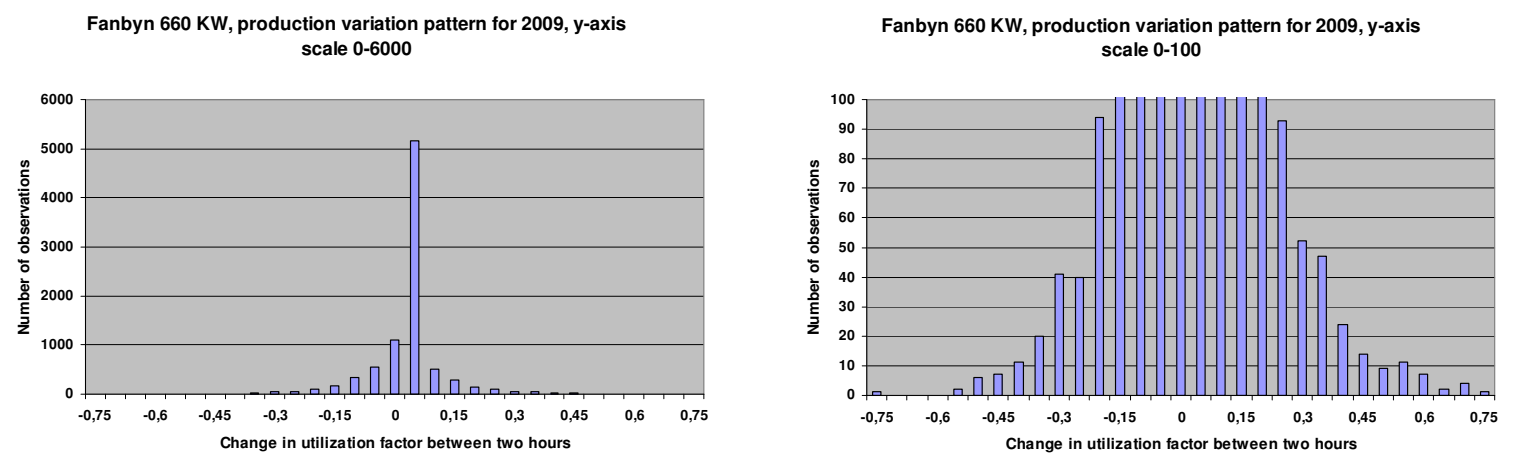

\section{Figure 17: Variation in production for Fanbyn wind turbine, expressed as utilization factor, grouped by size [42].}

In the left diagram the scale of the y-axis is 0-6000, which makes it possible to see that the most frequent change in utilization factor is between the values of -0.10 to 0.10 . In that diagram, it is however hard to see how large the largest changes in utilization factor is. To be able to see the largest changes in utilization factor, between two hours, and how many these large changes is, the diagram on the right is used. In the right diagram the y-axis scale, showing the number of observations, is changed to $0-100$, which gives an understanding of that there are quit often changes in utilization factor that is larger than -0.10 to 0.10 . It is also possible to see that change in utilization factor, between two hours, larger than -0.40 to 0.40 occurs quite frequent: the largest change in utilization factor is -0.75 down and 0.75 up for Fanbyn wind turbine.

\subsubsection{Production from one wind farm, hour to hour}

As described in the introduction to this chapter, the behaviour for one wind farm is also to be studied in order to compare it with a single turbine as well as a larger system. The chosen wind farm is Lillgrund wind farm consisting of 48 wind turbines with a total capacity of $110 \mathrm{MW}$. The 


\section{Vattenfall Research and Development AB}

data used is from Vattenfall follow up. To be able to compare the figures regarding Lillgrund with the figures for the single wind turbine Fanbyn the diagrams in the figures have the same spans on the axes and a straight forward comparison is made possible through the use of utilization factor. The only difference between the part about the wind turbine and the part about the wind farm is the origin of the data used.
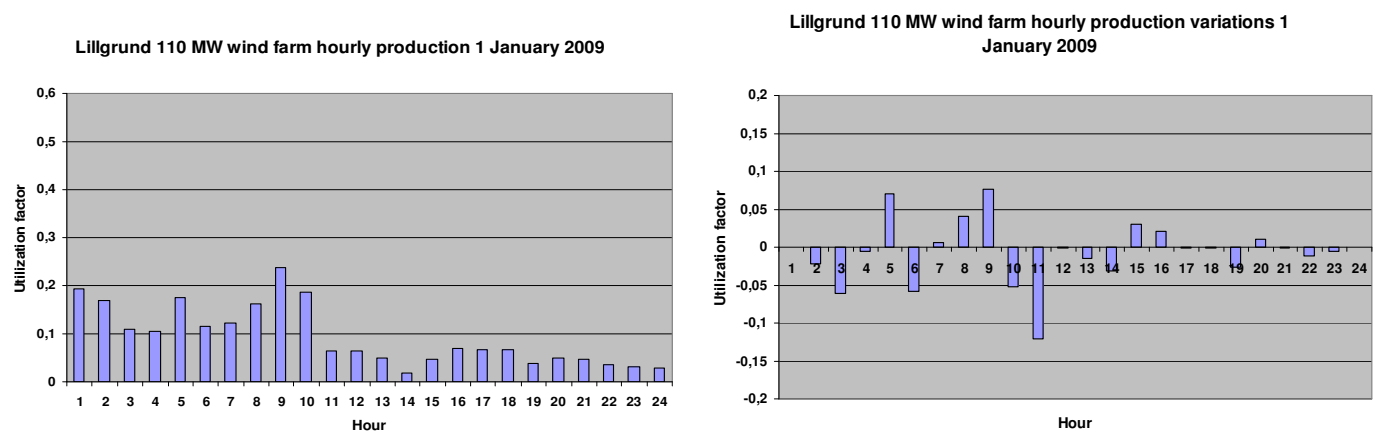

Figure 18: Lillgrund wind farm, 1st of April 2009. Left: Hourly production during a 24 hour period. Right: Production variation between hours [25].

Lillgrund $110 \mathrm{MW}$, production variation pattern for 2009, $y$-axis scale $0-6000$

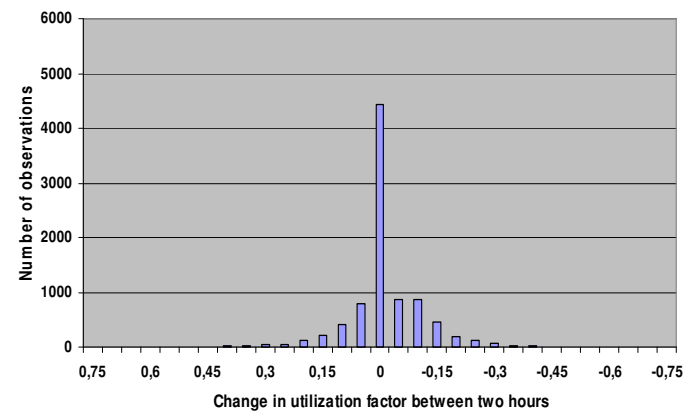

Lillgrund $110 \mathrm{MW}$, production variation pattern for 2009, $y$-axis scale 0-100

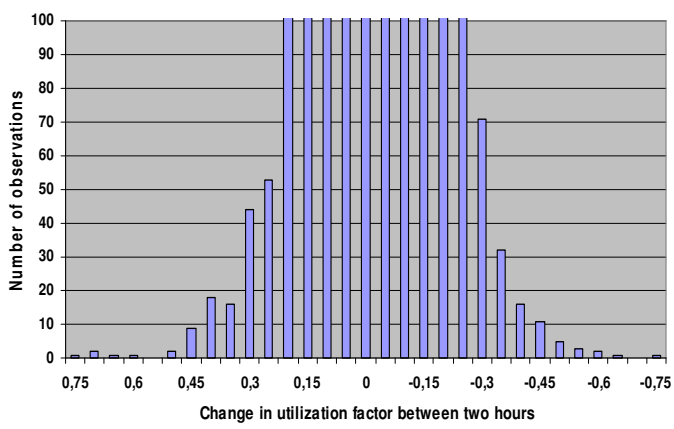

Figure 19: Variation in production for Lillgrund wind farm, expressed as utilization factor, grouped by size [25].

By studying the figures for Fanbyn wind turbine $660 \mathrm{~kW}$ and Lillgrund wind farm $110 \mathrm{MW}$ the following can be summarized: the change in utilization factor between two hours for Fanbyn wind turbine and Lillgrund wind farm is very much similar, both in size and number of observations.

Lillgrund wind farm operates as one producing unit and is spread over a relatively small geographical area. Even if Lillgrund consists of 48 Wind turbine with a total capacity more than 


\section{Vattenfall Research and Development AB}

160 times greater than Fanbyn, it still behaves, more or less, like one single wind turbine in the context of change in utilization factor between two hours.

\subsubsection{Wind production in larger areas}

In the previous parts we have seen that a wind turbine and a wind farm have similar behaviour. The production change between two hours has more or less the same relative size and number of observations (frequency).

When investigating how the production from wind turbines and wind farms within the same area behave a new term will be used. This term is production patterns. Instead of showing how the typical 24 hour production pattern looks like we will now instead show how the typical production during one year looks like, since we want the model to show the production patterns and production variation patterns within each area.

As above each area will presented by several figures to give a deeper understanding and in the end of the part a study for the entire Swedish wind power system is done. The reason for studying all four areas as one area is to give knowledge of how large wind power producing systems operate.

The understanding of how wind power units in each area behave can be gained by presenting each area with the following information.

- yearly production,

- yearly production variations in full scale,

- yearly production variations in scale.

The first area to be presented and studied is area 1, the used data is from SvK. 
Area 1, production pattern for 2009 total capacity 65 MW

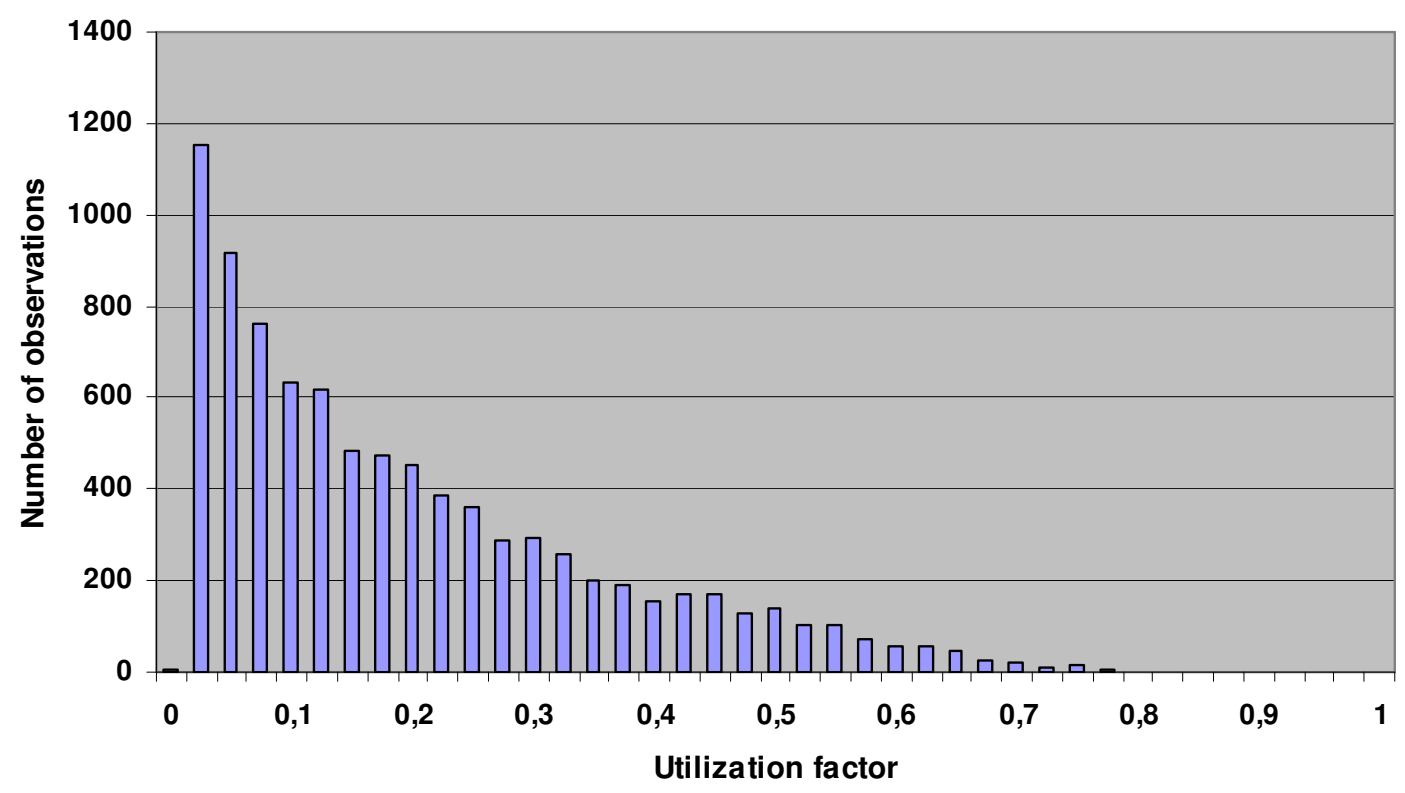

Figure 20: Production pattern for the wind turbines and farms located in area 1 during 2009 [22].

In the figure above it is possible to understand that in most part of the year there is production at a relatively low utilization factor. Peaks when a large share of the wind power capacity in the area is producing do occur. The most frequent utilization factor is clearly lower than 0.5 , meaning that at most of the time during one year, less than half of the total capacity for the area is producing electricity. 

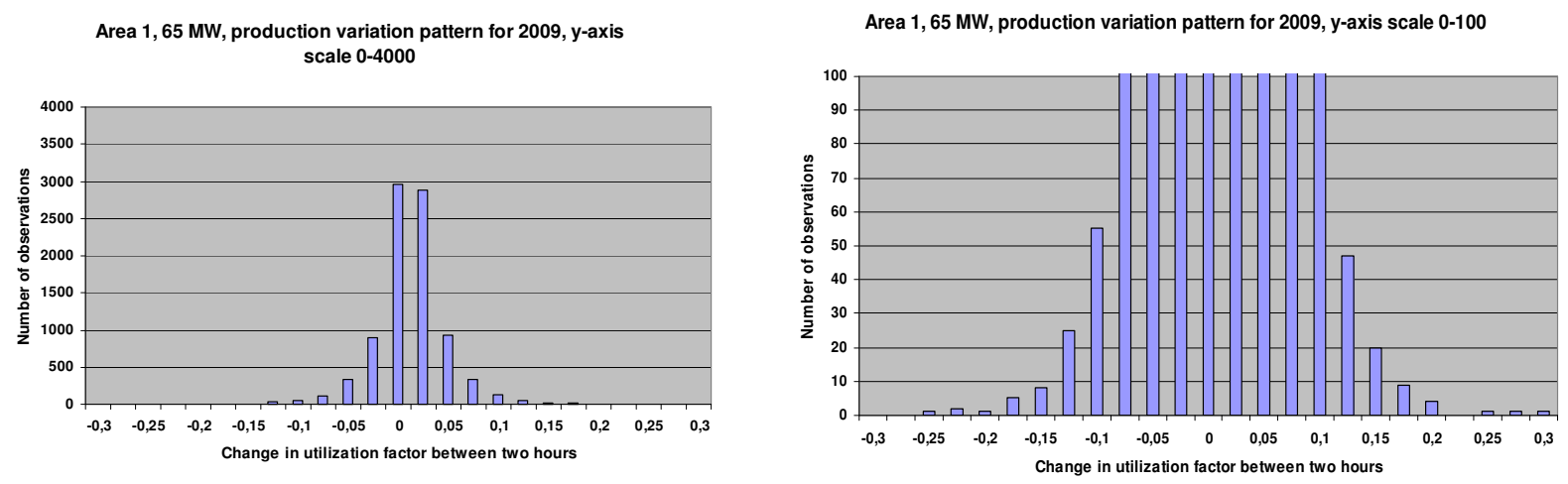

Figure 21: Production variation patterns for all turbines and farms in area 1 during 2009 [22].

In Figure 21 it is clear that the most frequent utilization factor change is in the range between -0.1 to 0.1 , meaning that there are changes in production from one hour to the next only that they are relatively small.

By using a scale factor for Figure 21 to change the range of the y-axis from 0-4000 number of observations to $0-100$ number of observations, the right diagram above is created. The data for the two diagrams in the figure is the same data, it is however possible to see in the diagram on the right that there are changes in utilization factor that are larger then from -0.1 to 0.1 , the largest changes is in the range between -0.3 to 0.3 . 
All areas, production pattern for 2009 total capacity 1450 MW

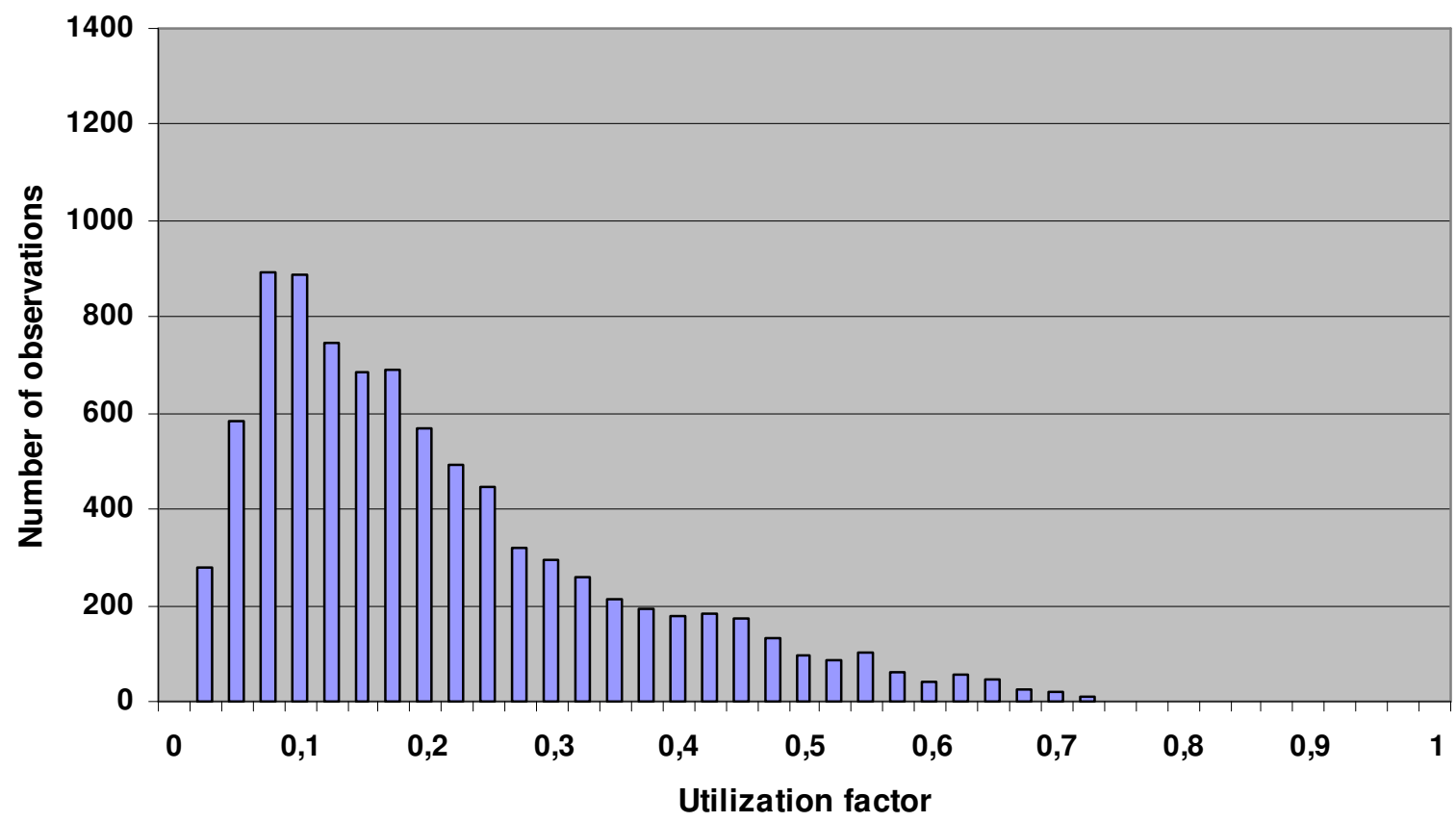

Figure 22: Production pattern for the wind turbines and farms located in all areas during 2009 [22].

All areas, $1450 \mathrm{MW}$, production variation pattern for 2009, $y$-axis scale $0-4000$

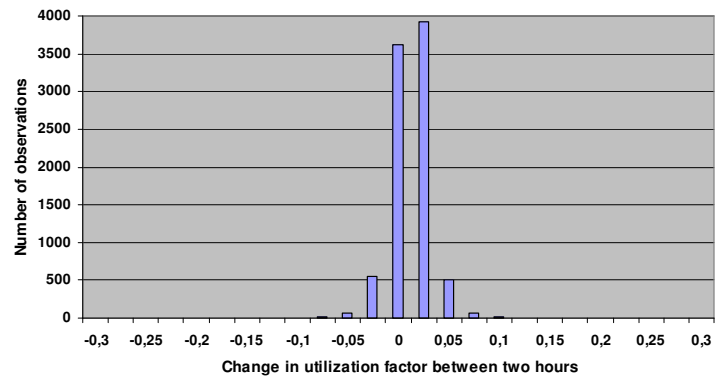

All areas, $1450 \mathrm{MW}$, production variation pattern for 2009 , $\mathrm{y}$-axis scale 0 100

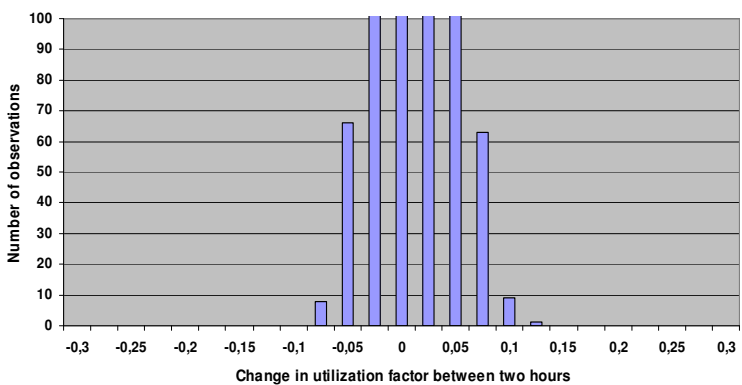

Figure 23: Production variation patterns for all turbines and farms in all areas during 2009.

Table 11: The maximum and minimum utilization of the installed capacity for the different areas during one year [22].

\begin{tabular}{cccccc}
\hline Utilization & Area 1 & Area 2 & Area 3 & Area 4 & All areas \\
\hline $\operatorname{Max}$ & 0,86 & 0,87 & 0,78 & 0,84 & 0,73 \\
\hline
\end{tabular}


Vattenfall Research and Development AB

\begin{tabular}{llllll}
\hline Min & 0,00 & 0,00 & 0,00 & 0,00 & 0,00 \\
\hline
\end{tabular}

Table 12: The largest variations between two hours expressed as utilization of the installed capacity for the different areas during one year [22].

\begin{tabular}{cccccc}
\hline Max change & Area 1 & Area 2 & Area 3 & Area 4 & All areas \\
\hline Up & 0,28 & 0,26 & 0,13 & 0,21 & 0,12 \\
\hline Down & $-0,25$ & $-0,16$ & $-0,11$ & $-0,22$ & $-0,09$ \\
\hline
\end{tabular}

Figures for are 2,3 and 4 can be found in the appendices.

\subsection{Production divided by season}

From the modelling of one year it is possible to see both the maximum and minimum utilization factor for the production within each area. It is also possible to see the largest changes in utilization factor between two hours. In the table below, there are information extracted from the SvK data regarding the maximum and minimum production - utilization factor and the Max up and Min down Production variations - Change in utilization factor between two hours.

\section{Production - season maximum utilization factor per area}

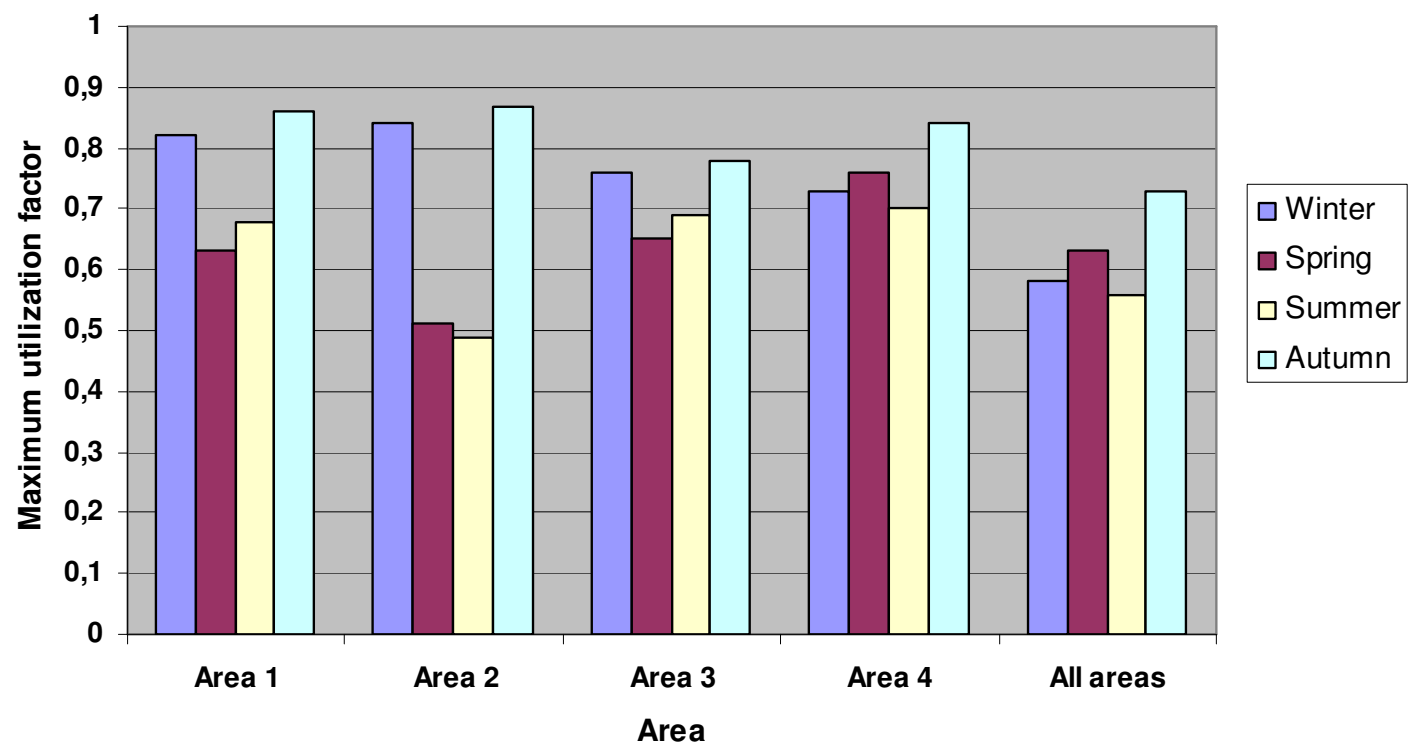

Figure 24: The maximum utilization of the four areas and all areas during one year divided into seasons [22]. 
Vattenfall Research and Development $A B$

Table 13: The maximum and minimum utilization of the capacity in each area and all areas during one year divided into seasons [22].

\begin{tabular}{ccccccc}
\hline Season & Utilization & Area 1 & Area 2 & Area 3 & Area 4 & All areas \\
\hline Winter & Max & 0,82 & 0,84 & 0,76 & 0,73 & 0,58 \\
\hline & Min & 0 & 0 & 0 & 0 & 0 \\
\hline Spring & Max & 0,63 & 0,51 & 0,65 & 0,76 & 0,63 \\
\hline & Min & 0 & 0 & 0 & 0 & 0 \\
\hline Summer & Max & 0,68 & 0,49 & 0,69 & 0,7 & 0,56 \\
\hline & Min & 0 & 0 & 0 & 0 & 0 \\
\hline Autumn & Max & 0,86 & 0,87 & 0,78 & 0,84 & 0,73 \\
\hline & Min & 0 & 0 & 0 & 0 & 0 \\
\hline
\end{tabular}
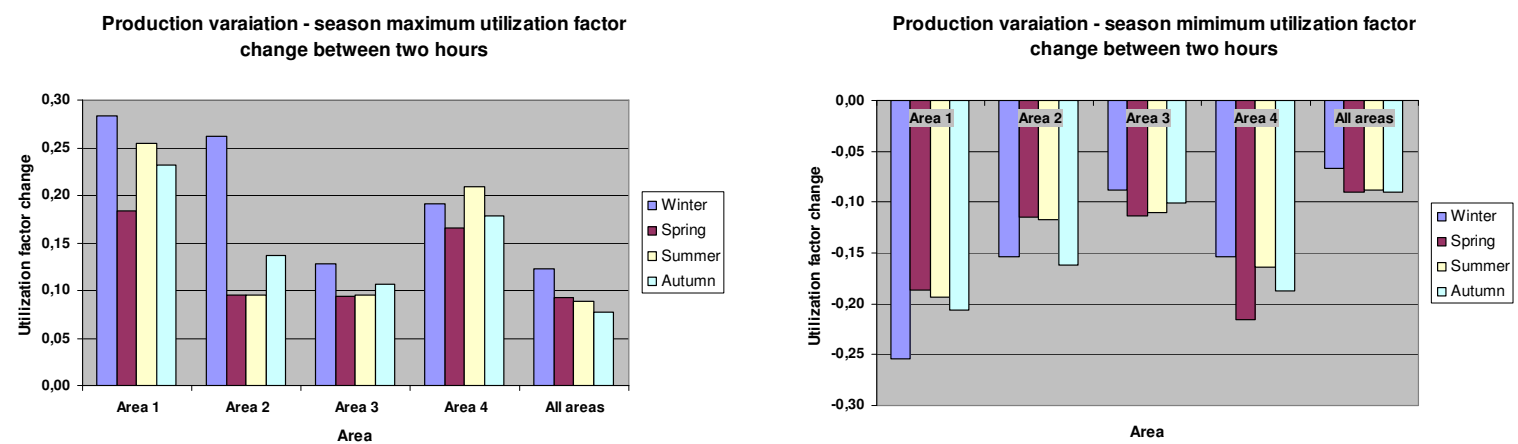

Figure 25: Left: The maximum production variations per area divided into seasons. Right: The minimum production variations per area divided into seasons [22].

Table 14: The production variations between two hours as utilization per season and area [22].

\begin{tabular}{ccccccc}
\hline Season & Max change & Area 1 & Area 2 & Area 3 & Area 4 & All areas \\
\hline Winter & Up & 0,28 & 0,26 & 0,13 & 0,19 & 0,12 \\
\hline & Down & $-0,25$ & $-0,15$ & $-0,09$ & $-0,15$ & $-0,07$ \\
\hline Spring & Up & 0,18 & 0,10 & 0,09 & 0,17 & 0,09 \\
\hline & Down & $-0,19$ & $-0,11$ & $-0,11$ & $-0,22$ & $-0,09$ \\
\hline Summer & Up & 0,25 & 0,09 & 0,10 & 0,21 & 0,09 \\
\hline & Down & $-0,19$ & $-0,12$ & $-0,11$ & $-0,16$ & $-0,09$ \\
\hline Autumn & Up & 0,23 & 0,14 & 0,11 & 0,18 & 0,08 \\
\hline & Down & $-0,21$ & $-0,16$ & $-0,10$ & $-0,19$ & $-0,09$ \\
\hline
\end{tabular}

When changing timescale from one year to four seasons, some general comments regarding production and production variation pattern can be made. 


\section{Vattenfall Research and Development $A B$}

Regarding the production one can see that for all areas the maximum utilization factor occurs during the autumn. The conclusion of this is that during the autumn it is most probable that most of the installed capacity is producing at a high rate and the most probable time for low production rate is during summer.

When studying the numbers in Table 14, it is hard to make any general comments. However even though the autumn is the season with the highest probability for high rate of production, it doesn't seem to be the season with the highest probability for big changes in production between two hours.

\subsection{Correlation}

From the previous chapters it is possible to understand how both production and production variations behaves in each of the four areas and for all areas.

Earlier in this report it is stated that wind power production units that are spread over a larger geographical area can have a partial smoothening effect due to the fact that there are different wind properties within the same geographical area. In the following chapters a comparative study between the four areas is done regarding production and production variation patterns. Before such a study can be done, the concept of correlation is introduced and explained.

Correlation is a mathematical function that, in this case is used to reveal whether the production and production variation pattern in one area is similar to the production and production variation pattern in another area. Parameters such as distance and time is included, this will be explained more in detail later on.

To explain how the concept of correlation is used in this thesis, a simple example is shown both in text and in figures.

In the two figures below, both correlation equal to -1 and correlation equal to +1 is shown, correlation equal to 0 is not possible to show graphically.

Correlation equal to +1

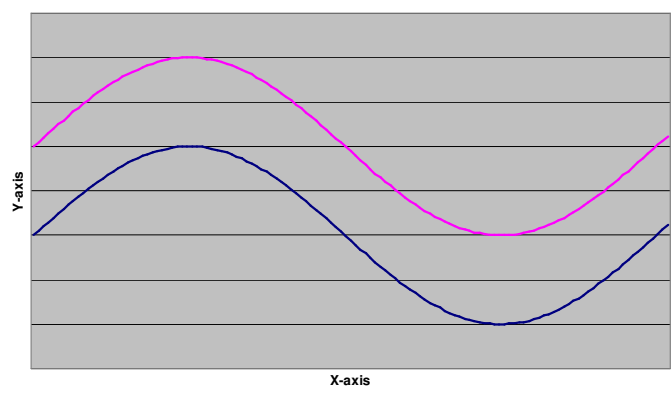

Correlation equal to -1

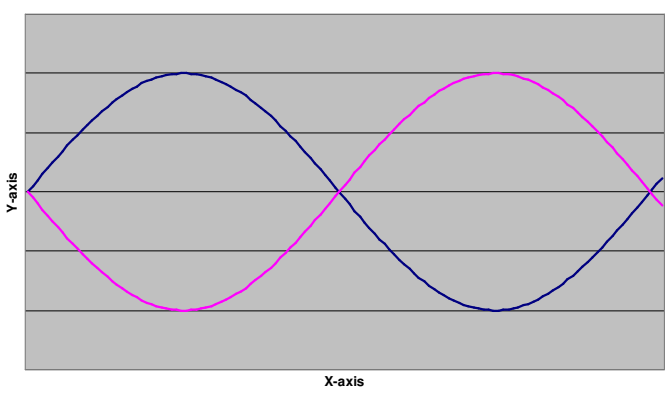

Figure 26: Visualisation of correlation equal to +1 (Left) and -1 (Right).

To understand what correlation equal to +1 actually means one must imagine two series of values where one of the series is the reference series. If the values in the other series always are directly 


\section{Vattenfall Research and Development $A B$}

proportionally to the values in the first series, given that each value from both series are on the same time step within the series, the correlation between the two series has the correlation equal to +1 . An example of this is given to the left in Figure 26, for any given $X$-value, there are two values from the $\mathrm{Y}$-axis returned. If we change the first given $\mathrm{X}$-axis value to a new $\mathrm{X}$-axis value two new $\mathrm{Y}$-axis values is returned. The relation between the two first returned $\mathrm{Y}$-axis values will however be equal to the relation between the two later returned $\mathrm{Y}$-axis values. If the relation between two $\mathrm{Y}$-axis values always is the same for all given $\mathrm{X}$-axis values the correlation between the two series is equal to +1 .

To the right in Figure 26 correlation equal to -1 is illustrated. Correlation equal to -1 is obtained when all $\mathrm{X}$-axis values returns $\mathrm{Y}$-axis values that has an inverse proportionality towards each other.

If the correlation between two series of values is equal to 0 there are no proportionality at al, it would be impossible to say anything about the second series of values from the information given from the first series of values.

\subsubsection{Correlation used for the model}

As previously explained, the base for the model is values given by Vattenfall follow up, Vattenfall wind centre and SvK. To understand how the production and the production variations between the areas are linked there is a need to use the function of correlation. 


\section{Correlation for hourly production and hourly production variation for all Swedish wind producing units 2009}

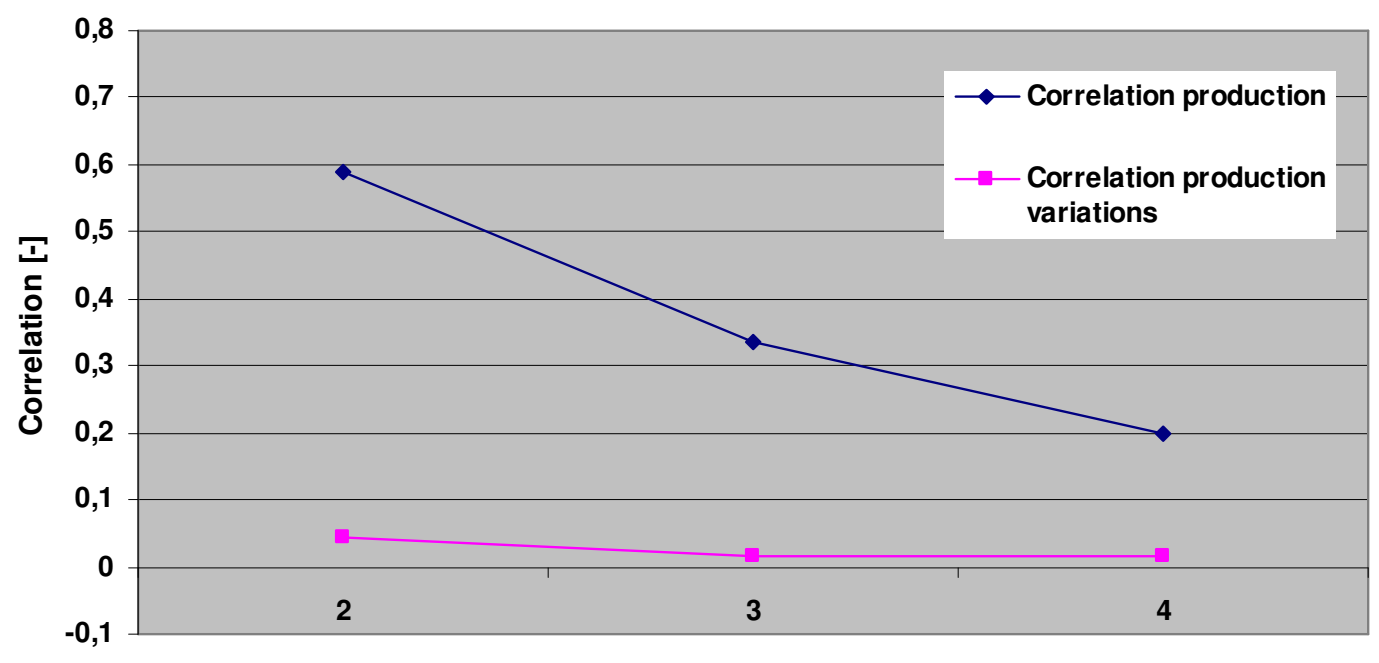

Area, Area 1 is reference

Figure 27: The correlation between wind power production and production variations in the four areas with area 1 as reference [22].

Data used for Figure 27 from SvK. As can be seen in Figure 13, measured from area 1, area 2 is the closest one, area 3 is the second closets and area 4 is the one farthest away.

In Figure 27, it is possible to obtain information regarding how the hourly production for area 2, area 3 , and area 4 is correlated to area 1 . Area 2 is the most correlated, whilst area 3 is secondly most correlated and area 4 is the least correlated. The summary of Figure 27 is that the closer the production sites are to one another, the more correlated is the hourly correlation. This means that if the hourly production is increased in area 1, there is a quite large possibility that it is also increased on area 2 . The possibility for increasing hourly production, assumed that the hourly production is increased in area 1, is decreasing with increasing distance due to the decreased correlation.

There is one factor that must be considered when evaluating Figure 27. There is a possibility that some wind producing units is very close to one another, measured in distance, but still be included in different areas, due to where the border between two areas is drawn.

To minimize the risk of this, a second figure and study is included. In this study, only Vattenfalls wind producing units is included. In this case Lillgrund wind farm is the reference unit, by the usage of the data given and geographical data regarding the distance between the wind power producing units the third figure is created. 
Table 15: Distance between Lillgrund and the turbines/farms used for correlation calculation and the distance between Lillgrund at the studied unit.

\begin{tabular}{cc}
\hline Unit & {$[\mathbf{k m}]$} \\
\hline Ruuthsbo & 60 \\
\hline Utgrunden & 250 \\
\hline Ryningsnäs & 350 \\
\hline Skärbo & 400 \\
\hline Fanbyn & 800 \\
\hline Klimpfjäll & 1000 \\
\hline Suorva & 1250 \\
\hline
\end{tabular}

In Table 15 the units (turbines/farms) and their distance in kilometres to Lillgrund are presented. In this case it is possible to follow how the correlation for production and production variations varies with distance.

\section{Correlation for horly production and hourly production variation for some of Vattenfall's swedish wind producing units, 2009}

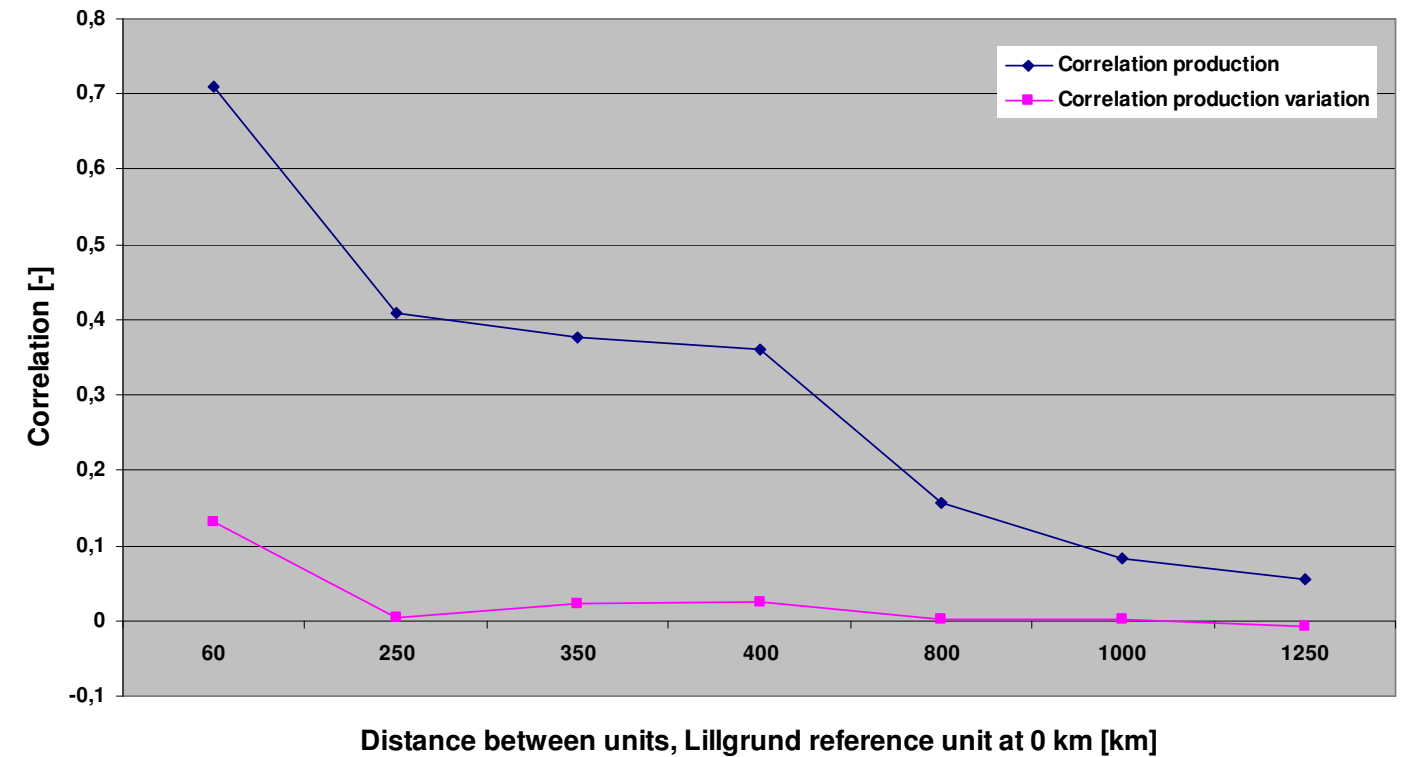

Figure 28: Correlation of production and production variations for Vattenfall's wind turbines and farms with Lillgrund as reference [42].

In Figure 28 the correlation for both hourly production and hourly production variation, in relation to distance, is shown. The pattern obtained from this figure is somewhat the same as in 


\section{Vattenfall Research and Development $A B$}

Figure 27 and Figure 28 regarding correlation in relation to the different areas. This means that the correlation for both hourly production and hourly production variation is decreasing with the distance. The correlation for hourly production variation does however start at a much lower value and reaches the value of 0 much faster than for the study regarding the four areas in Figure 27.

\subsubsection{Summarize of correlation for production and production variations}

The hourly production from two different wind producing units has a positive correlation that is decreasing with increasing distance. There is however a quite strong correlation if the distance is short.

The correlation for hourly production variation is also decreasing with increasing distance, however does the correlation start at a much lower positive value than what is does for the hourly production. At the farthest distance in the studies, between area 1 and area 4, or at $1250 \mathrm{~km}$, the correlation for hourly production variation is equal to or close to 0 .

\subsection{Understanding from the model used for the simulation}

From the data obtained from Vattenfall follow up, Vattenfall wind centre and SvK the model has been constructed. From the previous chapter a solid base on how wind producing units behaves in different sized units and how they are related to each other has been constructed. Before proceeding into the simulations a summary of the most important aspects from the construction of the model for the simulation will be stated.

The production and production variation pattern from a single wind turbine and a wind farm is very much alike, except for the difference in capacity.

When expanding the study from one wind turbine or one wind farm and instead study an entire area as a wind producing unit the behaviour is changed. Due to that the point of interest for this report is production variation patterns the results regarding these changes is what will be used in the simulation.

When expanding the system to include all four wind producing areas the variations decrease even more. From this fact, the conclusion is that the larger the system, measured both geographically and in capacity, the smaller the variations. There is however difference between the areas depending on what season that is studied. The figures and values that are used for the simulation are the results regarding maximum and minimum production variations and the results regarding correlation. 


\section{Simulation}

The collected production data from SvK is put into the future expansion plans for wind power to get an approximation of the future variations. From here on the SvK production data from 2009 is the only wind power production follow-up that will be used. In the following simulation all areas are studied.

When expanding the system according to 10/30/50 TWh scenarios, there are general comments that must be stated.

Since all the data used in this model only uses $\operatorname{logs}$ from 2009, there are some uncertainties in the results. The reason for only using data from 2009 is that the total wind power producing capacity is expanding at a relative high rate, meaning that the data for the year 2008 is not logged from the same total capacity.

The model is made in a linear way, meaning that if the production capacity in one area is doubled, so will also the production variations be. The reason for not correcting these figures with regard to for example correlation is that the correlation for production variations is as good as negligible. This was shown in chapter 5.5. However, when simulating all the four areas at once there are some self correctness in the simulation. This will be discussed in chapter 6.1.

The productions and production variations that were extracted and shown in Figure 20 to Figure 25 in chapter 5.3 and 5.4 is now used in order to determine the power production and production variations in a future system. As the basis for the new system the three expansion cases described in chapter 2.9 are used to get a possible future distribution of installed wind power production capacity between the different areas. The distribution for the expansion scenarios in MW for each area can be seen in Figure 29. For every area and case (10/30/50 TWh) the production variations are now calculated by using the model constructed earlier. The production variations for each area, expressed in utilization factor, are then multiplied with the power in megawatts (MW) for their respective area in the expansion scenarios. This will result in a fictitious production year showing the maximum and minimum values of variations in power output between two hours from wind power. The variations will now be shown in megawatts as well as percent for the future scenarios for each area. 

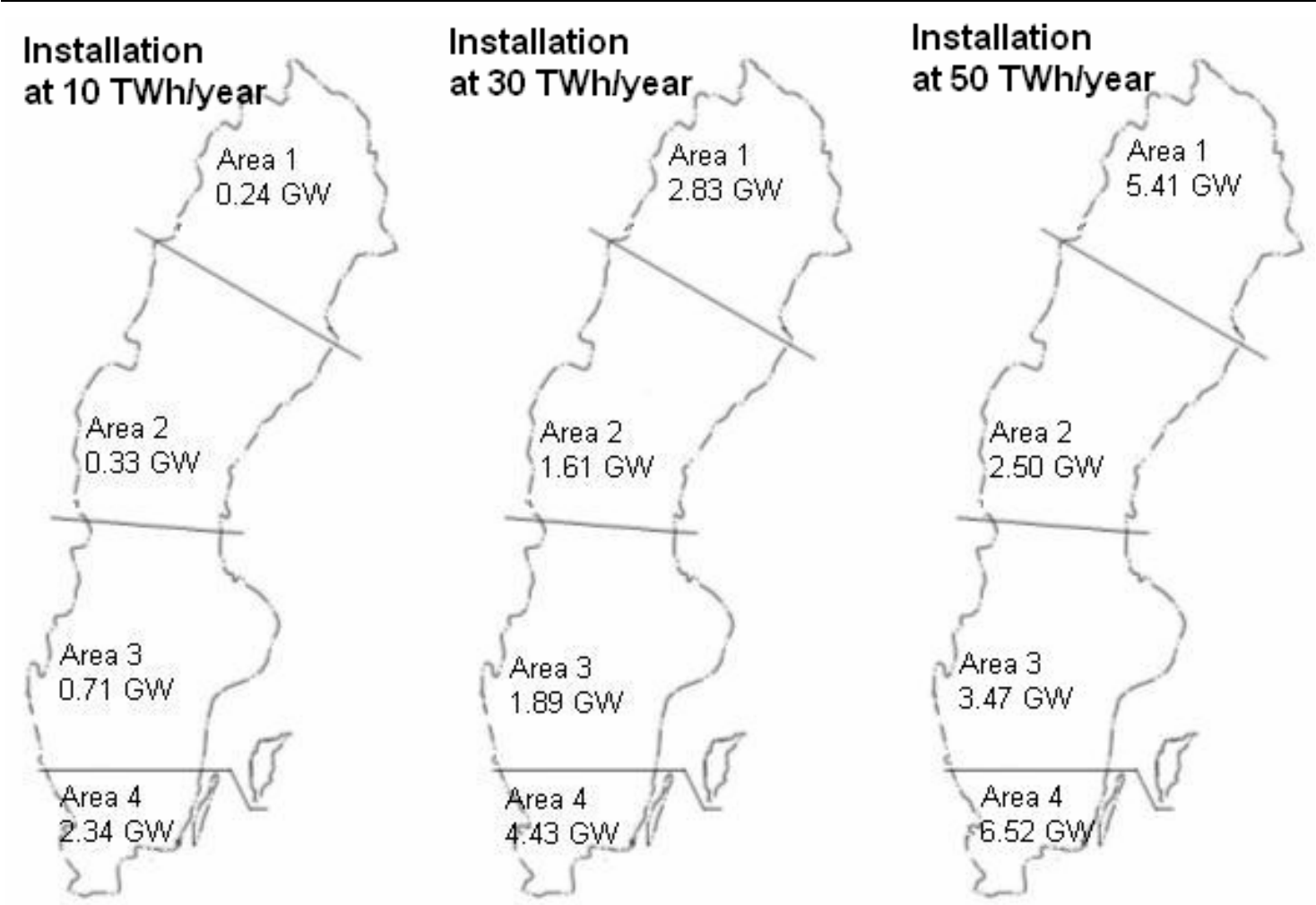

Figure 29: Wind power expansion in different areas of Sweden corresponding to yearly production scenarios [30].

\subsection{Results}

In Figure 30 to Figure 34 a simulation for each area for the three scenarios of 10/30/50 TWh is made. There are two diagrams for each area which is a graphical presentation of the histogram. For each expansion scenario the change in production between two hours is translated to a change in power output between two hours for the selected area. The MW value in top of column 2,3 and 4 is the wind power capacity for the selected area for the 10/30/50 TWh scenario respectively. From chapter 5, there are results of how often each variation do occur, hence the number of observations column.

As in previous chapter the two diagrams in the figures are based on the same data, to be able to get a good view there are once more different scaling in the two diagrams.

After the last table and figure, there are a general comments chapter regarding the simulation. 

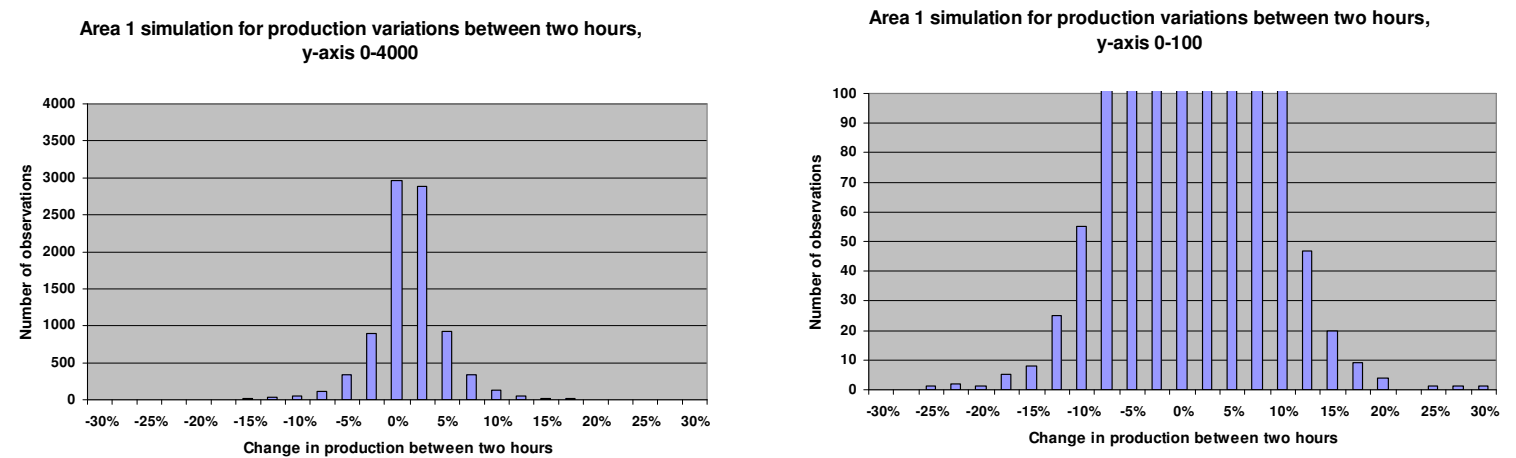

Figure 30: The changes in production between two hours for area 1 with number of observation for the different changes [22].
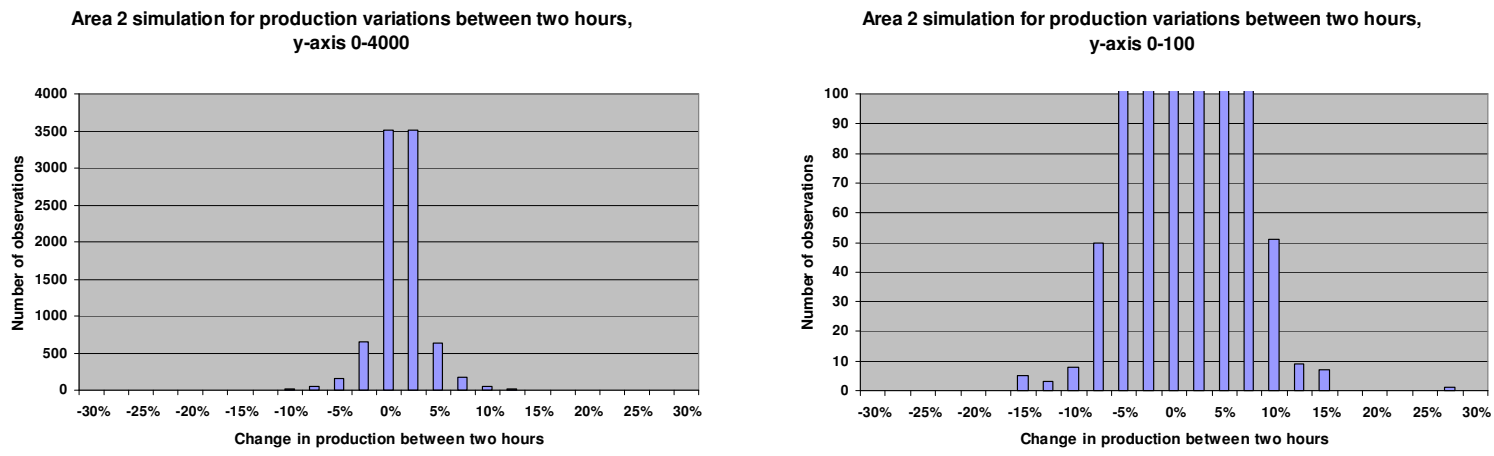

Figure 31: The changes in production between two hours for area 2 with number of observation for the different changes [22].

Area 3 simulation for production variations between two hours, $y$-axis $0-4000$

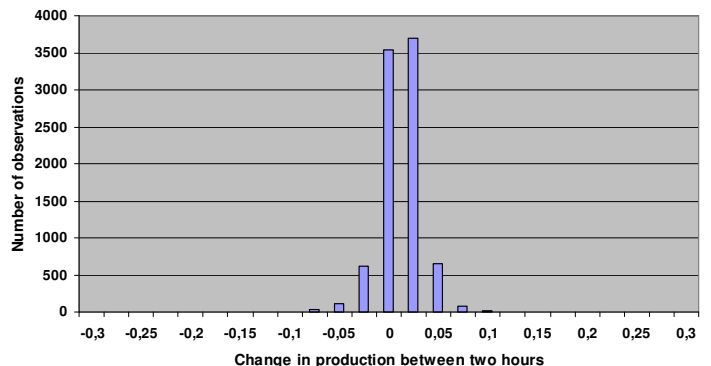

Area 3 simulation for production variations between two hours, $\mathrm{y}$-axis $0-100$

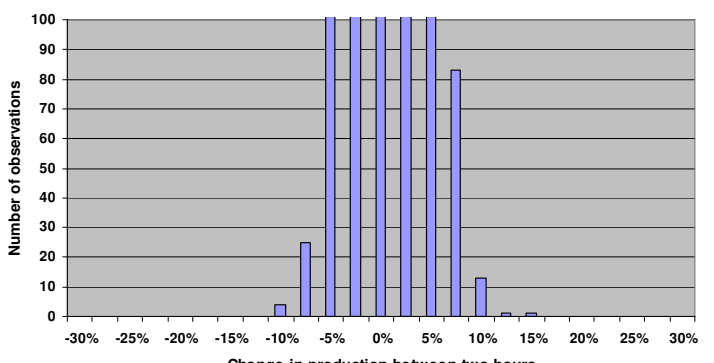

Figure 32: The changes in production between two hours for area 3 with number of observation for the different changes [22]. 

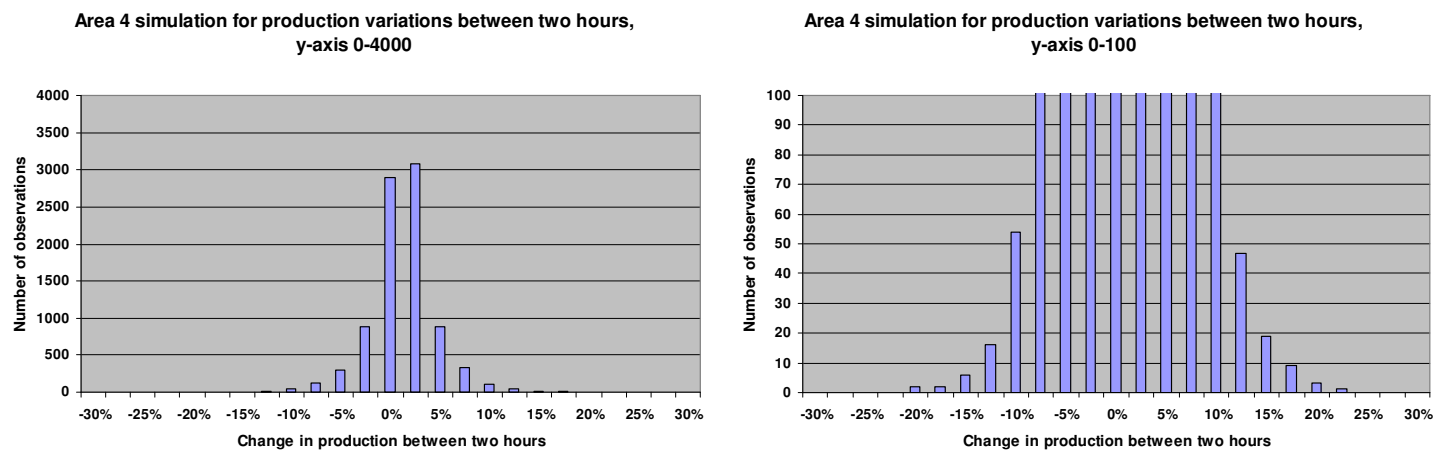

Figure 33: The changes in production between two hours for area 4 with number of observation for the different changes [22].
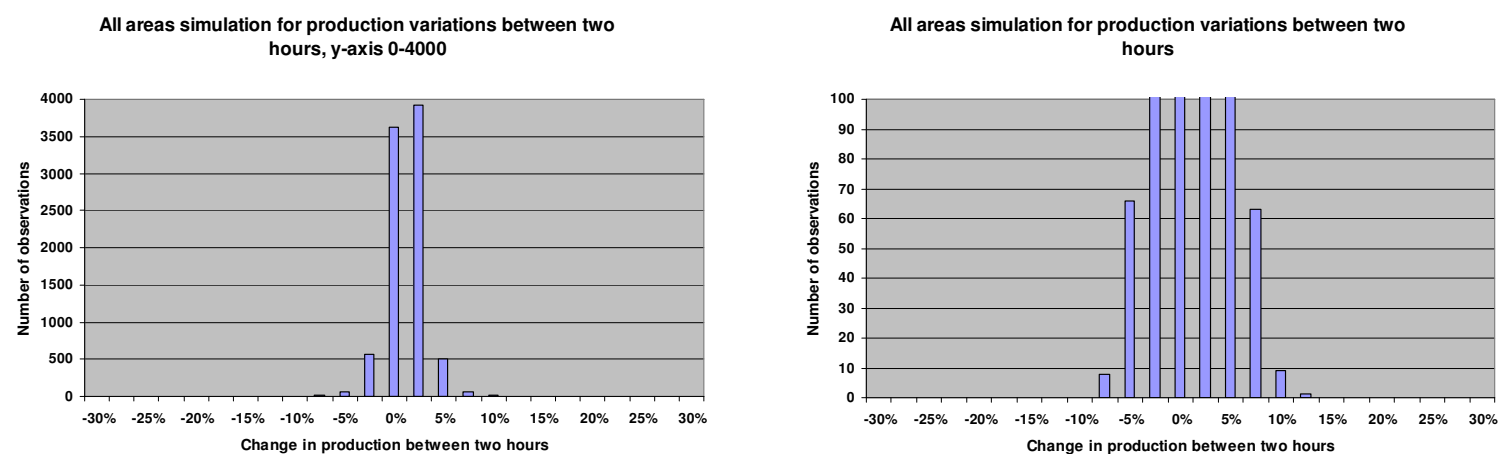

Figure 34: The changes in production between two hours for all areas with number of observation for the different changes [22].

After studying the simulation of the four areas and for all expansion scenarios, some general comments can be made.

For all areas, the most frequent changes are the ones that are in the range between $-10 \%$ to $10 \%$. There are however when studying each area, except for the part where all areas is studied together, changes over a larger range but they do only occur on a few number of observations.

As stated earlier the effect of spatial smoothening can be found when studying all areas at once. The change in production is in the range between $-7.5 \%$ to $12.5 \%$.

Since the spatial smoothening study is done on the largest geographical area it is probably the size of the area rather than the total capacity that contributes the most to the partial smoothening out effect. This means that if the capacity in one of the four areas is increased, it is not certain that there will be a partial smoothening out effect within that given area.

The figures showing the distribution of changes are based on frequency tables found in the appendices. 


\subsection{Most frequent variations}

For both the model and the simulation the largest variations in production between two hours, for each area and for all areas, are studied.

Table 16: Occurrence of variations, during one year, that are smaller or equal to $\pm 2,5 / 5 / 10 \%$ of the installed capacity for each area and for all areas [22].

\begin{tabular}{cccccc}
\hline Up/Down & Area 1 & Area 2 & Area 3 & Area 4 & All areas \\
\hline $\pm 2,5 \%$ & $84,18 \%$ & $90,66 \%$ & $91,17 \%$ & $85,33 \%$ & $93,46 \%$ \\
\hline $\pm 5 \%$ & $91,27 \%$ & $96,55 \%$ & $98,55 \%$ & $91,74 \%$ & $99,08 \%$ \\
\hline $\pm 10 \%$ & $98,57 \%$ & $99,71 \%$ & $99,98 \%$ & $98,80 \%$ & $99,99 \%$ \\
\hline
\end{tabular}

In Table 16 changes in production between two hours in the range of $\pm 2.5 \%, \pm 5 \%$ and $\pm 10 \%$ during 2009 is presented.

For all of the four areas, studied separated or as one area, more than $98 \%$ of the changes in production between two hours is $\pm 10 \%$ or smaller, for ranges of $\pm 5 \%$ and $\pm 2.5 \%$ the frequency is lower, it is however at no time lower than $84 \%$. On the other hand, during approximately $1,4 \%$ of the time for area 1 (122 hours), 0,3\% for area 2 (26 hours), $0,02 \%$ for area 3 ( 2 hours), 1,2\% for area 4 (105 hours) and $0,01 \%$ for all areas ( 1 hour) changes do occur that are larger than $\pm 10 \%$ of the installed capacity.

\subsection{Worst case scenario}

The worst case scenario are dimensioning for the electric power system when designing and operating it. Hence this worst case scenarios dimensioning factor, the change in production output between two hours measured in MW for each area at each expansion scenario will be presented below. This worst case scenario might just occur once a year it is however the largest obtained change from the simulation. To refer to a worst case scenario that currently is valid in today's electric power system a fast shut down of the large nuclear units Forsmark 3 and Oskarhamn 3. A worst case scenario can also be the failure of a large switchyard in the transmission grid. 


\begin{tabular}{ccc}
\hline \multicolumn{3}{c}{ Worst case 10 TWh scenario } \\
\hline & & {$[\mathrm{MW}]$} \\
\hline Area 1 & Max up & 60 \\
\hline 240 MW & Max down & -72 \\
\hline Area 2 & Max up & 91 \\
\hline 330 MW & Max down & -50 \\
\hline Area 3 & Max up & 89 \\
\hline 710 MW & Max down & -89 \\
\hline Area 4 & Max up & 486 \\
\hline 2430 MW & Max down & -547 \\
\hline All areas & Max up & 452 \\
\hline 3620 MW & Max down & -272 \\
\hline
\end{tabular}

Worst case scenario, change in production between two hours, 10 TWh

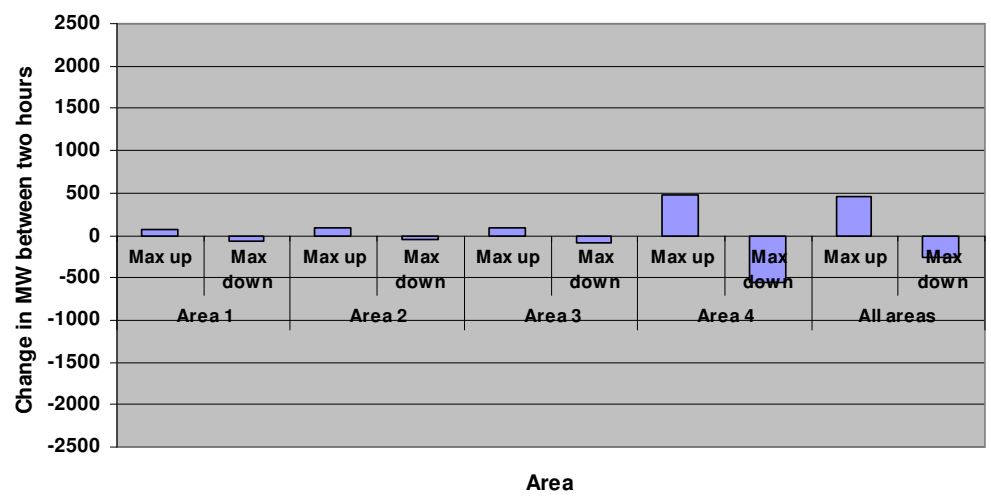

Figure 35: Worst case variations when looking at 10 TWh scenario [22].

\begin{tabular}{ccc}
\hline \multicolumn{3}{c}{ Worst case 30 TWh scenario } \\
\hline & & {$[\mathrm{MW}]$} \\
\hline Area 1 & Max up & 849 \\
\hline 2830 MW & Max down & -704 \\
\hline Area 2 & Max up & 443 \\
\hline 1610 MW & Max down & -242 \\
\hline Area 3 & Max up & 236 \\
\hline 1830 MW & Max down & -236 \\
\hline Area 4 & Max up & 886 \\
\hline 4430 MW & Max down & -997 \\
\hline All areas & Max up & 1289 \\
\hline 10310 MW & Max down & -773 \\
\hline
\end{tabular}

Worst case scenario, change in production between two hours, 30 TWh

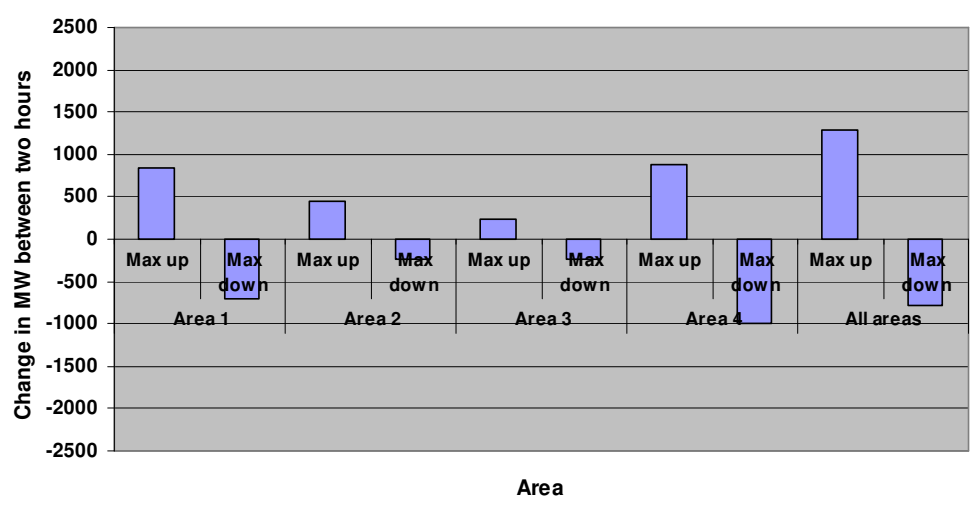

Figure 36: Worst case variations when looking at 30 TWh scenario [22]. 


\begin{tabular}{ccc}
\hline \multicolumn{3}{c}{ Worst case 50 TWh scenario } \\
\hline & & {$[\mathrm{MW}]$} \\
\hline Area 1 & Max up & 1623 \\
\hline $5410 \mathrm{MW}$ & Max down & -1352 \\
\hline Area 2 & Max up & 687 \\
\hline 2500 MW & Max down & -375 \\
\hline Area 3 & Max up & 434 \\
\hline 3470 MW & Max down & -434 \\
\hline Area 4 & Max up & 1304 \\
\hline 6520 MW & Max down & -1467 \\
\hline All areas & Max up & 2237 \\
\hline 17900 MW & Max down & -1343 \\
\hline
\end{tabular}

Worst case scenario, change in production between two hours, 50 TWh

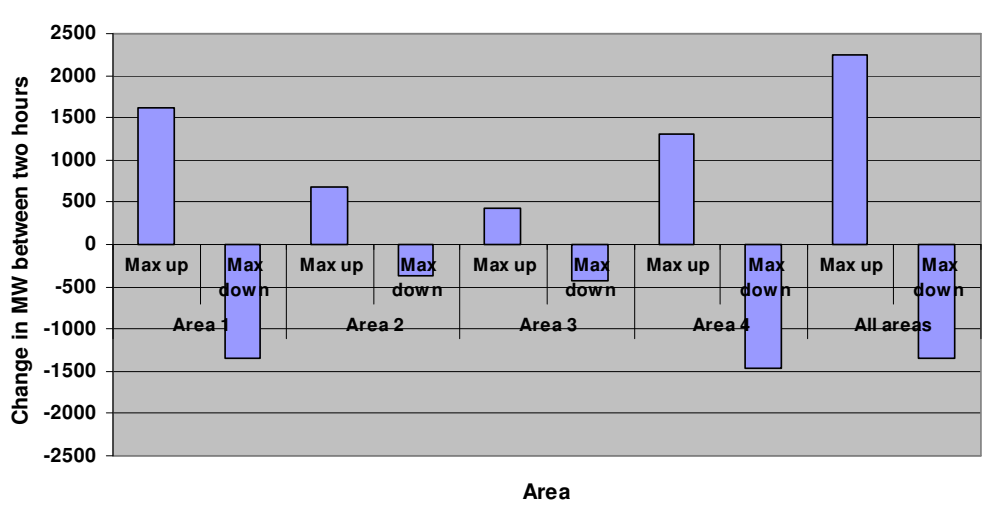

Figure 37: Worst case variations when looking at $50 \mathrm{TWh}$ scenario [22].

When studying the figures and tables in chapter 6.3, the ones regarding worst case scenario, one can see that for areas with a relatively high rate of wind power capacity the hour to hour variations can be of equal size or larger than for the entire system consisting of all the four areas capacity.

This is due to the spatial smoothening effects discussed in chapter 5.5. This is in some sense a positive effect, since the total variations in the system will probably be relatively small, the larger the total capacity is, given that the capacity is evenly distributed over the entire country. On the other hand, the negative effect of this is that in reality most of the future wind power expansion will take place in rather limited areas giving a rather limited contributing of partial smoothening out effect.

\subsection{Important scenario not found in data}

There is one change in production that has a large impact on the power system but which is hard to locate in the data. This is when the wind speed exceeds a wind turbines cut-off speed which means that the turbine goes from maximum production to a stand still in a very short period of time. Wind turbines are designed to do this in order to protect them when the wind becomes to strong. This gives a very special situation in the power system and can be compared to a fast shut down of a nuclear reactor if there is a large share of wind power in the system. Just before that the cut-off wind makes the turbine shut down and come to a halt in production, the output from the turbine will be at a maximum due to the good wind situation. Since the data used in this report has a highest drop of $40 \%$ of the installed capacity in area 4 , there is no case where the cut-off is occurring over the entire geographical area at the same time since that should have corresponded to a production decrease of $100 \%$. This could be regarded as a worst case scenario when the 


\section{Vattenfall Research and Development AB}

capacity for wind power in a limited geographic area becomes so large that it will clearly give a drop in frequency if all the turbines were to shut down at once.

\subsection{Simulation is worst case scenario}

The simulation results regarding hourly wind power production variations are based on the model constructed from the 2009 wind data. The results should be seen as a worst case scenario. This is based on the fact that when comparing a small and large geographic system the variations in percent will decrease. In this report the simulation of the future wind power is only an expansion of capacity at current locations. While in the future completely new sites will be used for wind turbines and wind farms. When the capacity is expanded and more geographically spread the relative variations will most likely decrease. This can be seen when comparing Figure 30, Figure 31, Figure 32 and Figure 33 individually to Figure 34. The base, giving the largest variations, of Figure 34 (all areas) is not as wide as for the other four figures (areas 1 to 4), since the system in Figure 34 is bigger geographically and larger measured in capacity.

To further strengthen this result a comparison of the current variations in area 3 and area 4 can be made. Even tough the installed capacity in the two areas are almost equal when measured in MW the hourly wind production variations in area 4 are larger then the once from area 3 . This reports conclusion to this is that the geographic size and therefore the spread of the turbines and farms in area 3 give a smaller total variation when looking at the area as one unit. In the future this would give that the variations in percent will probably be less with increased capacity in the entire country. The simulation that uses unchanged magnitude of the variations in percent is to be seen as a worst case scenario for a future wind power system. 


\section{Possible future solutions}

As previously mentioned there must at all time be a power balance in an electric power system. This is achieved by maintaining the level of power production and consumption at equal levels at all time. In the nearby future production mix with more intermittent energy sources will mean high demands on balancing the system. The balance can be arranged in many ways, one of them is to reinforce the grid to allow export or import power in periods of surplus or deficit. One other possibility is to develop the role of producers and consumers within the given system, in this context they will be a kind of ancillary service at the same time as they will be consumers and producers. In the following chapter, descriptions of possible solutions to create these consumers and producers ancillary services are presented.

\subsection{AGC}

Automatic Generation Control or AGC is a control system that enables generation equipment to automatically respond to signals from the systems TSO/ISO. The main task is to regulate and keep the frequency within a given area when an increase or decrease occurs in production/consumption. This aims to keep transmission capacity between areas on a desired level. The AGC system can also increase or decrease the production within an area if the load on a tie line changes [43].

\subsection{SmartGrids}

A solution to simplify implementation of large scale intermittent power generating sources might be so called SmartGrids.

There are many definitions of SmartGrids, one definition used is that smart grids might be considered as a toolbox with three different levels, the consumer level, the transmission level and the distribution level. Depending on how you use or combine these different tools on the different levels creates a SmartGrid that can handle certain tasks Fel! Hittar inte referenskälla.. Each of the three levels can be divided into subcategories. A few examples of these subcategories are given below in order to get a feeling for what a SmartGrid might be able to do depending on the technology used and how the subcategories for each level might work together to shape a function or application.

Example of the three levels and their subcategories:

- On the consumer level; an electric meter that gives the consumer the information needed to follow how changes in lifestyle regarding electric power consumption will affect consumer economy and where the electric power comes from. I.e. if small amount of electric power are used during peak hours money can be saved and electric power can be sourly supplied by local and, hopefully, renewable sources.

- On the distribution level; automation of distribution system meaning that all switches in the system can be operated from one control room eliminating onsite switching. The tree layout of distribution systems can be changed into a meshed layout in order to be able to 
more effectively isolate errors and reducing the size of the network those have to be taken offline when errors occur.

- On the transmission level; phase measurements in the entire system to keep the electric quality at a high level at all times can be used. Distributed and autonomous control systems that cooperate throughout the system in order to optimize the entire system

- By letting the consumers control the smart grid, consumption and thereby also price will be kept low. However, in times of crisis the control should be possible to transfer to the utility companies in order to avoid possible damage to the system Fel! Hittar inte referenskälla..

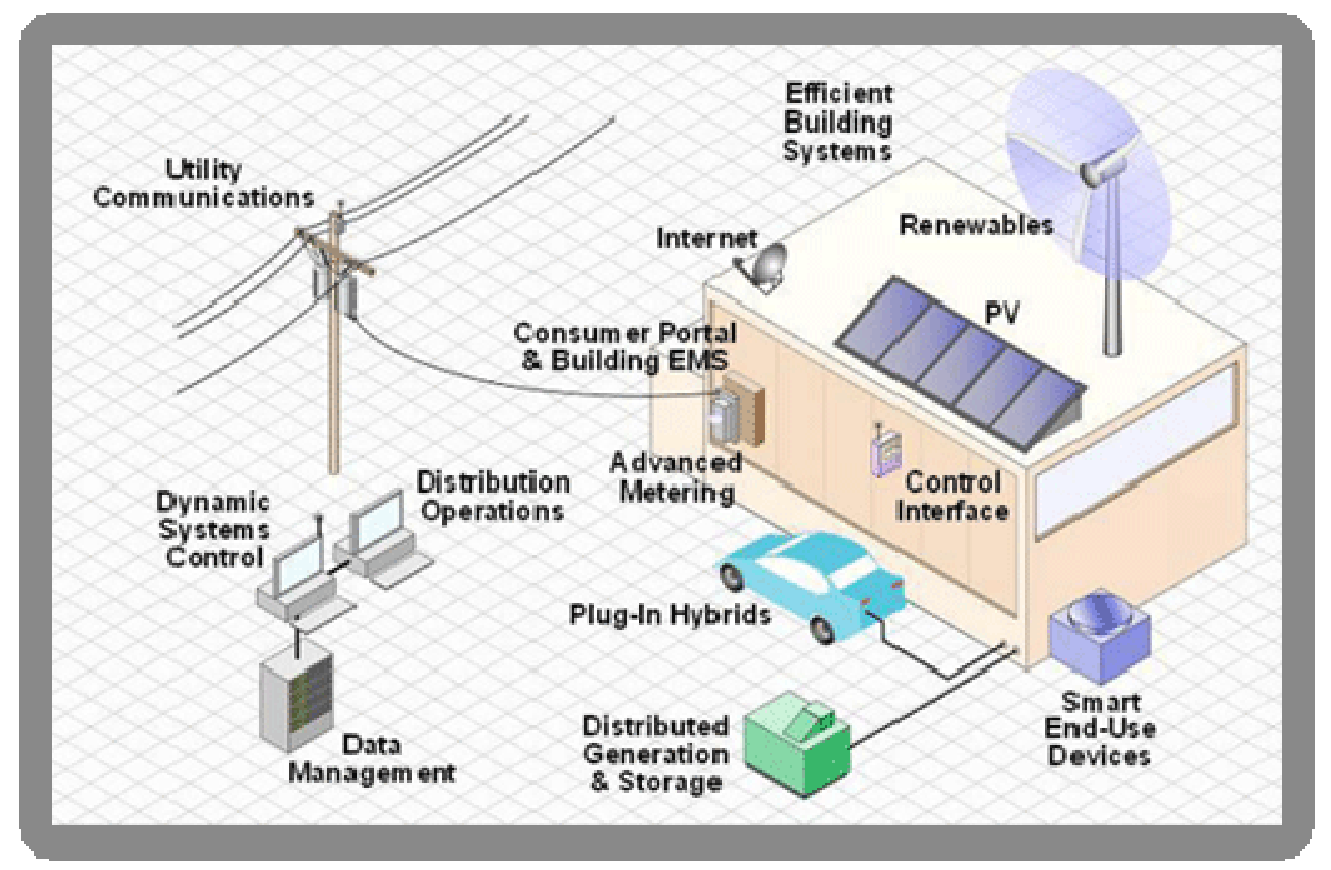

Figure 38: Example of a smart grid and its users and functions Fel! Hittar inte referenskälla..

\subsection{Hydro pump storage}

The hydroelectric pump and storage plant (HEPS) is not a new invention. The first was taken into operation in 1933. World wide HEPS plants has a total capacity of $140 \mathrm{GW}$ and it is mainly used for power balance control, as a backup plant when there are power surplus or power deficit.

The HEPS plant has the function of a reversible conventional hydro power plant, meaning that it works as a conventional hydro power plant but with the additional function that it can reverse the water flow [45]. So instead of generating electricity by converting kinetic energy from the running water, the HEPS plant can convert electric energy by potential energy buy pumping 
water from a lower level to a higher level. In Figure 39 the technical aspects of a HEPS plant can be seen.

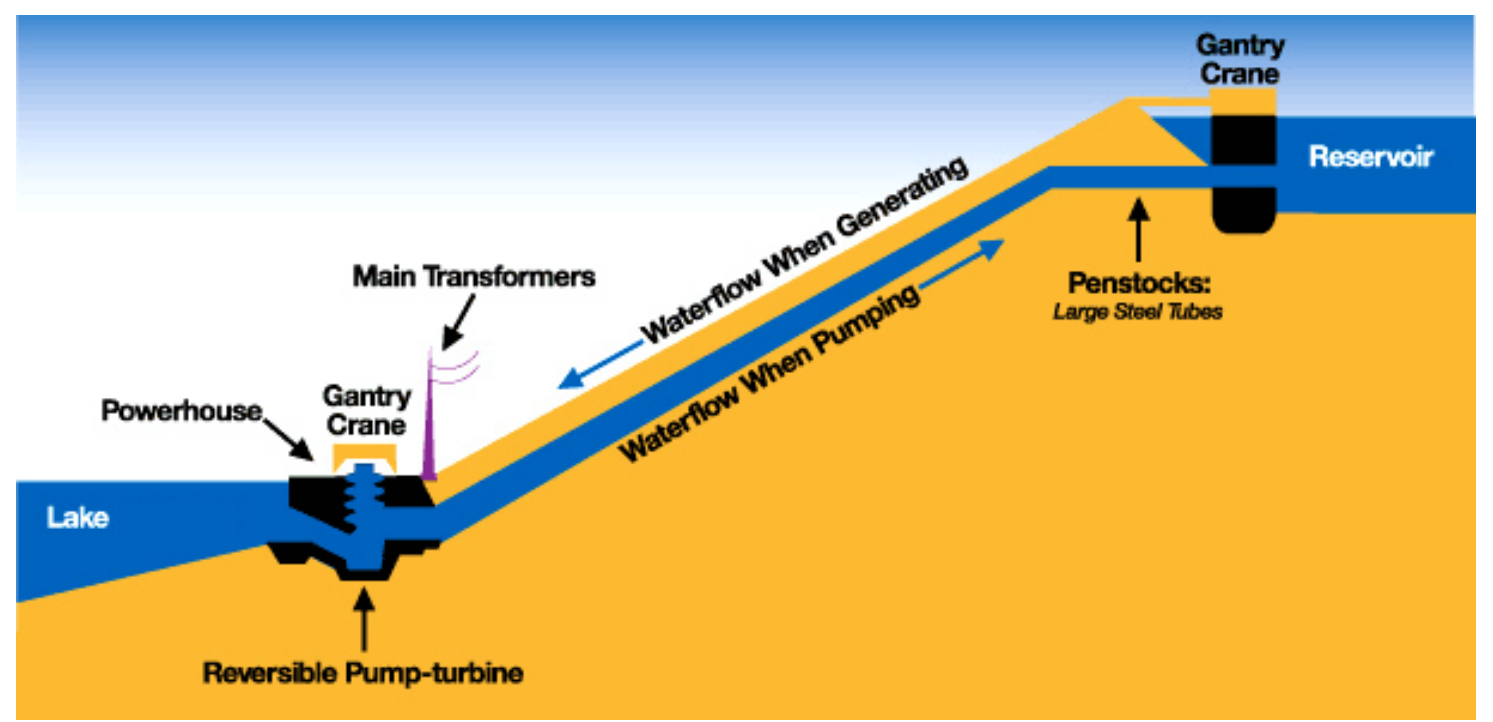

Figure 39: Example of the technical functions of a hydroelectric pump and storage plant [48].

In Figure 39 the basic principle of HEPS is explained. The functions for both the lake, the water tunnel and the reservoir is the same as in a conventional hydro power plant. However, in the power house of a HEPS plant, the turbine used only for power conversion from kinetic energy into electrical energy in a conventional plant, can be reversed and instead be used as a pump [45].

The question might be raised why energy already converted into electrical energy should be converted back to kinetic energy, then into potential energy and finally be converted back to electrical energy on a later occasion. In modern HEPS plants the total efficiency of the conversions electric energy-in to electric energy-out is some 75\% [49].

The answer to this question is two dimensional, meaning that there are two main reasons why this type of plant exists. The first reason is that today a HEPS plant is one of the few ways of storing large quantities of electric energy. The energy is of course not stored in the form of electricity, it is however very easy to use the stored water and convert it into electric energy once again.

The second reason has to do with the functionality of deregulated electrical markets. In a fully functional and competitive electric market, the price of electricity is higher when demand is high and lower when demand is low. This means that electricity can be bought relatively cheap in times with low demands, typically weekends and during night time, and use the bought electricity to pump water from a low altitude to a higher altitude. Once the water is pumped, the operator of the HEPS plant can put in an offer to the power market at a time when the demand is high and sell the electricity to a higher price per unit of electricity than what it was originally bought for when pumping the water. If the price difference on the electricity is big enough the producer can still make a profit even though the plant only has an efficiency of $75 \%$. 


\section{Vattenfall Research and Development $A B$}

If we look closer to reason one in the aspect of this chapter, future solutions, and also take in the results from this report, into consideration, we can see that hydro electric pump and storage plants might be a part of a future solution. The explanation of why is the following:

In an electrical system where there is a large intermittent power generating capacity there will be a need for balancing power. If a large share of the intermittent electric power sources is located in an area, in this context meaning one of the areas that can be found in Figure 12, that has low availability of balancing power there will most probably be moments where there is power surplus. This is due to the fact that the production could be larger than the consumption. In an area with those problems, a HEPS plant might be a suitable solution to handle the power balance problems.

There is however some problems related to the construction of new HEPS plants. It is costly: the location chosen must have physical properties that allow large quantities of water to flow from a higher to a lower altitude. Furthermore is it most probable that there are quite large local impacts on the environment if building a HEPS plant due to its sheer size and demands of water [45].

\subsection{Plug in hybrid electric vehicles}

Plug in hybrid electric vehicles (PHEV), are being developed, and in a relatively short period of time a significant share of the automobile fleet could be fully or partly electrified. The average car used for personnel transportation is only used for a few percent of the time. This means that during the majority of the time, the car could be plugged in to the electric power system.

By reading the chapter regarding Hydro electric pump and storage it is possible to deduce that one of the most beneficial functions of that type of plant is that it has the functionality of battery, meaning that it has the ability to uptake power when there is a surplus and to generate power when there is a deficit.

There is a study made regarding the future possibility of using the PHEV car fleet as a regulation power source. By the fact that the PHEV can be connected to the grid during times that it is not in operation there is a possibility to use the PHEVs battery for up and down regulation.

This might be a solution in a future system when the number of PHEV is expanded and when the PHEVs batteries will allow both charging and discharging, as a technical term this is called V2G, vehicle to grid [50].

In Figure 40 the corporation between Vattenfall $\mathrm{AB}$ and Volvo cars is shown, the goal is to have a plug in car for the market ready in 2012. Vattenfall will be the provider of charging stations [51]. 


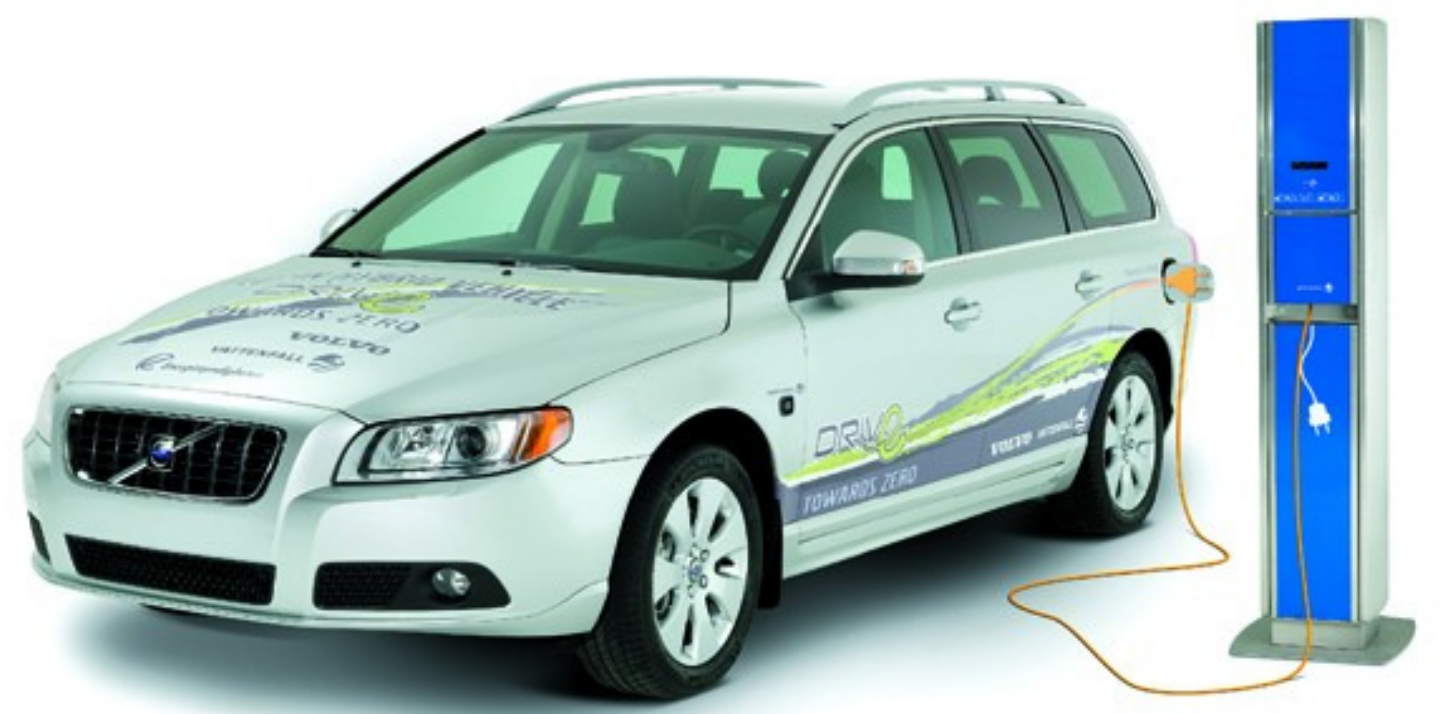

Figure 40: Corporation Volvo Cars and Vattenfall regarding PHEVs and charging stations [51]. 


\section{Conclusions and future work}

\subsection{Conclusions}

From the statistic data both the production for each hour in $\mathrm{MWh} / \mathrm{h}$ has been calculated but also the variations between each hour to get a view of how much the production varies between two hours. Part of the data for the wind power production is available at a 5-minutes interval which has been used to show how the production also can vary within the hour. By comparing the production for each hour with the installed capacity an overview of the average utilization factor for the wind power is given. In other words, how much of the installed wind power capacity that is generating electric power during a minimum, average and maximum production hour during 2009.

When studying Table 12 in chapter 5.3.3 the following can be concluded:

The production variations, measured in percent of total capacity for each area, between two hours is the following when only listing the largest variations, regardless of positive or negative change.

Table 17: Largest variations in each area in percent and in MW depending on expansion scenario [22].

\begin{tabular}{ccccc}
\hline Area & Change in [\%] & $\mathbf{1 0}$ TWh & 30 TWh & 50 TWh \\
\hline Area 1 & $28 \%$ & $72 \mathrm{MW}$ & $849 \mathrm{MW}$ & $1623 \mathrm{MW}$ \\
\hline Area 2 & $26 \%$ & $91 \mathrm{MW}$ & $443 \mathrm{MW}$ & $687 \mathrm{MW}$ \\
\hline Area 3 & $13 \%$ & $89 \mathrm{MW}$ & $236 \mathrm{MW}$ & $434 \mathrm{MW}$ \\
\hline Area 4 & $22 \%$ & $547 \mathrm{MW}$ & $997 \mathrm{MW}$ & $1467 \mathrm{MW}$ \\
\hline All areas & $12 \%$ & $452 \mathrm{MW}$ & $1289 \mathrm{MW}$ & $2237 \mathrm{MW}$ \\
\hline
\end{tabular}

The four areas in which Sweden is divided are not equally large measured in areal size, nor is the present wind power capacity equal in all of the areas.

If studying Table 6, one can see that in the present system area 3 has the largest present capacity (670 MW), followed by area 4 (540 MW), giving a 25\% higher capacity in area 3 than that in area 4.

The largest hourly variation in area 4 , as can be seen above, is $22 \%$ whilst it is $13 \%$ in area 3 . Even though it is not certain it is most probable that the reason for that the hourly production variation in area 3 is almost half of what it is in area 4 has its base, not in larger wind power capacity, in a more dispersed location of wind power producing units due to that area 3 is larger than area 4.

Both area 1 and area 2 is considerably larger than area 4, when simulating these areas future wind power production according to a future expansion scenario the largest change in production between two hours is $28 \%$ of total capacity for area 1 and $26 \%$ for area 2 . However in the present system that is the base for the data used in the simulation area 1 has $65 \mathrm{MW}$ of capacity and area 2 has $175 \mathrm{MW}$. Due to that there is a quite limited capacity in area 1 and area 2, in the present 


\section{Vattenfall Research and Development AB}

system, the results might be affected in a negative way. Area 1 and area 2 is, when measured by areal units, in the same size span as area 3 , giving that for the same expansion rates in area 1,2 and 3 there is a good chance that the hourly variations decreases according to the hourly variations in area $3(13 \%)$ in area 1 and 2.

As earlier presented, the area in which there are the lowest availability of regulation power is area 4. It is also presented in the text above that there is a limited chance for a decrease in hourly production variations (measured in percent of capacity) in area 4 due to that area 4 is relatively small, compared to area 1, 2 and $3 .$.

In all of the three expansion scenarios according to 10/30/50 TWh, see Figure 11, the largest part of the expansion will take place in area 4.

The summarized result of that the largest expansion is planned in area 4 and that area 4 is the area that has the highest probability for large hourly variations (measured in percent of the areas wind power capacity), regardless of the total wind power capacity, is not when considering it from an electrical power system perspective a pleasant result.

On the other hand, when looking at relatively small changes in production, see Table 16 difference and frequency in percent, it is important to understand that even though there can occur large changes in production between two hours the absolutely most frequent changes in production is relatively small. More than $98 \%$ of the changes in production between two hours are in the range of $\pm 10 \%$. Over $90 \%$ of the changes is $\pm 5 \%$ or smaller. For ranges of both $\pm 10 \%$ and $\pm 5 \%$ the values of $98 \%$ and $90 \%$ respectively is valid for each area separately and for the system consisting of all four areas. In Table 16 showing difference and frequency in percent, it is however possible to see a particularly interesting result. Area 4, that earlier has been stated as an area which is small and to have a large share of the future expansion of the future wind power expansion, has one of the largest occurrence of changes in production between two hours that are larger than $\pm 10 \%$.

One of the general conclusions is that area 4 will be the most interesting area in the future. It will be the subject of large wind power expansion, it will quite probable be an area with the largest changes in production between two hours and it will also quite probable be an area with a relatively large numbers of hours when the large changes in production between two hours occur. This is the conclusion that can be drawn from this report be there is an uncertainty since the capacity today in area 4 is dominated by the wind farm Lillgrund. Expanding the capacity in area 4 over the entire geographical area might have a bigger impact on the variations in area 4 then other areas in the country. This is due to the large impact that Lillgrund today have on the measured data for area 4.

Since the main concern is how the increased wind power capacity will affect the power system in general, i.e. will the variations from wind power have some sort of correlation due to the geographic spread? From the data figures showing the correlations between the different areas and correlation between wind turbines and farms at specific distances give a hint on how the production and production variations will be correlated. The findings are that the correlation is positive and tends to go towards zero which indicates that there is little or no correlation between 


\section{Vattenfall Research and Development AB}

the productions. For the production variations the correlation curves moves towards zero even faster. These results are the same both when looking at areas and turbines with specific distances in between.

When the system is enlarged using the logged data and future wind power expansion plans it is important to evaluate the results from different tables and diagrams. When only looking at the maximum variations it is easy to draw the conclusion that the negative variations are somewhat smoothened since the largest negative variation for all areas is lower than the largest negative variation for area 4 . When comparing this to the frequency tables however it can be seen that this should be regarded as an isolated occurrence since the largest negative value only occur once. Instead maximum values, like the one mentioned above, can be the one that will be setting the terms for how the future electric power system has to be designed in order to meet the fluctuation from wind power.

The difference between production variations from wind power when looking at the entire Swedish system and when dividing the system into the four areas is that even if the situation looks good for the system in general some of the areas might encounter problems. This can be seen in the worst case scenario diagrams where production variation in the different areas can be larger then the variations for the entire system. Sine this occurs it is important to remember the basic conditions for the Swedish electric power system and the problems that might occur first. Hydro power which is used for balancing is situated in the north, domestic transmission capacity determines how much electric power that can be supplied or exported from an area. These three combined (large variation in one area, electric power system conditions and problematic situations) gives a prerequisite for potential future problems.

As shown earlier in Table 4 it is clear that the available reserve power in area 4 for 2009 was approximately 1150 MW plus 300 MW available from Denmark. These total of 1450 MW of reserve power is only available if there is not a deficit of power in the power system. As shown in chapter 6.3, the largest changes in production of wind power between two hours in area 4 is 547 MW for the $10 \mathrm{TWh}$ scenario, $997 \mathrm{MW}$ for the $30 \mathrm{TWh}$ scenario and $1467 \mathrm{MW}$ for the $50 \mathrm{TWh}$ scenario. By comparing the maximum reserves in area 4 with the largest obtained changes in production between two hours, it is clear that at the case of $50 \mathrm{TWh}$, the change between two hours is larger than the reserves. For $10 \mathrm{TWh}$ and $30 \mathrm{TWh}$ the reserves are larger than the largest changes. However, these reserves are, as previously stated, not to be taken for granted. Especially not during winter when demand is at peak levels, and when there is a quite large chance for large hour to hour variations of the wind power production.

In the last chapter it could be found that another worst case scenario could occur when high wind speeds make a large share of wind power capacity are turned off at the same time. This is however something that in this report only has been mentioned from the literature study and has not been found in the production data material.

A subject that only have been mentioned in the report but that is important to consider is that there are times during all seasons of the year that the electric power production from wind power 


\section{Vattenfall Research and Development AB}

is zero. So even if there is a large installed capacity of wind power it is never a generating source that can be relied on to produce a minimum amount of electricity.

One positive thing however is the fact that the production variations become smaller in the terms of percent when the system is expanded. So even if an expansion will lead to increased magnitude in the terms of megawatts the increase will not be linear with the expanded capacity.

\subsection{Future work}

Due to that the production variations from hour to hour within each area can be relatively large, in relation to the installed capacity for each area, it would be interesting to study the availability of regulation power and transmission capacity within and from and to each area.

Since the production variations only is given on an hour to hour basis, and it is stated that the variations during one hour can be relatively large, a study concerning the production variations within the hour would also be of interest. A good timeframe to study would be the change between one five minute period and the next five minute period. This would present the changes that have more effects on the regulating power availability and also how the transmission system would be affected by possible congestion peaks within the system.

By the usage of the worst case scenarios for 10/30/50 TWh wind power production for each of the four areas, a study that allocates in which of the areas and at which wind power expansion rate problems concerning regulation power or transmission capacity would be of interest.

It is possible to develop the model even further by including some meteorological data for sites where large wind farms are planned to be built. And even including wind data from some of the places that today have no wind turbines at all but faces wind power expansion. Even if this would mean that calculated production is used this might give a hint on how the correlation and spatial smoothening effects would behave if the system is expanded over a larger geographic area.

Another aspect that could be included in the hour to hour variation study is a comparison of the wind power variations and the load variations in the system. This would give a picture if the variations from wind and the variations in the load would increase or decrease the total variation depending on their correlation.

- Smaller time frame for the production data, preferably 5-minute intervals.

- Include regulating power and transmission capacity to and from each area in the study to identify where problems will occur first. This study will demand the use of 5-minute data since regulating power operates with smaller timeframes then reserves.

- Expand the model with meteorological data for some sites where wind power turbines and farms are planned in order to see if the spatial smoothening have the desired effect.

- Compare the variations from wind power with the load curve to see how they relate to each other. 


\section{References}

[1] Communication from the commission. Europe 2020 - A European strategy for smart, sustainable and inclusive growth. Brussels Mars 2010.

[2] European Union: Proposal for a Directive of the European Parliament and of the Council on the promotion of the use of energy from renewable sources. http://ec.europa.eu/energy/climate_actions/doc/2008_res_directive_en.pdf. January 2008.

[3] Energimyndndigheten. Nytt planeringsmål för vindkraften år 2020. ER 2007:45

[4] P. Blomqvist, M. Nyborg, D. Simonsson, H. Sköldberg "Vindkraft i framtiden Möjlig utveckling i Sverige till 2020”, Elforsk rapport 08:17, Elforsk, Stockholm, 2008.

[5] Svenska Kraftnät, Storskalig utbyggnad av vindkraft - Konsekvenser för stamnätet och behovet av reglerkraft. Stockholm 2008.

[6] N. Andersson, "Stor andel vindkraft ur ett marknads- och teknikperspektiv underlag till Vindforsks syntesrapport", Elforsk rapport 7:08, Elforsk, Stockholm, 2009.

[7] F. Carlsson, V. Neimane "A massive introduction of wind power" Elforsk report 08:41, Elforsk, Stockholm, 2008.

[8] Personal communication with Christer Bäck, Svenska Kraftnät, Sundbyberg.

[9] Kungliga Vetenskapsakademiens Energiutskott. Uttalande om vindkraften 17 september 2009

[10] E. Hau, "Wind Turbines - Fundamentals, Technology, Application, Economics 2nd Edition," New York: Springer Berlin Heidelberg: 2006.

[11] "World Wind Energy Report 2009" Avaliable on homepage hwww.wwindea.org/home/images/stories/worldwindenergyreport2009_s.pdf, accesed 2010-05-15.

[12] C. Håkansson "Gröna elcertifikat - ett bakvänt och ineffektivt system”, SLU, Umeå, 2003.

[13] K. Lundgren "Förnyelsebara energibärares nuvarande och framtida konkurrenskraft - föreställningar om konkurrenskraft" Energy licensiate disseration, Lunds tekniska högskola, Lund, 1998.

[14] S. Bülow, "Med vind i segel - Den förnyelsebara elproduktionens ekonomi för de nordiska länderna" D-uppsats, Luleå tekniska universitet, Luleå, 2007.

[15] M. Lenzen, J. Munksgaard "Energy and CO2 life-cycle analyses of wind turbines review and applications" University of Sydney, Sydney, 2002.

[16] "Förnybara energikällor hela elmarknaden i förändring" Vinnova analys VA 2009:10, 2009.

[17] H. Hansson, S-E. Larsson, O. Nyström, F.Olsson, B. Ridell, ”El från nya anläggningar - 2007”, Elforsk rapport 07:50, Elforsk, Stockholm, 2007.

[18] Energimyndigheten, Avaliable on homepage: http://www.energimyndigheten.se accessed 2010-05-15. 
[19] "Vindkraft - Bygga och ansluta större vindkraftverk" Energimyndigheten, Avaliable on homepage http://www.lansstyrelsen.se/NR/rdonlyres/C813D3FE-6A53-49F28869-524317941B8C/97498/Vindkraft_handbok_stora_verk.pdf accesed 201005-15.

[20] T. Ackermann. Wind Power in Power Systems. Royal Institute of Technology, Stockholm, Sweden. 2005.

[21] "Forskning för mer och bättre vindkraft - Vindforsk -II syntesrapport", Elforsk rapport 08:46, Elforsk, Stockholm, 2008.

[22] Svenska Kraftnät. Elstatistik per snittområde. Avaliable on homepage: http://www.SvK.se/Energimarknaden/El/Statistik/Elstatistik-per-snittomrade/ Accesed 2010-04-10

[23] "The Swedish Electricity market and the role of Svenska Kraftnät", Svenska Kraftnät, Vällingby, 2007.

[24] "Fakta om Lillgrund" Available on homepage: www.vattenfall.se/sv/fakta-omlillgrund.htm, accesed 2010-05-10.

[25] Vattenfall production follow up, Vattenfall owned database for wind production follow up.

[26] K. Gustafsson, V. Neimane "Stora volymer vindkraft - Delrapport: Förändrade förutsättningar för planläggning och drift i ett elsystem med en ökad andel vindkraft" Elforsk rapport 09:103, Elforsk, Stockholm, 2009.

[27] H. Holttinen, "The Impact of Large Scale Wind Power Production on the Nordic Electricity System", PhD thesis, Helsinki University of Technology, Espo, 2004.

[28] U. Axelsson, R. Murray, V. Neimane. 4000MW wind power in Sweden - Impact on regulating and reserve requirements. Elforsk, Energimyndigheten, 2005

[29] Vindforsk homepage. www.vindforsk.se.

[30] Svensk Vindenergi, vindkraftsstatistik januari 2010. www.svenskvindenergi.org

[31] H. Haegermark. Kort historik om det svenska elsystemets framväxt och några framtidsfrågor. Förstudie för IVA-projektet Vägval Energi.

[32] L. Hjalmarsson, L. Söder, K. Forsberg, P. E. Springfeldt. Systemtjänster. Elforsk 2001.

[33] N. Dahlbäck. Utvecklingsbehov inom reglerkraftsområdet ur ett vattenkraftperspektiv. Svenskt Vattenkraftcentrum 2010.

[34] Personal communication with Kjell Lindquist, Vattenfall Nordic Generation Management.

[35] Svenska Elektriska Kommissionen. Standardspänningar för överföring och distribution av energi. SS 4210501

[36] Svensk Energi; Om el - Kraftsystemet. http://www.svenskenergi.se/sv/Omel/Kraftsystemet/

[37] "Driftuppföljning av vindkraftverk januari 2010", Avaliable on homepage www.vindstat.nu, accessed 2010-05-15.

[38] "Om Elforsk", Avaliable on homepage www.elforsk.se/elforsk/verksam_2008.html, accessed 2010-05-15 


\section{Vattenfall Research and Development $A B$}

[39] M. Magnusson, R. Krieg, M. Nord, H. Bergström "Effektvariationer av vindkraft En studie av vindenergiproduktionens tidsvariation", Elforsk rapport 04:34, Elforsk, Stockholm, 2004

[40] U. Focken, M. Lange, K. Mönnich, H. P. Waldl, H. G. Beyer and A. Luig. Shortterm prediction of the aggregated power output of wind farms-a statistical analysis of the reduction of the prediction error by spatial smoothing effects. University of Oldenburg \& University of Magdeburg, Germany. 2001.

[41] M. Amelin, C. Englund, A. Fagerberg "Balansering av vindkraft och vattenkraft i norra Sverige" Elforsk rapport 09:88, Elforsk, Stockholm, 2009.

[42] Vattenfall wind centre. Database logging of current wind power production from Vattenfall owned wind turbines. Sorted turbine by turbine in accumulated production.

[43] M. Korpås, J. O. G. Tande, K. Uhlen, E. Ståle Huse and T. Gjengedal. Planning and operation of large wind farms in areas with limited power transfer capacity. Dept. of Electrical Power Engineering, Norwegian University of Science and Technology, Trondheim, Norway. 2006

[44] M. Granger Morgan, Jay Apt, Lester B. Lave, Marija D. Ilic, Marvin Sirbu, and Jon M. Pecha. "The many meanings of Smart Grid" Carnegie Mellon University, department of engineering and public policy. July 2009. Available: www.epp.cmu.edu/Publications/Policy_Brief_Smart_Grid_July_09.pdf

[45] S.P. Chowdhury, S. Chowdhury, C.F. Ten and P.A. Crossley (2008) Operation and control of DG based power island in smart grid environment. CIRED Seminar 2008: SmartGrids for Distribution; 23-24 June 2008, Frankfurt. Paper 132.

[46] [http://www.naruc.org/SmartGrid/smart_grid_network_image.gif]

[47] Electricty storage association (Homepage) http://electricitystorage.org/tech/technologies_technologies_pumpedhydro.htm

[48] homepage: http://richard-rowland-perkins.com/wpcontent/uploads/2009/01/pumpedstorage.gif

[49] I.Allard, K. Sjöström "Hydrolager - en hållbar energilösning" Umeå Universitet, Umeå, 2009.

[50] S. Andersson, A.K Elofsson "Plug-in hybrid Electrich Vehicles as Reguation Power Providers" Master Thesis, Chalmers Göteborg, 2009.

[51] www.vattenfall.com 